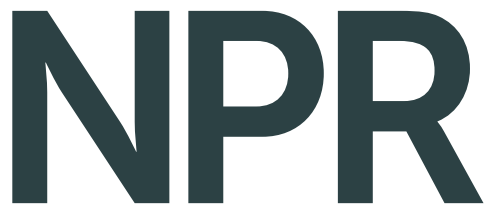

Natural Product Reports www.rsc.org/npr

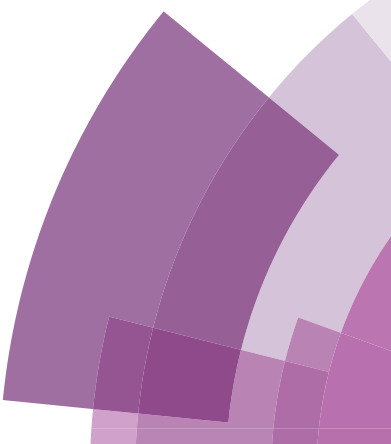<smiles>COC1C(C)C(C)C(C)C1C1COC(C)C1C</smiles>

\title{
Themed issue: Chemical Ecology
}

ISSN 0265-0568

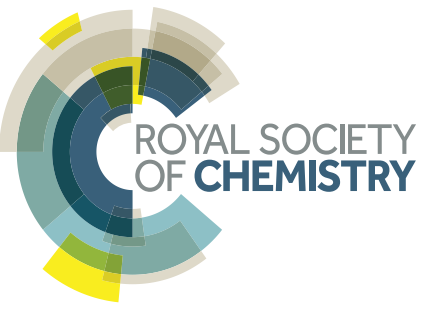




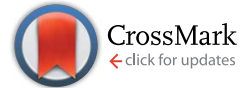

Cite this: Nat. Prod. Rep., 2015, 32, 904

\title{
Defensive symbioses of animals with prokaryotic and eukaryotic microorganisms $\uparrow$
}

\author{
Laura V. Flórez, $\$$ Peter H. W. Biedermann, $\$$ Tobias Engl $\$$ and Martin Kaltenpoth $\$ \S^{\star}$
}

Covering: through 2014

Many organisms team up with microbes for defense against predators, parasites, parasitoids, or pathogens. Here we review the described protective symbioses between animals (including marine invertebrates, nematodes, insects, and vertebrates) and bacteria, fungi, and dinoflagellates. We focus on associations where the microbial natural products mediating the protective activity have been elucidated or at least strong evidence for the role of symbiotic microbes in defense is available. In addition to providing an overview of the known defensive animal-microbe symbioses, we aim to derive general patterns on the chemistry, ecology, and evolution of such associations.

Received 30th January 2015

DOI: $10.1039 / c 5 n p 00010 f$

www.rsc.org/npr

\section{Introduction}

2 Defensive animal-microbe symbioses

2.1 Marine invertebrates

2.1.1 Sponges

2.1.2 Cnidarians

2.1.3 Bryozoans

2.1.4 Nemerteans

2.1.5 Mollusks

2.1.6 Crustaceans

2.1.7 Tunicates

2.2 Terrestrial invertebrates

2.2.1 Entomopathogenic nematodes

2.2.2 Insects

2.3 Vertebrates

3 Ecological and evolutionary implications

3.1 Implications of host ecology and lifestyle

3.2 Diversity of defensive symbionts and protective chemicals

3.3 Implications of symbiont localization

3.4 Evolutionary dynamics

3.5 Outlook: current status, challenges and opportunities of defensive symbiosis research

$4 \quad$ Acknowledgements

5 References

Max Planck Institute for Chemical Ecology, Insect Symbiosis Research Group, Hans-Knöll-Str. 8, 07745 Jena, Germany.E-mail: mkaltenpoth@ice.mpg.de

$\dagger$ Electronic supplementary information (ESI) available. See DOI: 10.1039/c5np00010f

\$ All authors contributed equally to this work.

$\S$ Present address: Johannes Gutenberg University Mainz, Institute for Zoology, Department for Evolutionary Ecology, Johann-Joachim-Becher-Weg 13, 55128 Mainz, Germany. Email: mkaltenp@uni-mainz.de
All organisms are threatened by antagonistic encounters with predators, pathogens, parasites, and/or parasitoids, which exert strong selective pressures on evolving efficient defense strategies. Such protective adaptations include behavioral, mechanical, and structural defenses against predators, ${ }^{1}$ as well as a sophisticated immune system providing protection from microbial intruders and parasitoids. ${ }^{2}$ In addition, many animals across a broad range of taxa use an arsenal of chemicals to defend themselves against various antagonists., ${ }^{3,4}$ Many of these defensive compounds are produced by the animals themselves, but it is becoming increasingly evident that microbial symbionts can make important contributions to their host's defense. ${ }^{5,6}$

While symbiosis research has traditionally focused on the nutritional aspects of mutualistic associations between animals and microorganisms, more recent research has revealed the importance of defensive alliances with microorganisms for their hosts' ecology and evolution., ${ }^{5,6}$ In general, there are four different ways in which microbial symbionts can contribute to their host's protection from antagonists (Fig. 1): (i) microbial partners can improve the overall vigor of their host and thereby enable it to allocate an increased amount of resources into defense. This is likely true for many, if not all, nutritional symbioses, even though it is not often discussed in this context, given the usually more obvious (and more dramatic) direct effects of nutritional symbiosis on host survival and fecundity. (ii) Microbial symbionts can provide protection to their host by competitively excluding pathogenic microbes. ${ }^{7}$ (iii) The interaction with symbiotic microorganisms can stimulate or prime 
the host's immune system and thereby enhance resistance against pathogens, parasites, or parasitoids. ${ }^{8}$ (iv) Microbes can produce bioactive compounds or their precursors and thereby contribute to their host's defensive chemistry. ${ }^{\mathbf{9 , 1 0}}$ In the context of natural products chemistry, defensive symbioses of the last category are the most interesting, as they often involve novel compounds of potential interest for application in human medicine, agriculture, or food technology.

In the present review, we aim to provide an overview of the known defensive symbioses between Metazoa and microorganisms, with an emphasis on associations where host protection is mediated by symbiont-produced secondary metabolites. We are building on previous reviews of microbial protective symbioses in particular groups of animals, including marine organisms, ${ }^{11-14}$ insects, ${ }^{15-19}$ and nematodes, ${ }^{20-22}$ as well as on reviews covering the metabolites produced by symbiotic bacteria., ${ }^{\mathbf{9} 10}$ Generally, we focus particularly on symbioses for which the defensive chemistry

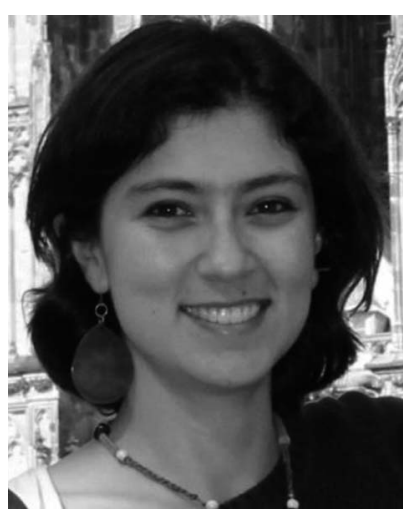

Laura V. Flórez received her B.Sc. in Biology and Chemistry in 2011 at Universidad de los Andes in Bogotá, Colombia. She carried out her undergraduate thesis at the Max Planck Institute for Polymer Research in Mainz, Germany, on the interaction between human cells and polymeric nanoparticles. In 2011, she received a scholarship from the International Max Planck Research School to carry out her PhD under the supervision of Dr Martin Kaltenpoth at the Max Planck Institute for Chemical Ecology. Her current research is focused on the ecology and evolution of symbiotic associations between bacteria and insects, and in particular on a novel defensive symbiosis in lagriid beetles.

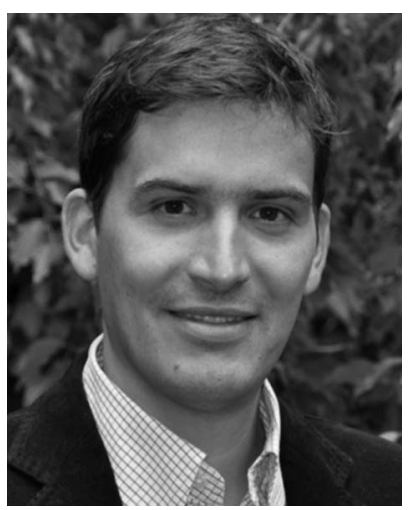

Peter H. W. Biedermann received his B.Sc. in Biology from the University of Graz, Austria, in 2005 and then moved to Switzerland to do his M.Sc. and Ph.D. at the University of Bern on the behavioral ecology of fungus-farming ambrosia beetles (finished 2012). Currently, he is an SNSF postdoctoral fellow with Dr Martin Kaltenpoth at the Max Planck Institute for Chemical Ecology and investigates the behavior, chemistry, and microbial symbioses of fungus-farming ambrosia beetles. has been elucidated, and a protective benefit for the host has been demonstrated or is at least very likely. Most of these involve associations with bacteria, but a few defensive alliances with fungi and dinoflagellates have also been described. As might be expected, bioactive compounds derived from polyketide synthases (PKS) and non-ribosomal peptide synthetases (NRPS) are particularly widespread in defensive symbioses, occurring in marine systems like sponges, corals, ascidians and bryozoans, as well as in terrestrial associations involving nematodes and insects. However, a diverse range of other compound classes with interesting activities occur across symbiotic associations and habitats, including organic acids, phenolics, ribosomal peptides and terpenes (Table S1†). Following our review of the literature on defensive microbial symbioses in animals, we conclude with a synthesis section aimed at deriving general patterns on the chemistry, ecology and evolution of defensive animal-microbe symbioses.

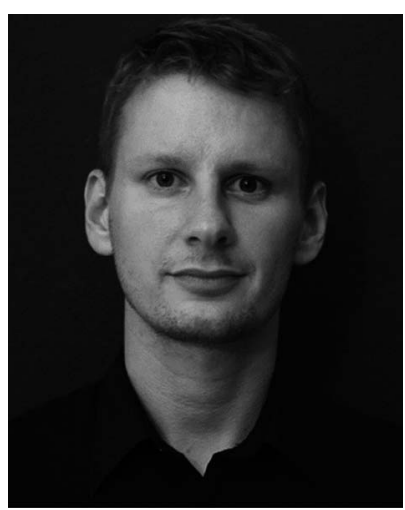

Tobias Engl studied Chemistry and Biology at the University of Regensburg, Germany, obtaining his diploma in biology in 2008. His dissertation project in the Evolutionary Ecology group of Dr Erhard Strohm in Regensburg focused on anti-fungal defenses of the European beewolf. Since 2011, he is a postdoctoral researcher at the Max Planck Institute for Chemical Ecology in Jena, Germany, extending his focus to the chemistry of symbiont-mediated defense in beewolves as well as the ecological and evolutionary implications of insect-microbe interactions in general.

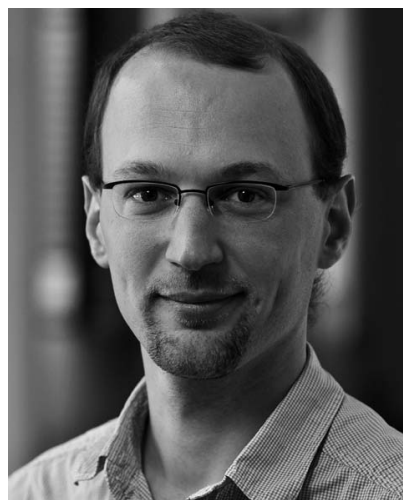

Martin Kaltenpoth obtained his $\mathrm{MSc}$ and PhD degrees from the University of Würzburg, followed by postdoctoral research at the University of Regensburg and the University of Utah in Salt Lake City. In 2009, he established the Insect Symbiosis Research Group at the Max Planck Institute for Chemical Ecology in Jena. From April 2015, he will be a full professor for Evolutionary Ecology at the University of Mainz. His research focuses on the evolution, chemical and molecular ecology of insect-microbe symbioses, with a special interest in defensive alliances. 

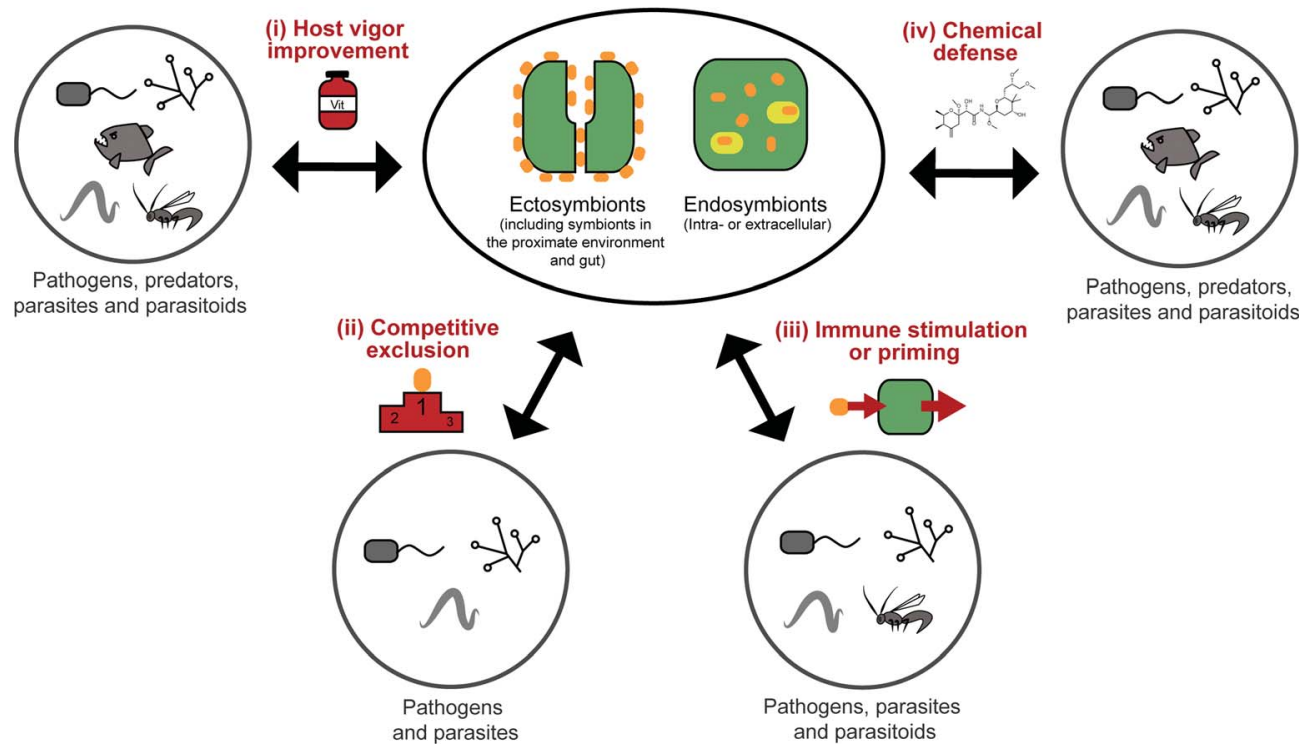

parasites and parasitoids

Fig. 1 Types of defense mechanisms in animals mediated by ectosymbionts (including those in the gut and in the proximate environment of the host) or endosymbionts (intra- or extracellular) against different possible antagonists (described or likely effective against).

\section{Defensive animal-microbe symbioses}

\subsection{Marine invertebrates}

2.1.1 Sponges. Due to their soft bodies and immobile lifestyle, many sponges heavily rely on chemical defenses. This is reflected in a rich repertoire of secondary metabolites that can be self-produced, sequestered from the food, or provided by symbiotic partners. ${ }^{23}$ In fact, many sponges harbor a diverse community of microorganisms that can be transient, digested as a nutrient source, or stably associated with the sponge. ${ }^{24,25}$ Past and recent developments in molecular techniques have enormously improved our understanding of sponge symbioses, by providing the opportunity to localize individual bacterial cells in host tissue through fluorescence in situ hybridization (FISH), characterizing microbial communities taxonomically by high-throughput amplicon sequencing as well as functionally by metagenomics, sorting of unculturable bacteria through fluorescence-assisted cell sorting (FACS) and elucidating their metabolic capabilities by single cell genomics. However, the task of characterizing relationships between sponges and key members of their microbial community as well as elucidating the nature and function of bioactive metabolites in an ecological and evolutionary context remains challenging. ${ }^{26}$ In particular, experimental manipulation of sponge-microbiota associations to reveal symbiont contributions to host fitness is often impossible and remains limited to very few amenable systems. As several recent reviews summarize the literature on natural products from microbes associated with or isolated from sponges, ${ }^{27}$ on methodological developments and approaches to study the possible bacterial origin of spongederived defensive compounds, ${ }^{28-30}$ on sponge symbioses in general, ${ }^{25,31,32}$ and on metabolites isolated from marine organisms including sponges ${ }^{33}$ as well as their potential applications, ${ }^{34-36}$ we focus here on examples where the mutualistic nature of defense, the involved chemistry, and the ecological context have been studied.

Culture-dependent approaches to isolate defensive symbionts. Some of the first insights in sponge defensive symbioses were gained by culture-dependent approaches. Konya et al. ${ }^{37}$ followed the reports of surface-associated compounds influencing the settlement of invertebrate larvae causing fouling, and the idea that bacteria might produce these compounds. Concordantly, they succeeded in isolating an Alteromonas strain from the sponge Halichondria okadai that inhibited the settlement of Balanus amphitrite cyprids. The active compound was identified by bioassay-guided fractionation as ubiquinone-8 1. Several structurally related compounds like other ubiquinones but also vitamin $\mathrm{K}$ inhibited larval settlement as well. ${ }^{37}$ Using a similar approach, Dash et al. ${ }^{38}$ isolated Winogradskyella poriferum from Lissodendoryx isodictyalis, which directly inhibits the settlement of B. amphitite and Hydroides elegans larvae and additionally reduces the growth and biofilm formation of several bacteria that are known to induce larval settlement on sponges. The active compound was identified as a poly-ether 2 of variable chain length. ${ }^{39}$ However, the specificity and prevalence of both associations and their effect on host fitness remain unknown. A different function was reported by Miki et al. ${ }^{40}$ for two Flexibacter sp. isolated from the sponge Reniera japonica. The bacteria produce the carotenoid $3 \mathrm{R}, 3^{\prime} \mathrm{R}$-zeaxanthine $\mathbf{3}$, which is a potent quencher of singlet molecular oxygen and a scavenger of free organic radicals, suggesting a protective role against reactive oxygen species (ROS). 
<smiles>COC1=C(OC)C(=O)C(C/C=C(\C)CC/C=C(\C)CCC=C(C)C)=C(C)C1=O</smiles><smiles>CCOCCOC(C)COC(C)CC</smiles><smiles>CC1=C(/C=C/C(C)=C/C=C/C(C)=C/C=C/C=C(C)/C=C/C=C(C)/C=C/C2=C(C)[C@H](O)CC2(C)C)[C@H](C)C[C@H](O)C1</smiles>

Defensive cyanobacterial symbionts in dictyoceratid sponges. The first culture-independent approaches for the identification of symbiont-produced defensive chemicals in sponges relied on the physical separation of host and symbiont cells. Unson and Faulkner used flow cytometric cell sorting and subsequently located the sesquiterpenes herbadysidolide and spirodysin only<smiles>CC(/C=C1/C(=O)N(C)[C@@H](C[C@@H](C)C(Cl)(Cl)Cl)C(=O)N1C)C(Cl)(Cl)Cl</smiles><smiles>CC(CC(=O)N(C)[C@@H](CCC(Cl)(Cl)Cl)C(=O)NCc1nccs1)C(Cl)(Cl)Cl</smiles><smiles>Oc1c(Br)cc(Br)cc1Oc1ccc(Br)cc1Br</smiles><smiles>Oc1c(Br)c(Br)c(Br)c(Br)c1Oc1ccc(Br)cc1Br</smiles><smiles>COc1c(Br)cc(Br)cc1Oc1c(O)c(C)c(Br)c(C)c1Br</smiles><smiles>CC(NC(=O)C(CC(C)C(Cl)(Cl)Cl)N(C)C(=O)CC(C)(Cl)C(F)(F)Cl)c1nccs1</smiles><smiles>CC(NC(=O)[C@H](CC(C)(C)C)N(C)C(=O)CC(C)C(Cl)(Cl)Cl)c1nccs1</smiles><smiles>CC(CC(=O)N[C@@H](CC(C)(Cl)C(F)(F)Cl)C(=O)N(C)[C@@H](C)c1nccs1)C(Cl)(Cl)Cl</smiles><smiles>CC(CC(=O)N(C)C(CC(C)(C)C)C(N)=O)C(F)(F)F</smiles><smiles>C[C@H](CC(=O)N[C@H](CC(C)(C)C(F)(F)Cl)C(N)=O)C(Cl)(Cl)Cl</smiles><smiles>[Y10]Cc1nccs1</smiles><smiles>CCC1=NCC=C1</smiles>

in tissue of the sponge Dysidea herbacea itself, whereas the polychlorinated diketopiperazides dihydrodysamide $\mathrm{C} 4$ and demethyl-dihydrodysamide $\mathrm{C}$, as well as 13-demethylisodysidenin 5 were only present in the fraction containing the symbiotic cyanobacterium Oscillatoria spongeliae. ${ }^{\mathbf{4 1}}$ Flowers et al. repeated the experiment using density gradient centrifugation, verifying the earlier findings and additionally locating didechlorodihydrodysamide $\mathrm{C}$ within $O$. spongeliae. ${ }^{42}$ They further found a cyanobacterial cell fraction devoid of the chlorinated compounds, indicating either different physiological states or strains of the symbionts. The symbiont-derived compounds were tested for their bioactive potential and shown to strongly deter fish-feeding, suggesting that they are involved in defense against predators in the natural environment. ${ }^{41}$ Interestingly, $D$. herbacea can also carry a different strain of $O$. spongeliae that - instead of the chlorinated compounds produces polybrominated biphenyl ethers 6-8 that not only deter fish-feeding, ${ }^{\mathbf{4 3}}$ but also show antimicrobial activity. ${ }^{\mathbf{4 4}}$ Importantly, these results provided the first description of different sponge chemotypes due to variation in the metabolic profiles of their symbionts, a pattern that was subsequently found repeatedly across several sponge taxa as well as other marine invertebrates. ${ }^{44}$

Using fluorescence in situ hybridization (FISH) and polymerase chain reaction (PCR) amplification, O. spongeliae was also identified as the producer of polychlorinated peptides like dysidenin 9, iso- 10 and neodysidenin 11, 13-demethylisodysidenin 12 and nor-dysidenin 13 in D. herbacea, ${ }^{45}$ some of which have been shown to be toxic for fish. ${ }^{46}$ The primers and probes used for the detection of the dysidenins were based on the biosynthetic gene cluster derived from the cyanobacterium Lyngbya majuscula that produces the homologous compounds barbamide and nordysidenin. The PCR results revealed that not all $O$. spongeliae strains contain the dysidenin gene cluster, resulting in different chemotypes of the sponge host depending on the symbiont strain. ${ }^{45}$ In a more extensive screen, Ridley et al. found species-specific secondary metabolite profiles in four dictyoceratid sponge species, comprising either chlorinated peptides, brominated diphenyl ethers or nonhalogenated compounds, mainly sterols. ${ }^{47}$ Phylogenetic analyses supported a general pattern of co-speciation of the sponges with their respective $O$. spongeliae symbionts, but also revealed a likely host switch. Additional studies confirmed that the presence of unique symbiont strains in different sponge species of the family Dysideidae ${ }^{48}$ conferred the characteristic chemical profiles to their hosts and supported the occurrence of host switches and independent infection events. ${ }^{49}$ Furthermore, $D$. herbacea individuals can harbor an additional symbiont of the genus Synechocystis, which produces the potent neurotoxin dysiherbaine $\mathbf{1 4} .^{\mathbf{5 0}}$ In analogy to the Oscillatoria symbionts, Synechocystis strains vary in their ability to synthesize dysiherbaine, thereby resulting in different host chemotypes. However, the ecological significance of symbiont-mediated dysiherbaine production for the host remains elusive.

Production of bioactive polyketides by sponge symbionts. Polyketide synthases (PKS) ${ }^{51}$ and non-ribosomal peptide synthetases 
(NRPS) $^{52}$ are enzyme complexes that synthesize secondary metabolites based on a stepwise elongation of the product, catalyzed by often repetitive and conserved modules that are encoded in a single operon. The conserved nature of the individual modules provides the opportunity for PCR-based screens with degenerate primers and allows for in silico predictions of possible metabolite structures based on the architecture of the gene cluster. ${ }^{28-30,53}$ PKS and NRPS gene clusters and/or their products have been reported for several different sponge taxa. From the sponge Pseudoceratina clavata, Kim et al. isolated multiple Salinispora spp. that contained a rifamycin-like PKS gene cluster and showed strong in vitro antibiotic activity. ${ }^{54}$ Concordantly, rifamycin B and SV could be isolated in vitro, and specific primers detected the biosynthetic genes in most isolated strains. The carribbean sponge Plakortis simplex contains the polyketide plakortin and several derivatives, in addition to the glycosphingolipids plakosides and simplexides, as well as the crasserides and bacteriohopanoids, all of which are mainly or exclusively known from Sphingomonas bacteria. ${ }^{55}$ Together, these compounds exhibit a wide spectrum of biological activities that might be involved in chemical defense of the sponge against microbes (plakortins: antimicrobial/antimalarial ${ }^{56-58}$ ), fish or other predators (crasserides, ${ }^{59}$ plakortethers ${ }^{60}$ ), or in regulating its microbial community by modulating the host's immune system (plakosides, ${ }^{61}$ simplexides $^{62}$ ). An attempt to isolate the plakortin biosynthesis genes failed, but yielded an unusual polyketide-fatty acid synthase hybrid that supposedly synthesizes an acyl chain with various functional groups, probably containing a sulfate group. ${ }^{63}$ Fisch et al. also exploited the conserved sequence of the ketosynthase (KS) domain to screen metagenomic fosmid libraries from the sponges Psammocinia aff. bulbosa and Mycale hentscheli for candidate bacterial gene clusters involved in the production of psymberin (=ircinastatin A) and mycalamide A, respectively. ${ }^{64}$ These compounds were long known to exert antiviral $^{65,66}$ and selective cytotoxic activity against certain tumor cell lines. ${ }^{67} \mathrm{KS}$ sequences were successfully amplified from both sponge metagenomes, and the entire psymberin locus

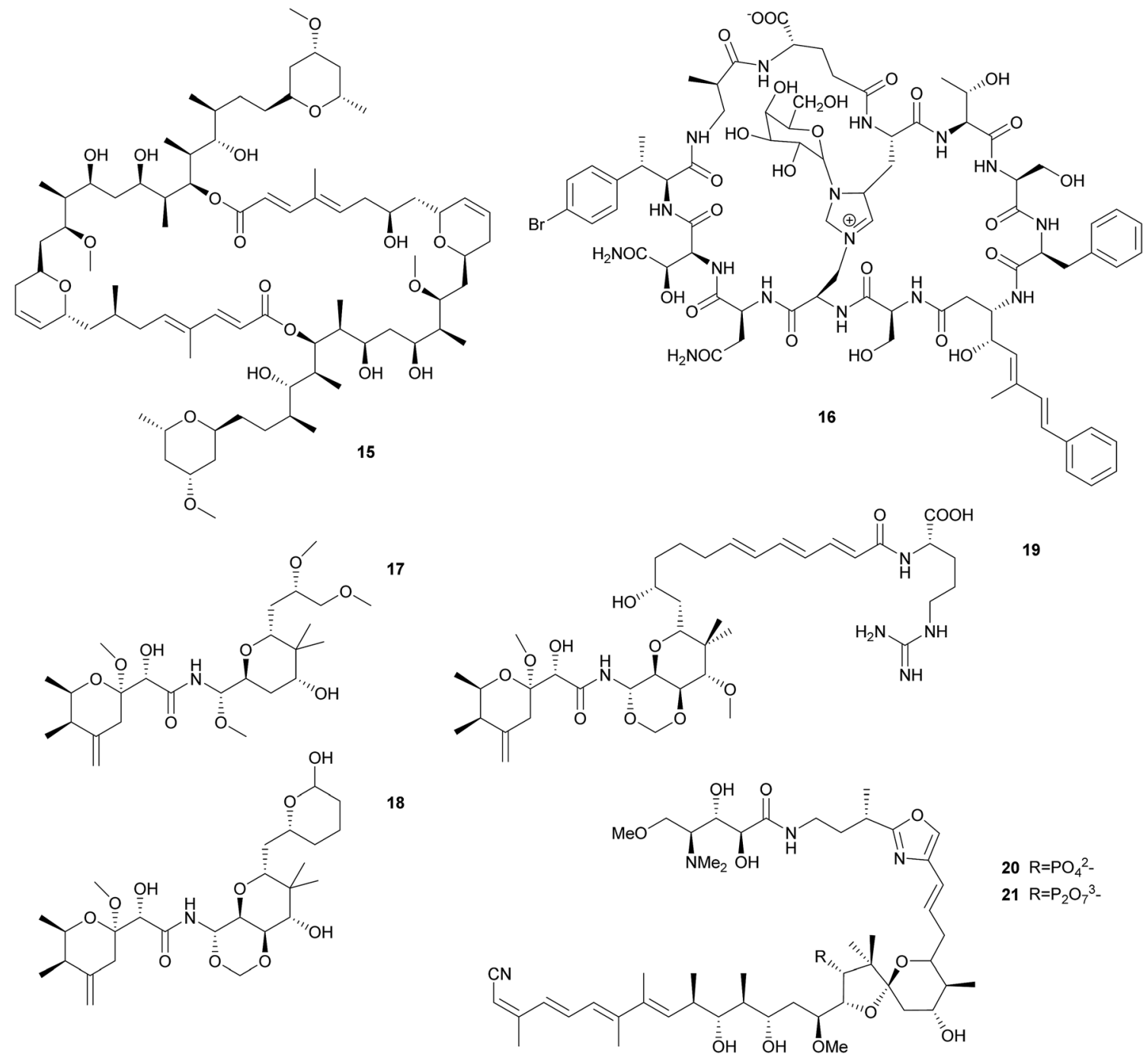


from $P$. aff. bulbosa was sequenced, but the producing bacteria have not been identified.

Sponge-associated symbionts in the candidate genus Entotheonella proved to be an especially rich source of polyketides. Using differential centrifugation, Bewley et al. were able to separate the bacteria associated with the lithistid sponge Theonella swinhoei into three fractions, containing unicellular cyanobacteria, unicellular heterotrophic bacteria, and filamentous heterotrophic bacteria, respectively ${ }^{68}$ The antifungal and cytotoxic $^{69}$ macrolide swinholide A $\mathbf{1 5}$ was isolated from the unicellular heterotrophic fraction, while a cyclic peptide was isolated from the filamentous heterotrophic bacteria. The latter shows high structural similarity to the antifungal theonegramid $^{70}$ and was later named theopalauamide $\mathbf{1 6}$ and also characterized as antifungal. ${ }^{71}$ Schmidt et al. characterized the filamentous symbiont from different $T$. swinhoei chemotypes on the $16 \mathrm{~S}$ rRNA level and found very closely related species in the chemotypes containing theopalauamide, theonegramide and theonellamide A, respectively. ${ }^{72}$ The name 'Candidatus Entotheonella palauensis' was proposed for the strain from the theopalauamide producing chemotype.

The subsequent exploration of the Entotheonella symbionts in T. swinhoei revealed an extraordinarily large biosynthetic repertoire, including the potential for the production of theopederin A, onnamide A, polytheonamides, as well as keramamides, cyclotheonamides, nazumamide, and proteusins. ${ }^{73}$ Interestingly, the identification of a bacterium of the genus Pseudomonas as the producer of the polyketide pederin $\mathbf{1 7}$ in a beetle and the elucidation of its biosynthesis (see 2.2.2) was a useful starting point to identify the genes responsible for polyketide biosynthesis in T. swinhoei, due to the structural similarity of pederin and the cytotoxic theopederin A $18^{74}$ as well as the cytotoxic and antiviral onnamide A 19. ${ }^{75}$ PCR-based screening and subsequent sequencing of metagenomic cosmid libraries of different $T$. swinhoei chemotypes revealed the onnamide gene cluster, ${ }^{53}$ which was confirmed to be of bacterial origin and closely resembles the pederin cluster. This cluster was only detected within the sponge Y chemotype, which contains solely pederin-like metabolites. ${ }^{76}$ Later, Freeman et al. reported the ribosome-produced polytheonamides as additional bacterial products from T. swinhoei, ${ }^{77}$ which form unimolecular ion channels ${ }^{78}$ and are active against Gram-positive bacteria. Wilson et al. finally attributed the metabolic genes of both onnamide and the polytheonamides to Entotheonella by analyzing single cells via differential centrifugation and fluorescence-assisted cell sorting, followed by multiple displacement amplification and whole genome sequencing of individual bacterial cells. ${ }^{73}$ Interestingly, the genome sequences of Entotheonella revealed two very similar strains that both carried a plasmid containing the onnamide and polytheonamide genes, but differed remarkably with regard to chromosomally encoded secondary metabolite gene clusters. In addition to the plasmid-localized clusters, the biosynthetically rich TSY1 strain carried 28 secondary metabolite biosynthetic gene clusters, including those for the synthesis of keramamides, cyclotheonamides, nazumamide, and proteusins, as well as a non-functional konbamide cluster. By contrast, the TSY2 strain carried 'only' seven additional biosynthetic gene cluster, with nearly no overlap in the secondary metabolite repertoire with TSY1. This diversity in biosynthetic potential was found to extend to the Entotheonella symbionts across several sponge taxa, indicating that Entotheonella strains in the newly described bacterial phylum 'Tectomicrobia' will likely serve as a rich source for future discoveries of novel natural products.

Similar to Theonella, the sponge genus Discodermia contains a diversity of bioactive secondary metabolites produced by symbiotic microbes. In fact, Entotheonella symbionts have been reported from different Discodermia species, ${ }^{79-81}$ which present a large diversity of PKS clusters. ${ }^{79,81}$ Additionally, the cytotoxic cyclic peptides calyxamide A and B, structurally similar to the above mentioned keramamides, were isolated from Discodermia calyx. ${ }^{81}$ However, it has only been possible in a single case to unambiguously connect secondary metabolite production to a specific bacterium in a Discodermia host: Wakimoto et al. sequenced the gene cluster responsible for the production of calyculins from the metagenome of $D$. calyx, localized the PKS cluster using FISH within filamentous bacteria and isolated these by laser microdissection..$^{82}$ PCR on the isolated bacteria confirmed the PKS localization and identified the symbionts via 16S rRNA analysis as an Entotheonella species. Interestingly, the authors were also able to characterize a means for storage of a defensive compound in a form that is harmless for the host. The usually cytotoxic calyculin A $\mathbf{2 0}$ is phosphorylated by the Entotheonella symbionts and stored as the less toxic diphosphate 21 . Upon wounding of the sponge, the phosphocalyculin is rapidly converted by a host-derived enzyme to the more than a thousand times more toxic calyculin, thus representing an activated chemical defense mechanism. ${ }^{82}$

Fungal defensive symbioses in sponges. In contrast to the wealth of knowledge on protective bacterial symbionts in sponges, convincing evidence for defensive fungal symbionts is lacking. ${ }^{25,83}$ This is insofar surprising as the number of fungal species isolated from sponges ${ }^{84}$ and their potential for secondary metabolite production is tremendous. ${ }^{33,85} \mathrm{~A}$ few studies have addressed the symbiotic aspect of sponge-fungi relationships, and shown maternal transmission of a yeast in the sponge Chondrilla ${ }^{86}$ horizontal gene transfer between fungi and sponge mitochondria, ${ }^{87}$ as well as fungal recognition proteins in sponges. ${ }^{88}$ Another indication of the potentially symbiotic nature of fungi in sponges is the presence of specific fungal $18 \mathrm{~S}$ rRNA sequences in sponge databases. ${ }^{24}$ Furthermore, sponge-associated fungi were found to contain a large diversity of PKS and NRPS genes, ${ }^{89}$ but their possible roles in the defense of the host remain enigmatic.

2.1.2 Cnidarians. Many corals are intimately associated with algal symbionts as well as a diverse community of bacteria. In particular, dinoflagellate symbionts of the genus Symbiodinium are well-known for their important contributions to the coral hosts' metabolism by providing photosynthetically derived nutrients, ${ }^{90}$ as well as by recycling and assimilating ammonia produced by the host. ${ }^{91}$ Furthermore, endolithic algae of the genus Ostreobium can contribute carbon sources to their host, ${ }^{90}$ and diazotrophic bacteria have 
been found to fix atmospheric nitrogen in the Caribbean coral Montastrea cavernosa. ${ }^{92,93}$ In addition to these nutritional benefits, the microbial associates of corals can play important roles in the defense of their hosts against pathogens and predators. Concordantly, several studies provided theoretical and empirical evidence for the involvement of coral-associated bacterial communities in the defense against microbial pathogens. ${ }^{94-98}$ However, to our knowledge, the chemical basis of bacteria-mediated defensive activities remains unknown. Therefore, we will focus here on the dinoflagellate symbionts of corals and their involvement in the production of two groups of defensive compounds, bioactive diterpenes and secosterols.

Defensive diterpenes. Like many other sessile marine animals, corals are a rich source of bioactive secondary metabolites that play an important role in the defense against predators. ${ }^{\text {99-101 }}$ Among these, the pseudopterosins 22-25 are a group of tricyclic diterpene glycosides with potent antiinflammatory and analgesic activity that were originally isolated from the soft coral Pseudopterogorgia elisabethae. ${ }^{\mathbf{1 0 2 - 1 0 4}}$ Enrichment of $P$. elisabethae's symbiotic dinoflagellates of the genus Symbiodinium by differential centrifugation revealed the predominant localization of the pseudopterosins in the symbiont fraction, suggesting that they are produced by the dinoflagellates. ${ }^{105}$ Concordantly, incubation of this fraction with either $\mathrm{NaH}^{14} \mathrm{CO}_{3}$ or tritiated geranylgeranyl diphosphate $\left({ }^{3} \mathrm{H}\right.$-GGDP) resulted in labeled pseudopterosins. ${ }^{105}$ A similar strategy of symbiont cell enrichment and subsequent radioactive labeling with ${ }^{3} \mathrm{H}$-GGDP revealed the Symbiodiniummediated production of kallolide A 26 in Pseudopterogorgia bipinnata. ${ }^{\mathbf{1 0 6}}$ Interestingly, only one out of four different Symbiodinium strains exhibited kallolide production in vivo, indicating differences in chemical properties and defensive capabilities across different symbionts. ${ }^{\mathbf{1 0 6}}$ Even though the adaptive significance of the symbiont-produced
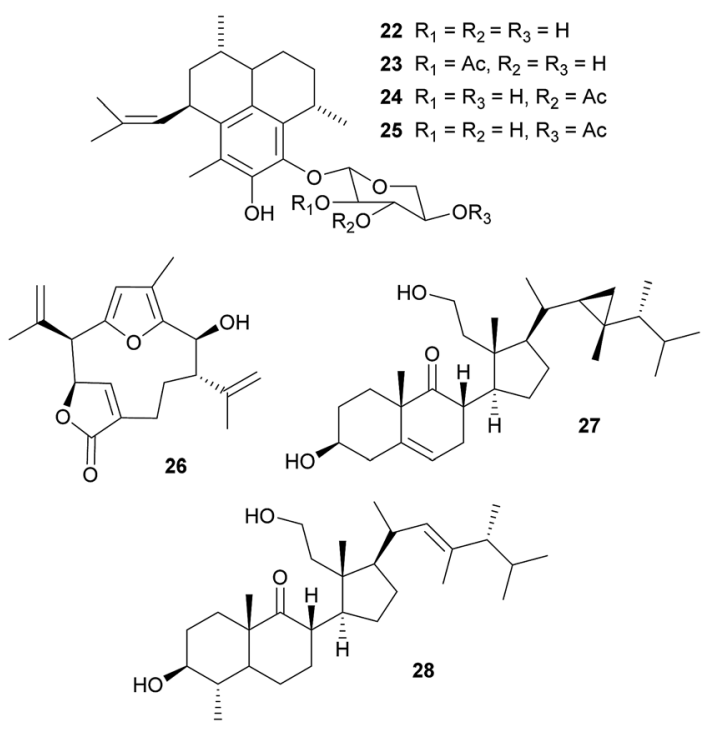

pseudopterosins and kallolides for the coral hosts has not yet been demonstrated in vivo, extracts of both coral species $(P$. elisabethae and $P$. bipinnata) were unpalatable to the generalist fish predator Thalassoma bifasciatum ${ }^{\mathbf{1 0 1}}$ highlighting the potential importance of the Symbiodinium-produced bioactive compounds for the antipredator defense of the coral host.

Secosterols. Secosterols isolated from corals, sponges, and ascidians can exhibit a diverse range of biological activities, including antiproliferative, antifouling, antiinflammatory, antimicrobial, ichthyotoxic and antiviral. ${ }^{\mathbf{1 0 7}}$ In the octocoral Pseudopterogorgia americana, bioassay-guided fractionation revealed the deterrent activity of 9,11-secogorgosterol 27 and 9,11-secodinosterol 28 against predatory fish in laboratory and field assays. ${ }^{108}$ Even though the source of the secosterols in $P$. americana has not been unambiguously identified, zooxanthellae isolated from other marine organisms (including a coral) were reported to produce gorgosterol and dinosterol. ${ }^{\mathbf{1 0 9}}$ Furthermore, gorgosterol is transformed to 9,11-secogorgosterol by enzyme preparations of $P$. americana colonies. ${ }^{\mathbf{1 1 0}}$ Thus, it seems likely that dinoflagellate symbiont-produced precursors are modified by host enzymes to synthesize the defensive secosterols.

Protective symbionts in Hydra. The epithelial surfaces of freshwater polyps in the genus Hydra harbor stable and speciesspecific bacterial assemblages ${ }^{\mathbf{1 1 1 , 1 1 2}}$ that are shaped by the host via antimicrobial peptides. ${ }^{113}$ By generating germ-free animals and reinfecting them with individual bacterial taxa or combinations thereof, a recent study revealed that the symbiotic community of Hydra vulgaris plays an important role in protecting the host against fungal infestation. ${ }^{114}$ Although the mechanistic basis of the protective effect remains to be elucidated, both in vitro and in vivo studies point to a combined activity of the host and its microbiota in pathogen defense. ${ }^{\mathbf{1 1 4}}$

2.1.3 Bryozoans. Bryozoans are a group of sessile marine animals with a dispersive larval stage, comprising close to 6000 described species to date. Although only a small fraction of this biodiversity has been investigated chemically, a large number of compounds with bioactive properties have already been described that may play a role in defense against predators, competitors, parasites, or pathogenic bacteria and fungi.115 Based on (i) the structural similarity to microbially produced substances, (ii) the occurrence of similar compounds in taxonomically distinct bryozoan lineages, and/or (iii) the differences in secondary metabolite profiles across populations of the same species, several defensive compounds isolated from bryozoans have been hypothesized to be of microbial origin, including the phidolopins and other nitrophenols of Phidolopora pacifica, Diaperoecia californica, Heteropora alaskensis, Tricellaria ternata, and Hippodiplosia insculpta, ${ }^{\mathbf{1 1 6}}$ the brominated convolutamides, convolutamines, convolutamydines, convolutindole, volutamides, amathamides, and amathaspiramides in Amathia spp., ${ }^{115,117-119}$ the perfragilins of Biflustra perfragilis, ${ }^{\mathbf{1 2 0 , 1 2 1}}$ as well as various secondary metabolites isolated from Flustra foliacea. ${ }^{\mathbf{1 2 2}}$ However, we will focus here on cases where more direct evidence for a microbial involvement in secondary metabolite production has been provided. 
Bryostatins. The cosmopolitan bryozoan Bugula neritina is chemically defended against predators by a cocktail of cyclic polyketides, the bryostatins. ${ }^{\mathbf{1 2 3 , 1 2 4}}$ While these compounds are present in low concentrations in adult $B$. neritina colonies, the abundance of bryostatin 1029 and bryostatin 2030 is strongly increased in young larvae. ${ }^{125}$ By binding to the diacylglycerol binding site of protein kinase C's regulatory domain, ${ }^{\mathbf{1 2 6}}$ the bryostatins exert toxicity and deterrence to fish, corals, and sea anemones and thereby protect $B$. neritina larvae from predation. ${ }^{\mathbf{1 2 5 , 1 2 7 - 1 3 0}}$ Importantly, attacked and rejected larvae show high rates of settlement, demonstrating a direct fitness benefit from chemical protection. ${ }^{\mathbf{1 2 9 , 1 3 0}}$ After settlement and metamorphosis, bryostatin levels rapidly decrease, indicating a switch from chemical to structural defense as the colony matures. ${ }^{125}$

Soon after the structure elucidation of bryostatin 1 , this compound was suspected to be of bacterial origin rather than produced by $B$. neritina itself. ${ }^{\mathbf{1 3 1}}$ Concordantly, earlier studies had already reported on rod-shaped bacteria that are consistently associated with adult and larval $B$. neritina. ${ }^{132,133}$ Based on the 16S rRNA sequence, these bacteria were later described as a new taxon within the $\gamma$-Proteobacteria and named 'Candidatus Endobugula sertula'. ${ }^{134}$ A series of subsequent studies provided convincing evidence that the bryostatins are indeed produced by ' $\mathrm{Ca}$. E. sertula', thereby constituting one of the best documented cases of defensive symbiosis between animals and microorganisms in the marine environment. Davidson et al. ${ }^{\mathbf{1 3 5}}$ used in situ hybridization to co-localize the symbiotic bacteria and a polyketide synthase (PKS) gene fragment putatively involved in bryostatin synthesis. Simultaneous fluorescent detection of ' $\mathrm{Ca}$. E. sertula' and the bryostatins later revealed the dynamics of bryostatin production during the life cycle of $B$. neritina. ${ }^{115}$ As expected under the hypothesis of symbiontmediated bryostatin synthesis, reduction of symbiont titers in adult $B$. neritina by antibiotic treatment resulted in a strong decrease in bryostatin concentrations. ${ }^{135}$ The offspring of antibiotic-treated colonies likewise showed strong reductions in symbiont abundance and bryostatin concentrations, and symbiont-free larvae failed to deter predatory fish. ${ }^{\mathbf{1 2 8}}$ Interestingly, however, settlement and growth of juvenile $B$. neritina was not affected by symbiont elimination, indicating that the defensive capacities of the symbionts are the only or at least the most important benefit for the host. ${ }^{128}$

Efforts to elucidate the genomic basis of bryostatin production resulted in the discovery of a single large PKS gene cluster (bry) in a $B$. neritina genomic library enriched for bacterial DNA. ${ }^{136,137}$ This gene cluster is expressed in ' $\mathrm{Ca}$. E. sertula' cells in the pallial sinus of $B$. neritina larvae, and expression is not detectable after symbiont elimination through antibiotic treatment, providing further evidence that it is indeed encoded by the ' $C a$. E. sertula' genome. ${ }^{135}$ Bioinformatic predictions supported the biosynthesis of the bryostatin core structure by the bry gene cluster, ${ }^{\mathbf{1 2 4}, \mathbf{1 3 8}}$ and heterologous expression of bryP and bryA confirmed the functionality of these genes. ${ }^{139,140}$ The symbionts of two sibling species of $B$. neritina exhibited high similarity in structure and sequence (98\%) of the bry gene cluster, indicating a common ancestry. ${ }^{\mathbf{1 3 7}}$

The occurrence of bryostatin-producing symbionts was confirmed for two sibling species of $B$. neritina as well as for Bugula simplex. ${ }^{\mathbf{1 4 1 , 1 4 2}}$ Surprisingly, a third sibling species of $B$. neritina was devoid of bryostatin-producing symbionts, ${ }^{\mathbf{1 4 3}}$ but still exhibited deterrence to a fish predator, providing evidence for additional defensive compounds produced by the bryozoan itself or an as yet unknown symbiont. ${ }^{128}$ In Bugula pacifica and $B$. turbinata, symbionts closely related to ' $\mathrm{Ca}$. E. sertula' and ' $\mathrm{Ca}$. E. glebosa' (the symbiont of $B$. simplex) were discovered, but no bryostatin activity could be detected. ${ }^{\mathbf{1 4 4}}$ Interestingly, extracts from $B$. pacifica showed broad-spectrum antibacterial activity, suggesting that defensive compounds other than bryostatins are present and may be produced by the symbionts. ${ }^{145}$ Three additional Bugula species - B. dentata, B. stolonifera, and B. turrita - appeared to be devoid of the symbionts. ${ }^{144}$ The patchy occurrence of Endobugula symbionts across host species indicates a dynamic symbiotic association with frequent host switches or symbiont acquisitions/losses. Given the deficiency in recombination of the symbionts, ${ }^{\mathbf{1 2 4}}$ changes in defensive chemistry by symbiont switches or replacements might be advantageous in the arms race against co-adapting predators. Alternatively, the symbiotic partnership may respond by changing the absolute or relative composition of the bryostatin cocktail, which can influence its activity against predators. ${ }^{128}$

Tambjamines. The tambjamines 31-36 are a group of 4methoxypyrolic natural products that occur across several

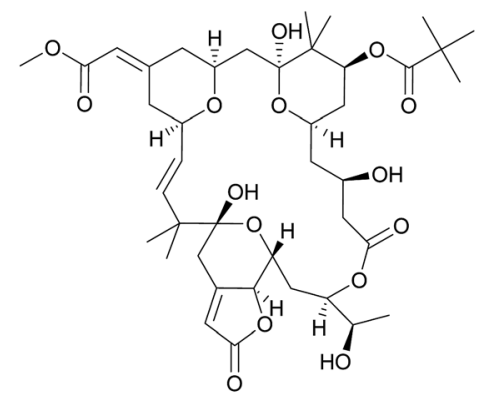

29

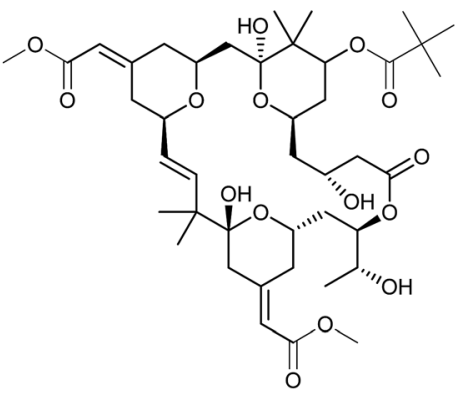

30
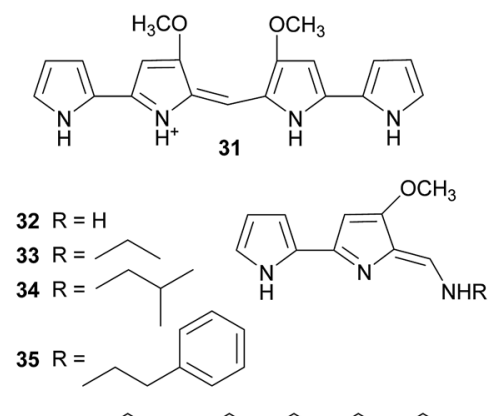

$36 \mathrm{R}=$ 
taxonomically distinct groups of marine organisms, including bryozoans, ${ }^{146,147}$ nudibranchs, ${ }^{148}$ and ascidians. ${ }^{149,150}$ Based on this disparate distribution and the occurrence of identical or closely related compounds in bacteria, ${ }^{\mathbf{1 5 1 , 1 5 2}}$ the tambjamines were suspected to be of microbial origin. The discovery of the tambjamine-producing marine bacterium Pseudoalteromonas tunicata $^{\mathbf{1 5 2}}$ and its association with a range of marine animals ${ }^{\mathbf{1 5 3}}$ - including bryozoans, mussels, ascidians, fish, corals, and sponges ${ }^{153-155}$ - support this hypothesis. Recently, the molecular basis of tambjamine production in P. tunicata was elucidated by heterologous expression of the tam gene cluster in E. coli. ${ }^{\mathbf{1 5 6}}$ The tambjamines show toxicity and/or deterrence against predatory fish as well as antimicrobial activity, indicating that they might confer protection from both pathogens and predators. ${ }^{152,157-161}$ Some predatory nudibranchs, however, are resistant to the adverse effects of tambjamines; in fact, they sequester the bioactive compounds from their bryozoan or ascidian diet and use them for their own defense. ${ }^{\mathbf{1 4 8 , 1 6 0}}$

2.1.4 Nemerteans. Tetrodotoxin 37 (TTX) is a highly potent neurotoxin that is found across a wide range of marine organisms, as well as a few terrestrial animals. ${ }^{162}$ Its chemical structure consists of a guanidine derivative connected to a highly oxygenated carbon skeleton with 30 known analogues. ${ }^{\mathbf{1 6 2}}$ The prevalent hypothesis is that it serves as an antipredatory agent, ${ }^{162}$ although it is also known to be employed by some predators to paralyze their prey. ${ }^{163}$ Owing to the broad array of unrelated metazoans that contain TTX, it has been suggested that the compound is not of endogenous origin but produced by microbial symbionts. ${ }^{164,165}$ In fact, there is strong evidence demonstrating that a number of different bacteria are capable of synthesizing the molecule, ${ }^{\mathbf{1 6 6 , 1 6 7}}$ but insufficient support for a true symbiotic association of these bacteria with the respective host species. Recently, the nemertean ribbon worm Cephalothrix simula was found to contain high concentrations of TTX and several of its analogues. ${ }^{168}$ Shortly after, Magarlamov et al. isolated TTX-producing Bacillus species from $C$. simula individuals and used immunohistochemical methods to tie TTX production to the bacteria and localize the compound in the maturing spores. ${ }^{166}$ If substantiated and combined with more detailed analyses on the nature and consistency of the Bacillus-C. simula association, these results could provide the first demonstration of symbiont-produced defensive TTX. Interestingly, $C$. simula is known to be a food source of the pufferfish, the organism from which TTX was first described, so the fish might sequester TTX from its nemertean diet.

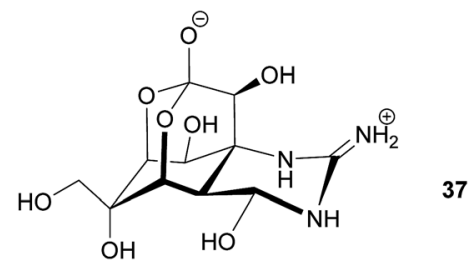

2.1.5 Mollusks. Several mollusks also contain TTX, the prime example being the blue-ringed octopuses of the genus Hapalochlaena, which also carry several bacterial species that produce TTX in culture. ${ }^{162,169}$ However, the nature of the bacteria-octopus association as well as the source of TTX in further mollusks has not been unambiguously identified, so the microbial origin remains speculative. ${ }^{\mathbf{1 6 2 , 1 7 0}}$

Gastropods. An interesting case of symbiont-mediated structural protection has been described in the scaly snail Crysomallon squamiferum, a gastropod occurring at hydrothermal vents. ${ }^{171}$ The snail's foot is covered in hardened scales of multiple layers that likely confer protection against predation. ${ }^{171,172}$ The outer layer is composed of pyrite $\left(\mathrm{FeS}_{2}\right)$ and greigite $\left(\mathrm{Fe}_{3} \mathrm{~S}_{4}\right)$, whose biosynthesis has not been described in metazoans. Interestingly, a community of $\delta$ - and $\varepsilon$-Proteobacteria, which are known for their ability to recycle sulfur and mineralize iron sulfides, were found to live in association with the snail. ${ }^{171}$ Thus, it was suggested that the bacterial partners are responsible for depositing the outer scale layer and thereby confer protection to the snail host. ${ }^{171}$ However, another study based on the structural and chemical composition of the scales suggests that the snail itself controls the biomineralization via sulfur compounds derived from the hydrothermal vents. ${ }^{173}$ To our knowledge, no study to date has taken an experimental approach that aims to manipulate the bacterial community associated with the snail, so the case remains unresolved.

As cone snails are well-known for their arsenal of protective peptide toxins, further microbe-derived defensive compounds were not expected. Surprisingly, however, Peraud et al. found a diverse actinomycete community associated with different cone snails of the genus Conus that displayed bioactive properties. ${ }^{174}$ Streptomyces sp. CP32 isolated from C. pulicarius produces several benzyl thiazole and thiazoline compounds (aerugine, pulicatins $\mathrm{A}-\mathrm{G}$ and watasemycins $\mathrm{A} \& \mathrm{~B}$ ) that exhibit antimicrobial, anti-inflammatory and antihypotensive activity. ${ }^{175}$ Another Streptomyces isolate from C. tribblei that also produces pulicatin A was hypothesized to protect the snail surface against microbial colonization. ${ }^{175}$ Eight nobilamides and two related compounds were identified in further isolates from C. tribblei and Chicoreus nobilis, some of which inhibit the TRPV1 cation channel that is a major mediator of pain and inflammation in vertebrates. ${ }^{176}$ A Gordonia sp. isolate from a different Conus species produces a number of circumcin derivatives that show neuroactivity or broad antimicrobial activity. ${ }^{177}$ Also, another Streptomyces sp. isolated from the recently discovered turrid gastropod Lienardia totopotens produces the antibacterial and cytotoxic lobophorins $\mathbf{3 8 .}{ }^{\mathbf{1 7 8}}$ However, for the majority of these compounds, evidence for a beneficial effect on the host's fitness is lacking, so the possible mutualistic nature of the associations remains to be established. Unlike the previous cases, nocapyrones $\mathbf{3 9}$ are already long known from mollusk secreted mucus. Some are either toxic for various predators or induce escape reactions in conspecifics. ${ }^{179}$ Interestingly, the $n c p$ PKS gene cluster for three derivatives of this class of compounds, which are secreted in the mucus of $C$. tribblei and C. rolani, were identified in the bacterium Nocardiopsis alba. ${ }^{\mathbf{1 8 0}}$

Wood boring bivalve mollusks in the family Teredinidae ("shipworms") harbor various symbionts in their gills ${ }^{\mathbf{1 8 1}}$ and 
gastric caeca, ${ }^{182}$ that are known to contribute to the host's carbon metabolism by providing cellulose degrading enzymes. ${ }^{183}$ Furthermore, Teredinibacter turnerae, found in the gills of the shipworms, seems to be involved in structuring the community of shipworm-associated bacteria. The sequenced genome contains three PKS and six NRPS gene clusters, ${ }^{\mathbf{1 8 4}}$ one of which encodes for the biosynthesis of tartrolons $\mathbf{4 0}$ that occur across all shipworm tissues. ${ }^{\mathbf{1 8 5}}$ While the two isolated tartrolons (one as the free form and the other chelating a boron atom) show no activity against eukaryotic cells or the shipworm's native microbial community, they inhibit the growth of $B$. subtilis and marine pathogenic bacteria. ${ }^{\mathbf{1 8 5}}$
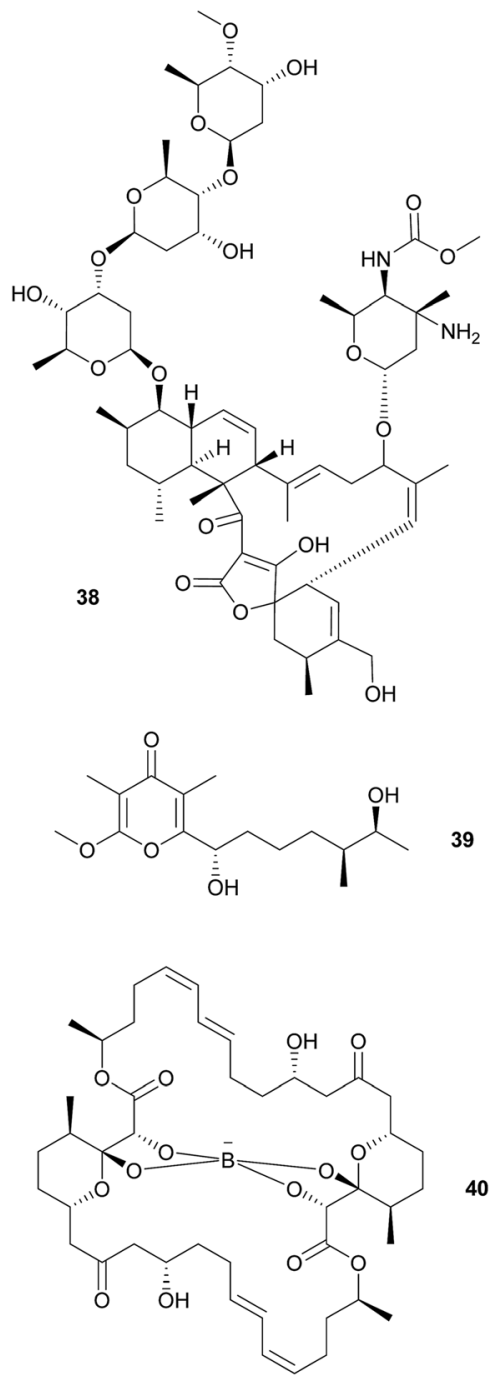

Cephalopods. The association of the Hawaiian bobtail squid, Euprymna scolopes, with the luminescent bacterium Vibrio fischeri is undoubtedly one of the best-studied symbiotic model systems, particularly with regard to the molecular basis of hostsymbiont interactions mediating the specific establishment and maintenance of the association. ${ }^{\mathbf{1 8 6 , 1 8 7}}$ The squid carries $V$. fischeri bacteria in a specialized light organ that helps to disguise the squid from predators and prey through 'counterillumination'. ${ }^{188}$ While not a chemical defense per se, the symbionts' light emission is a by-product of a biochemical

reaction in which luciferase catalyzes the reaction between an aliphatic aldehyde substrate (reduced flavin mononucleotide) and molecular oxygen. ${ }^{\mathbf{1 8 9}}$ The association with bioluminescent $V$. fischeri is not confined to E. scolopes, but also occurs in several other squid as well as fish species. ${ }^{189}$

Presumably, symbiotic bacteria also reside within the accessory nidamental gland (ANG) of several squid genera, including Loligo, Sepia and Euprymna. The ANG houses a highly specific bacterial community of $\alpha$ - and $\gamma$-Proteobacteria as well as Bacteroidetes, with Roseobacter dominating in Loligo and Sepia species, and Phaeobacter in Euprymna scolopes. ${ }^{\mathbf{1 9 0 - 1 9 2}}$ Sexual maturity in these squids is accompanied by the enrichment of symbiont-synthesized carotenoids, although the exact function of those carotenoids remains unknown. It is also uncertain whether a specific carotenoid-producing physiological stage in the bacteria is required for maturity of the females, or whether maturing females induce the bacteria to produce the carotenoids. ${ }^{193-195}$ During oviposition, the bacteria are transferred from the ANG to the eggs and likely serve as an inoculum resulting in dense bacterial populations within the egg capsules. $^{192}$ However, no symbiotic bacteria were found on hatched embryos, indicating that the squids acquire their symbiotic microbiota de novo from the environment in every generation. ${ }^{196,197}$ Extracts from the ANG contained high amounts of unsaturated fatty acids and exhibited antimicrobial activity, as did egg extracts and bacterial isolates. ${ }^{198-200}$ In addition to active inhibition, the secreted bacteria might provide colonization resistance of the egg capsules by depleting nutritional resources. ${ }^{201}$

2.1.6 Crustaceans. The best studied protective symbioses in crustaceans are among the earliest known examples of defensive alliances in animals. Gil-Turnes and colleagues were able to show that symbiont-produced chemicals protect embryos of both the shrimp Palaemon macrodactylus and the lobster Homarus americanus against phycomycetous fungi, including the pathogen Lagenidium callinectes. ${ }^{202,203}$ In P. macrodactylus, the symbiont was identified as an Alteromonas species that produces 2,3-indolinedione (istatine) 41. This compound restored the protective effect in embryos that had previously been experimentally depleted of their symbionts. ${ }^{202}$ In $H$. americanus, epibiotic Gram-negative bacteria protect the embryos from pathogenic fungi by producing 4-hydroxyphenethyl alcohol (tyrosol) $\mathbf{4 2 ,},{ }^{203}$ which has also been described as a protectant of fungal plant symbionts against phytopathogens. ${ }^{204,205}$<smiles>O=C1Nc2ccccc2C1=O</smiles>

41

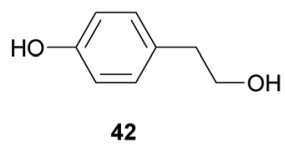

A symbiosis with both nutritional and defensive benefits occurs in marine isopods of the genus Santia. ${ }^{206}$ These crustaceans harbor a photosynthetically active episymbiotic community comprising Cyanobacteria of the genus Synechocystis. In order to provide their symbionts with suitable conditions for 
photosynthesis, the isopods occupy exposed areas with sufficient sunlight. Two investigated populations or species (the actual status has not been determined) showed remarkable differences regarding their symbionts and the defense against predators. One population, whose large epibiotic Synechocystis symbionts confer a characteristic red coloration to their hosts, is usually ignored or rejected by predatory fish, while the other population carrying an inconspicuous brown Synechocystis strain is readily consumed. ${ }^{206}$ The symbiont seems to be vertically transmitted from mothers to newly emerged juveniles and - in addition to the difference in color - shows morphological strain variation across the two host populations. ${ }^{206}$ When experimentally removed from their surface, the isopods were equally consumed by fish. Methanol extracts of isopods with their red symbionts partially restored protection, indicating that symbiont-produced bioactive metabolites are involved in their host's defense against predators. ${ }^{206}$ However, the chemical basis of the protective effect remains to be elucidated.

2.1.7 Tunicates. Tunicates are sessile or pelagic filter feeders that occur worldwide in marine environments. Among tunicates, the colonial ascidians are an especially rich source of secondary metabolites, many of which are believed to originate from microbial associates. Comprehensive reviews on ascidian natural products including many compounds of likely microbial origin - based on the structural similarity to metabolites of free-living bacteria - have been published previously. ${ }^{207-209}$ As for the other marine invertebrates, we will focus here on cases with experimental evidence for symbiont-produced secondary metabolites that are putatively involved in the defense of the host against antagonists. One group of compounds, the tambjamines, is present across diverse marine animals including tunicates, bryozoans, and mollusks. These compounds have already been discussed collectively in the section on bryozoa.

Didemnid ascidians. Colonial ascidians of the family Didemnidae have been studied extensively as producers of a rich repertoire of bioactive secondary metabolites, many of which are produced by microbial symbionts. ${ }^{12,207-210} \mathrm{We}$ will focus here on five groups of compounds, for which a symbiotic origin has been demonstrated or is at least very likely: the cyanobactins (including patellamides, trunkamide, lissoclinamides, patellins, and many others), didemnins, patellazoles, bistramides, and palmerolides.

Many didemnid ascidians live in an obligate symbiosis with vertically transmitted Cyanobacteria of the genera Prochloron or Synechocystis. ${ }^{\mathbf{2 1 1 - 2 1 3}}$ Prochloron symbionts have been found on the surface and/or in the common cloacal cavity of colonial didemnids such as Lissoclinum patella, L. bistratum, L. voeltzkowi, L. punctatum, Trididemnum cyclops, T. clinides, Didemnum molle, and Diplosoma virens, ${ }^{212,213}$ while Synechocystis is associated with ascidians of the genus Trididemnum. ${ }^{211}$ Through photosynthesis, the cyanobacterial symbionts make a major contribution to the hosts' energy demands, and they play an important role in the recycling of nitrogenous compounds. ${ }^{214}$ In addition to these nutritional contributions, the symbionts have been implicated in the production of bioactive secondary metabolites that play a role in the defense of the host. ${ }^{207,209}$

The didemnins, potent antiviral and antitumor cyclic peptides, were first isolated from the Caribbean ascidian Trididemnum solidum, ${ }^{215,216}$ which hosts the cyanobacterial symbiont Synechocystis trididemni. ${ }^{\mathbf{2 1 1}}$ Behavioral assays demonstrated that $T$. solidum larvae are distasteful to predatory fish species, and two isolated didemnins (didemnin B 43 and nordidemnin B 44) significantly deterred predators when applied at naturally occurring concentrations. ${ }^{158,217,218}$ Since didemnin B was also found in a phylogenetically distant ascidian and shows structural similarity to metabolites from free-living cyanobacteria, it was suspected to be of symbiotic origin in T. solidum. ${ }^{209}$ While there is to our knowledge no direct evidence supporting a cyanobacterial source of the didemnins in T. solidum, the recent discovery of a plasmid-localized didemnin biosynthetic gene cluster in the free-living $\alpha$-Proteobacteria Tistrella mobilis and $T$. bauzanensis $\mathbf{2 1 9 2 0}^{\mathbf{1 9}}$ raises the possibility that $S$. trididemni has acquired the potential for didemnin biosynthesis via horizontal gene transfer.

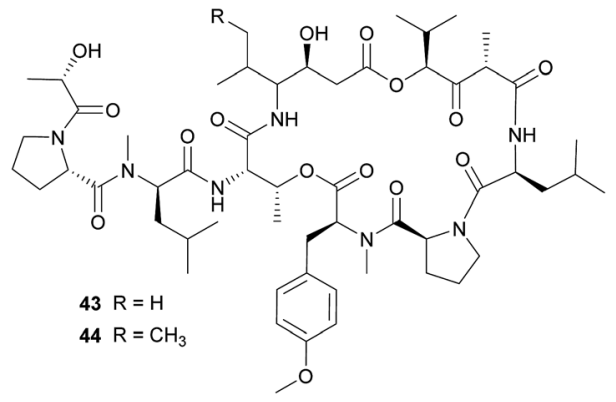

In analogy to the didemnins, it was long suspected that another group of cyclic peptides in ascidians, the cyanobactins (including the patellamides 45 , trunkamide 46 , lissoclinamides 47, patellins 48, and many others), are produced by cyanobacterial symbionts. This hypothesis was based on the cooccurrence of Prochloron symbionts and cyanobactins in several didemnid ascidians, particularly those of the genus Lissoclinum. ${ }^{221}$ Indeed, more recent studies identified the Prochloron gene cluster responsible for patellamide production (pat) and demonstrated its activity by heterologous expression in Escherichia coli. ${ }^{222-224}$ Notably, the discovery of the pat gene cluster ${ }^{224}$ represents one of the first examples to elucidate the biosynthetic pathway for the production of a symbiont-produced defensive metabolite in a marine system by whole genome sequencing. Interestingly, the pat cluster is highly conserved across Prochloron symbionts of diverse hosts, but hypervariable cassettes in the precursor peptide result in the large diversity of cyclic peptides. ${ }^{222}$ Analogously, the tru cluster is responsible for the synthesis of diverse patellins, including trunkamide, and it shares a high degree of similarity with the pat genes, except for the region that is likely involved in the prenylation of the patellins. ${ }^{25}$ Thus, the variability of the cyanobactin gene clusters confers the metabolic versatility to the ascidian symbiosis as well as to free-living cyanobacterial relatives. ${ }^{225}$ Even though the fitness benefits of symbiont-mediated cyanobactin 


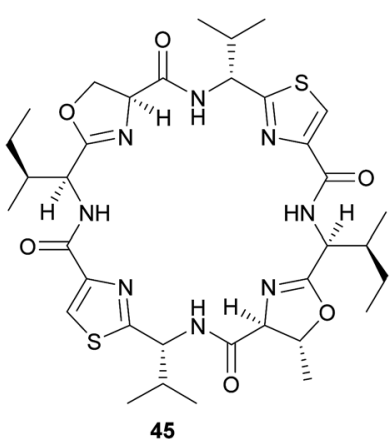

45<smiles>C=CC(C)(C)OC[C@H](NC(=O)[C@H](NC(=O)C1CSC(Cc2ccccc2)=N1)[C@@H](C)OC(C)(C)C=C)C(=O)N[C@@H](Cc1ccccc1)C(=O)N[C@@H](C)C(=O)N1CCC[C@H]1C(=O)O</smiles><smiles>[Z17]C(C)C[C@H](NC(=O)[C@H]1C=NC([C@@H]2CCCN2C(=O)[C@H](Cc2ccccc2)NC(=O)c2csc(C(Cc3ccccc3)NC(=O)C3CSC(C(C)C)O3)n2)=N1)C(C)C</smiles>

46<smiles>COC(/C(C)=C/C=C/C(C)C(OC(=O)C(C)(CCC(C)CC(O)C(C)C(=O)C(C)/C=C/CC(C)C(O)C(O)C(C)O)OC(=O)C(C)C(C)O)C(C)(O)/C=C(\C)Cc1csc(C2(C)OC2C)n1)C(C)C(C)O</smiles>

production for the host have not been demonstrated, their abundance in ascidian tissues and toxicity against eukaryotic cells strongly imply a protective function..$^{1,209}$

In addition to the cyanobactins, individuals of the ascidian Lissoclinum patella are occasionally found to contain the toxic patellazoles 49, a group of thiazole-containing polyketides. ${ }^{226,227}$ Metagenomic approaches towards the identification of the patellazole-producing organisms excluded the Prochloron symbionts as possible candidates and rather pointed to a proteobacterial origin of these secondary metabolites. ${ }^{228}$ Subsequent studies verified this by identifying the patellazole gene cluster (ptz) in the intracellular $\alpha$-proteobacterial symbiont 'Candidatus Endolissoclinum faulkneri'. ${ }^{229}$ Interestingly, apart from the trans-AT PKS gene cluster responsible for patellazole synthesis, the genome of ' $\mathrm{Ca}$. E. faulkneri' shows clear signs of erosion, with a strongly reduced size and coding density, an ATbiased nucleotide composition, and the loss of regulatory genes involved in DNA replication and cell division. ${ }^{229}$ Thus, ' $\mathrm{Ca}$. E. faulkneri' appears to be an obligate defensive mutualist of $L$. patella, similar to the recently discovered 'Candidatus Profftella armatura' in the asian citrus psyllid, which retained the complete pathway for the putatively defensive compound diaphorin in an otherwise eroded genome ${ }^{230}$ (see 2.2.2). As for the cyanobactins, the role of the patellazoles in the defense of the symbiosis against antagonists still needs to be established.

Other polyketides in didemnid ascidians include the bistramides 50 of Lissoclinum bistratum, ${ }^{231-234}$ and the palmerolides 51 of Synoicum adareanum. ${ }^{235}$ While the former were localized to the Prochloron symbionts by cell fractionation, ${ }^{231}$ the evidence for a microbial origin of the latter is limited to the sequencing of bacterial trans-AT PKS ketosynthase domain fragments putatively involved in palmerolide synthesis. ${ }^{235}$ Finally, it should be noted that metagenomic analyses of Prochloron symbionts in L. patella revealed further secondary

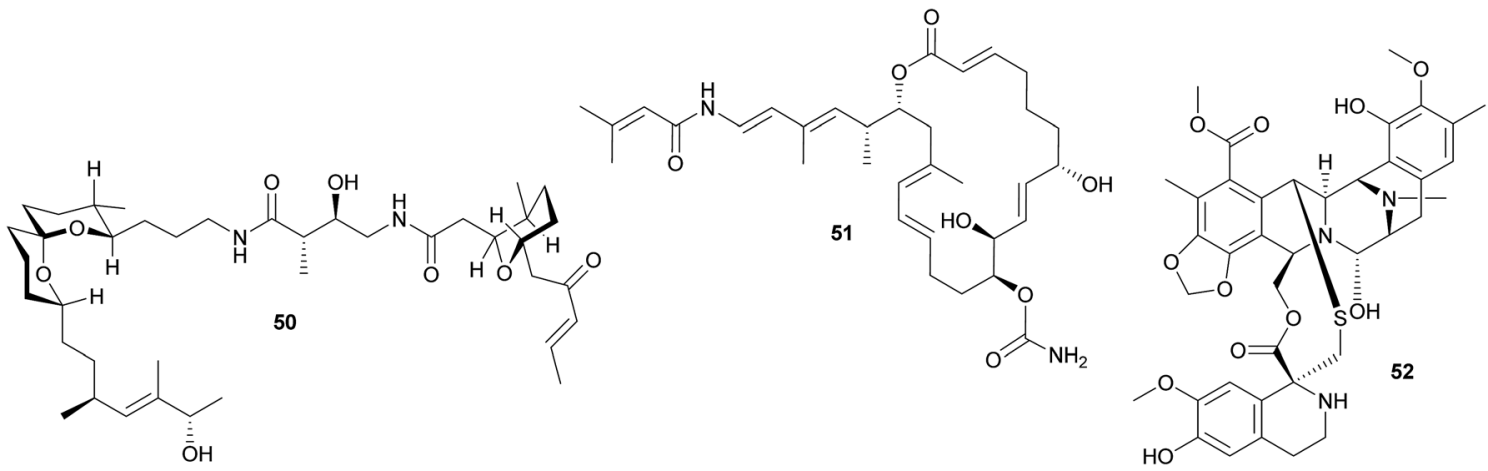


metabolite gene clusters, which may be involved in the synthesis of as yet unknown bioactive compounds for protection against antagonists. ${ }^{236}$

Other ascidians. The intracellular $\gamma$-proteobacterial symbiont 'Candidatus Endoecteinascidia frumentensis' was identified in the mangrove ascidian Ecteinascidia turbinata (Perophoridae). ${ }^{237,238}$ The bacteria are probably vertically transmitted, and recent studies identified the core of an NRPS biosynthetic gene cluster that could be tied to the intracellular symbiont through analyses of the codon usage. ${ }^{239}$ This cluster is likely responsible for the synthesis of the secondary metabolite ecteinascidin 743 52 (ET-743), ${ }^{239}$ a promising anti-cancer agent that is highly toxic to eukaryotic cells and may therefore serve as an anti-predator defense in the ascidian symbiosis.

\subsection{Terrestrial invertebrates}

2.2.1 Entomopathogenic nematodes. Among the chemically best-studied defensive symbioses are those between entomopathogenic nematodes and their bacterial partners. ${ }^{\mathbf{2 0 2 4 0 - 2 4 3}}$ Following the speculation of bioactive compounds produced by bacterial symbionts of Steinernema nematodes in $1959,{ }^{\mathbf{2 4 4}}$ and the first identification of symbiont-produced compounds in $1981,{ }^{245}$ a steady flow of reports has resulted in the description of more than 40 bioactive metabolites from nematode symbionts.

The two entomopathogenic nematode families Steinernematidae and Heterorhabditidae are characterized by their obligate association with bacteria in the $\gamma$-proteobacterial genera Xenorhabdus and Photorhabdus, respectively. Although some of these symbionts can occur in multiple hosts, most strains are species-specific and essential for growth and reproduction of their nematode hosts. ${ }^{20}$ Specifically, they assist the nematode in overcoming the immune system of the insect prey, killing it, and protecting the cadaver against microbial and animal competitors. $^{246}$ To this end, an arsenal of diverse bacterial metabolites do not only repel insect scavengers like ants, but are also active against viruses, con- and hetero-specific bacteria, saprobic fungi, protozoa and nematode competitors. Their defensive chemistry enables the bacteria to essentially monopolize the insect for 1-2 weeks after colonization, which ensures optimal resource use by the nematode-symbiont consortium as well as successful acquisition of the symbiont by the host offspring. ${ }^{20}$ Here we review the protection of the insect cadaver through defensive chemical compounds synthesized by the bacteria, but do not discuss the chemistry involved in killing the insect host, which is an offensive rather than defensive symbiont-provided benefit and has been reviewed extensively elsewhere. ${ }^{20,241,243}$

All Steinernema and Heterorhabditis nematodes go through an infective free-living juvenile phase, during which they carry the bacterial symbionts in their intestinal tract. After location of a suitable prey by active search or ambushing, the nematode enters the insect through the respiratory or digestive system, penetrates the hemocoel and releases the bacterial symbionts. $^{247}$ The host insect is typically killed 24-48 hours after infection, which is when the bacteria reach high abundances.
Most defensive compounds are produced by the bacteria during the following post-exponential phase of growth. For both nematodes and their symbionts, successful colonization of the insect host is crucial, as nematodes cannot re-emerge from an insect after infection and thus have only a single chance to colonize a host. ${ }^{247}$ This may explain why both Xenorhabdus and Photorhabdus independently evolved extraordinarily effective insect-killing and carcass-defending abilities. ${ }^{248}$ However, although functionally similar by conferring protection against the same enemies, the defensive metabolites of both groups are structurally very different.

Broad-spectrum antibiotic activity of metabolites from the bacterial symbionts of nematodes against Gram-positive and Gram-negative bacteria, yeasts and filamentous fungi was already demonstrated in the 1980's, long before the chemical nature of most of the antibiotic substances was known. ${ }^{249-251}$ Subsequently, researchers attributed these antimicrobial effects to a series of (i) highly specific proteinaceous bacteriocins, i.e. lumicins ${ }^{252}$ and photorhabdicins ${ }^{253}$ from Photorhabdus spp., and xenorhabdicins ${ }^{254-256}$ from Xenorhabdus spp.; (ii) broadspectrum antibacterial and antifungal compounds, including isopropylstilbenes, ${ }^{245,257,258}$ antraquinones, ${ }^{242,259}$ and a carbapenem $^{260}$ from Photorhabdus spp., as well as fabclavines, ${ }^{261}$ xenorhabdins, ${ }^{262,263}$ xenorxides, ${ }^{242}$ and nematophins, ${ }^{245,264}$ from Xenorhabdus spp.; and (iii) narrow-spectrum anti-Gram-positive xenobactin, ${ }^{265}$ xenematide ${ }^{266}$ and xenocoumacins, ${ }^{267}$ and antiGram-negative benzylideneacetone ${ }^{\mathbf{2 6 8}}$ from Xenorhabdus spp. Additionally, several other metabolites including xenoamicin, ${ }^{265}$ taxlllaids,${ }^{269}$ cyclohexandione, ${ }^{270}$ chaiyaphumine ${ }^{271}$ and szentiamide ${ }^{272,273}$ with activity against human-disease causing protozoa (Plasmodium falciparum, Trypanosoma brucei) have been identified. While it is possible that these compounds defend the nematodes against competitors within the insect cadaver, direct evidence for their ecological role is thus far lacking. Finally, both Photorhabdus and Xenorhabdus spp. produce rhabduscin $\mathbf{5 3}$ and chitinases, both with a dual function - the promotion of prey killing/digestion and defense against fungal competitors ${ }^{274-276}$ - and small molecules that deter animal scavengers. ${ }^{20}$ In the following paragraphs, we will expand on the nature and function of the defensive compounds, with a focus on the bacteriocins and the anti-bacterial small molecules.

Bacteriocins are killer proteins used by bacteria to defend themselves against closely related competitors. ${ }^{20,253}$ In Photorhabdus and Xenorhabdus, three kinds of bacteriocins, the lumicins, photorhabdicins and xenorhabdicins, have been described. Normally detectable in low quantities, their production is strongly induced when bacterial cells are lysed. ${ }^{255}$ Xenorhabdicins were first described from $X$. nematophila and shown to be active against strains of Xenorhabdus, Photorhabdus, and related sister taxa. ${ }^{256}$ Likewise, Photorhabdus spp. synthesize photorhabdicins and lumicins. ${ }^{252}$ The biosynthetic genes for lumicins have been shown to be co-localized with the respective resistance genes, which together are highly diverse between symbiont strains. ${ }^{253}$ This likely ensures specificity of the bacteria-nematode partnership, if multiple founder nematodes colonize the same insect. Indeed, assays with different 
Xenorhabdus strains showed that their bacteriocins are primarily active against conspecific rather than heterospecific strains. ${ }^{254}$

Defense against unrelated bacterial competitors (e.g. the insect's gut community), fungi and animals is mediated by extracellular, non-proteinaceous small molecules with variable narrow- to broad-spectrum activity. ${ }^{\mathbf{2 0 2 4 2 , 2 5 0}}$ Together, these compounds assure that the insect carcass does not putrefy for several weeks until the nematodes disperse. ${ }^{277}$ In Photorhabdus, carbapenem-like molecules, as well as isopropylstilbenes and anthraquinone pigments are mainly responsible for this effect. ${ }^{245,258,259,277,278}$ Carbapenems are $\beta$ lactam antibiotics that are best known from Enterobacteria. In $P$. luminescens, a gene cluster responsible for the production of a carbapenem-like molecule with specific activity against Gram-negative bacteria has been identified. ${ }^{277}$ This strain also synthesizes isopropylstilbene antibiotics that generally suppress bacterial growth by inhibiting RNA synthesis, of which one, 3,5-dihydroxy-4-isopropylstilbene $\mathbf{5 4}$, is also strongly fungicidal, nematicidal and insecticidal. ${ }^{20,251,258,279}$ This compound is probably of crucial importance for defense, as large amounts are synthesized by the symbionts from days 2-5 after colonization of the insect prey throughout the following weeks until the cadaver is abandoned. ${ }^{257,280}$ Anthraquinone pigments 55 produced by a type II $\mathrm{PKS}^{281}$ are responsible for the red color of insects killed by Photorhabdus. ${ }^{278}$ Several of these pigments have been isolated from the bacterial symbionts, which is remarkable as these compounds normally occur only in higher plants, lichens and fungi. ${ }^{242,258,259,282}$ Anthraquinone derivatives have antibiotic and nematicidal properties, thus indicating a defensive function. ${ }^{241,259}$ This is also assumed for photobactin 56, a catechol siderophore from $P$. luminescens, although its exact function remains to be determined. ${ }^{260}$

Xenorhabdus spp. synthesize a different array of bioactive small molecules, including xenorhabdins, xenorxides, fabclavines, indole derivatives, xenocoumacins, xenematide, xenobactin, and benzylideneacetone..$^{20,241,251,261}$ Xenorhabdins 57-63, the largest group among these, are dithiolopyrrolone derivatives (compounds also known from Streptomyces) with suppression of Gram-positive bacteria and fungi by inhibition of RNA and protein synthesis..$^{251,262,283}$ In many cases, several xenorhabdins are produced by the same bacterial strain, and as some are also insecticidal, they fulfill a double function by killing the insect and preserving/protecting the carcass against competitors. ${ }^{242}$ Oxidized xenorhabdins, the so-called xenorxides, are broad-spectrum defensive metabolites against both Gram-positive and Gram-negative bacteria as well as fungi. ${ }^{242}$ Four types of fabclavines have been identified from $X$. budapestensis and $X$. szentirmaii and are active against a broad spectrum of bacteria, fungi and protozoa. ${ }^{261}$ Indole derivatives, like nematophin from $X$. nematophilus, ${ }^{264}$ likewise have a broad activity spectrum and are comparable to isopropylstilbenes in terms of their mode of action. ${ }^{245,251}$ By contrast, xenocoumacins, xenematide and xenobactin inhibit Gram-positive bacteria, ${ }^{\mathbf{2 4 1 , 2 6 6 , 2 6 7}}$ with xenobactin 64, a hexadepsipeptide, also being active against protozoa. ${ }^{265}$
Complementary to xenobactin, benzylideneacetone (trans-4phenyl-3-buten-2-one) 65 specifically suppresses growth of Gram-negative bacteria. ${ }^{268}$<smiles>[C-]#[N+]/C=C/c1ccc(OC2C(C)C(O)C(O)C(NC(C)=O)C2O)cc1</smiles><smiles>CC(C)c1c(O)cc(/C=C/c2ccccc2)cc1O</smiles><smiles>CC(C)(C)c1cc(O)cc(O)c1C(=O)c1cccc(O)c1</smiles><smiles>CC1OC(c2cccc(O)c2O)=NC1C(=O)NCCCCNC(=O)c1cccc(O)c1O</smiles>

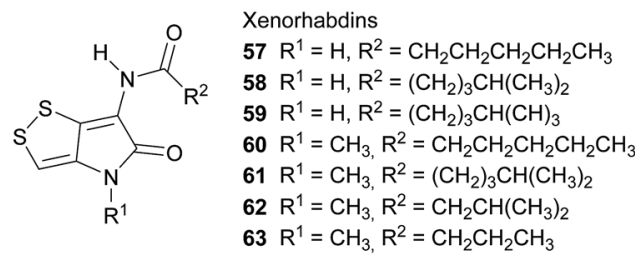

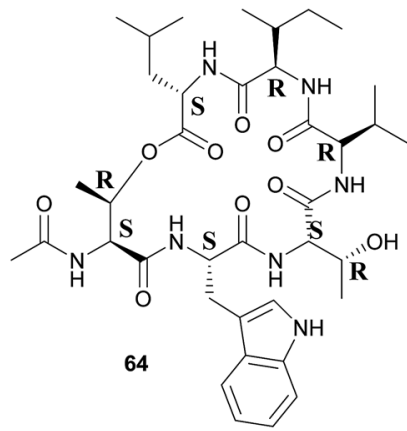<smiles>CC(=O)/C=C/c1ccccc1</smiles>

65

Ant-deterrent factors (ADFs) are small extracellular molecules that protect insect cadavers infected by both the Heterorhabditis-Photorhabdus and the Steinernema-Xenorhabdus symbiotic complexes against scavenging arthropods, particularly ants. ${ }^{284}$ ADF repellency depends on the strain and age of the bacteria and the ant species tested, ${ }^{285}$ with the Heterorhabditis-Photorhabdus association being the better protected complex. ${ }^{284}$ To date, however, the chemicals responsible for antdeterrent effects have not been identified.

2.2.2 Insects. The exploration of insect-microbe interactions has shed light on many important aspects of the ecology and evolution of symbiotic associations. ${ }^{286}$ While research in this area has traditionally focused on interactions with a nutritional basis, more and more defensive symbioses are being discovered that significantly expand our understanding of the 
prevalence, diversity, relevance, and mechanistic basis of protective symbioses in general. ${ }^{15-17,19}$

Symbiotic antipredator defense. Natural enemies of insects include predators, parasitoids, and microbial pathogens, as well as nematodes and viruses. Examples of symbiontconferred protection have been discovered against all of these antagonists. However, an anti-predator function has so far only been demonstrated for the association between rove beetles (Paederus spp.) and a close relative of Pseudomonas aeruginosa. ${ }^{287}$ These $\gamma$-Proteobacteria are capable of producing pederin 14, a potent toxin that is synthesized using enzymes of the trans-AT PKS family and resembles onnamide-type natural products found in sponges (see 2.1.1). ${ }^{10}$ The ecological relevance of this defensive compound is supported by the observation that beetle larvae hatching from pederincontaining eggs experience reduced predation from wolf spiders as compared to pederin-free larvae. ${ }^{288}$ Interestingly, there is evidence that the symbionts have horizontally acquired the genes required for the production of pederin, suggesting that mobile genetic elements may explain the widespread capability of producing highly similar bioactive metabolites in a range of phylogenetically distant symbiotic partners. ${ }^{289}$ In fact, a recently described case of a probable defensive symbiosis between the asian citrus psyllid and the $\beta$-Proteobacterium 'Candidatus Profftella armatura' further supports this hypothesis. ${ }^{230}$ The highly reduced genome of the bacterial symbiont encodes the complete gene cluster for the synthesis of diaphorin $\mathbf{6 6}$, a toxin that is structurally very similar to onnamides and pederin. Thus, the gene cluster might have been transferred to or from the rove beetle symbiont. Notably, ' $\mathrm{Ca}$. P. armatura' and the production of diaphorin are observed without exception among individuals within and across geographically distant psyllid populations. This high prevalence suggests an obligate mutualistic association and diverges from the usually intermediate infection frequencies described for the majority of defensive symbioses. ${ }^{230}$

Symbiont-mediated protection against parasitoids, fungi, and nematodes in aphids and fruit flies. One of the earliest known cases of symbiont-mediated defense in insects involves the protection against parasitoid wasps in aphids. In the aphid Acyrthosiphon pisum, Hamiltonella defensa bacteria confer protection against the wasp Aphidius ervi. ${ }^{290}$ However, this defensive action depends on the presence of the bacteriophage APSE (A. pisum secondary endosymbiont) in the symbiont, which encodes toxins that are likely candidates for the defensive activity. Concordantly, three APSE variants that confer different degrees of protection carry distinct toxin genes, encoding for the production of shiga toxin, cytolethal distending toxin, and YD-repeat toxin, respectively. ${ }^{19} \mathrm{H}$. defensa also protects other aphid species against parasitoids, i.e. Aphis fabae and likely also Aphis craccivora,${ }^{19}$ although the same defense mechanism might not operate in other host species like the grain aphid (Sitobion avenae). Interestingly, however, an alternative strategy for protection by this secondary symbiont in $S$. avenae is still likely, as parasitoid wasps preferentially oviposit in $H$. defensa-free eggs. ${ }^{291}$ In addition to Hamiltonella, the secondary symbionts
Regiella insecticola and Serratia symbiotica can provide resistance against parasitic wasps in aphids. These cases, however, are not bacteriophage-mediated, suggesting alternative strategies for protection. ${ }^{19}$ Symbiont-conferred protection against parasitoids has also been reported in other insects, e.g. Drosophila hydei, in which Spiroplasma can defend the larvae against the wasp Leptopilina heteroma. ${ }^{292}$ Additionally, some studies suggested that Arsenophonus in psyllids ${ }^{293}$ and Wolbachia in the weevil Hypera postica ${ }^{294}$ can similarly enhance the resistance of the host against parasitoids. In both cases, however, further experimental evidence is required to confirm the existence of a defensive symbiosis and to elucidate the mechanistic basis of protection.

The role of facultative symbionts in the defense against pathogenic fungi has also been studied in aphids. While Hamiltonella appears to have no effect on aphid susceptibility to fungal pathogens, at least four other secondary symbionts of the pea aphid (Rickettsia, Rickettsiella, Regiella and Spiroplasma) are capable of increasing survival chances of aphids exposed to the entomopathogen Pandora neoaphidis. ${ }^{295,296}$ In addition, the presence of these symbionts also reduces sporulation efficiency of the fungus in those cases where the pathogen kills the aphid. This may be adaptive for the aphids by reducing the spread of infection among groups of clonal aphids, thereby enhancing the inclusive fitness of the clone ${ }^{295,296}$ However, the mechanistic basis of the symbiont-mediated protection against pathogenic fungi in aphids remains to be elucidated.

Little is known about symbiont-mediated defense against nematodes, with only one reported case in Drosophila neotestacea, in which Spiroplasma symbionts significantly enhance the reproductive output of flies that are parasitized by the nematode Howardula aoronymphium both in laboratory and wild populations. ${ }^{297,298}$ The presence of Spiroplasma results in reduced growth of the adult female nematodes within the host and ultimately in impaired fertility of the parasite as well as a reduced virulence against the host. ${ }^{298}$ Although the mechanistic basis of Spiroplasma's protective activity is not yet fully known, transcriptional profiling suggests the production of toxins that may inactivate the ribosomes of parasitic nematodes. ${ }^{297}$

Protection against pathogens: Actinobacteria as defensive symbionts. Actinobacteria are of great importance for humans most of our antibiotics today originate from these bacteria, specifically from members in the genus Streptomyces. But also other organisms make use of Actinobacteria and their defensive capabilities through protective symbioses. ${ }^{16}$ Interestingly, however, it remains a matter of debate whether antibiotics primarily evolved to defend their producers in nature. Instead, their immense diversity and occurrence in often sub-inhibitory concentrations in nature suggest that they may be used as signaling molecules, which modulate gene expression in the recipient organisms at low dosage. ${ }^{299}$ Thus, an increase in antibiotic production may have evolved secondarily in interactions with other organisms. ${ }^{300}$ Independent of their original function, antibiotics of Actinobacteria play a crucial role for the protection of several animals against pathogens. In insects, their roles are best understood in beewolf digger wasps and fungus-growing ants. 
Solitary wasps of the tribe Philanthini within the Crabronidae ("beewolves") dig underground nests in soil, mass provision individual progeny in brood cells with insect prey and engage in a defensive symbiosis with 'Candidatus Streptomyces philanthi' bacteria to protect their larvae against mold fungi from the surrounding soil..$^{\text {301-305 }}$ Uniquely, bacterial symbionts are applied to the brood chambers from antennal reservoirs of the females. ${ }^{306} S$. philanthi strains display their protective abilities after incorporation into the cocoon by the larvae. ${ }^{302}$ For the following two weeks, the symbionts produce a cocktail of streptochlorin 67 and eight piericidin 68-75 derivatives, which are distributed all over the surface of the cocoon and protect the immature wasp against opportunistic pathogens until its emergence several months later. ${ }^{302,307-309}$

Like beewolves, fungus-farming ants nest in the soil and are confronted with environmental pathogens that threaten their brood and the fungal cultivars. Moreover, leaf-cutter ant gardens are challenged by specialized Escovopsis fungal pathogens and endophytic fungi, brought in by the ants with the plant substrate supplying the cultivars with nutrition. ${ }^{\mathbf{3 1 0}}$ To counteract these threats, ant workers combine continuous fungus-weeding and -tending behavior with the application of antimicrobial secretions from their metapleural glands ${ }^{\mathbf{3 1 1}}$ as well as antimicrobials produced by symbiotic Actinobacteria. ${ }^{312,313}$ These Actinobacteria comprise vertically and occasionally horizontally transmitted Pseudonocardia symbionts $^{310,314-316}$ as well as environmentally acquired members of the genera Streptomyces and Amycolatopsis. ${ }^{317-319}$ The Pseudonocardia symbionts defend the fungus garden against the specialized Escovopsis cultivar pathogens, by producing dentigerumycin $\mathbf{7 6}$ and five angucyclines (in a Pseudonocardia isolate from Apterostigma dentigerum),,$^{320,321}$ or a nystatin-like compound (in a Pseudonocardia isolate from Acromyrmex octospinosus), respectively. ${ }^{317}$ Streptomyces and Amycolatopsis, on the other hand, produce candicidin 77 and antimycin with broad-spectrum activities against fungal competitors of the cultivars (e.g. endophytic fungi in the leaf substrate). ${ }^{322,323}$ Furthermore, Streptomyces in small crypts on the body surface of adult ants may also protect the ants themselves against pathogens by producing actinomycins and valinomycin..$^{317,323,324}$

Apart from leaf-cutter ants, other Myrmicinae ants in the genus Allomerus possibly make use of Streptomyces and Amycolatopsis as defensive symbionts. These ants farm Chaetothyriales mould fungi within their ant-plant nests, but instead of food, these fungi give structure to the ant galleries. ${ }^{325}$ The galleries are used to trap and catch insect prey for nutrition. ${ }^{326}$ Several Actinobacteria showing antifungal activities were isolated from the cuticle of Allomerus ants, and these bacteria were hypothesized to play a role in the defense of the galleries against fungal pathogens and competitors. ${ }^{327}$ The examples of attine and Allomerus ants indicate that defensive secondary metabolites of Actinobacteria can play an important role in ant fungiculture. Given that only a handful of ant symbionts has been studied, it is likely that many more antibiotics may be isolated from such symbioses. $^{328}$<smiles>[R]CC([R])C[C@H]1O[C@@H](C([R])NC(=O)[C@@H](O)[C@]2(OC)CC(=C)[C@@H](C)[C@@H](C)O2)C[C@H](O)C1(C)C</smiles><smiles>Clc1ncoc1-c1c[nH]c2ccccc12</smiles>

$66 \mathrm{R}=\mathrm{OH}$<smiles>[R]C=[14C](C)[C@@H](O[R])[C@@H](C)/C=C(C)/C=C/C/C(C)=C/Cc1nc(OC)c(OC)c(O)c1C</smiles>
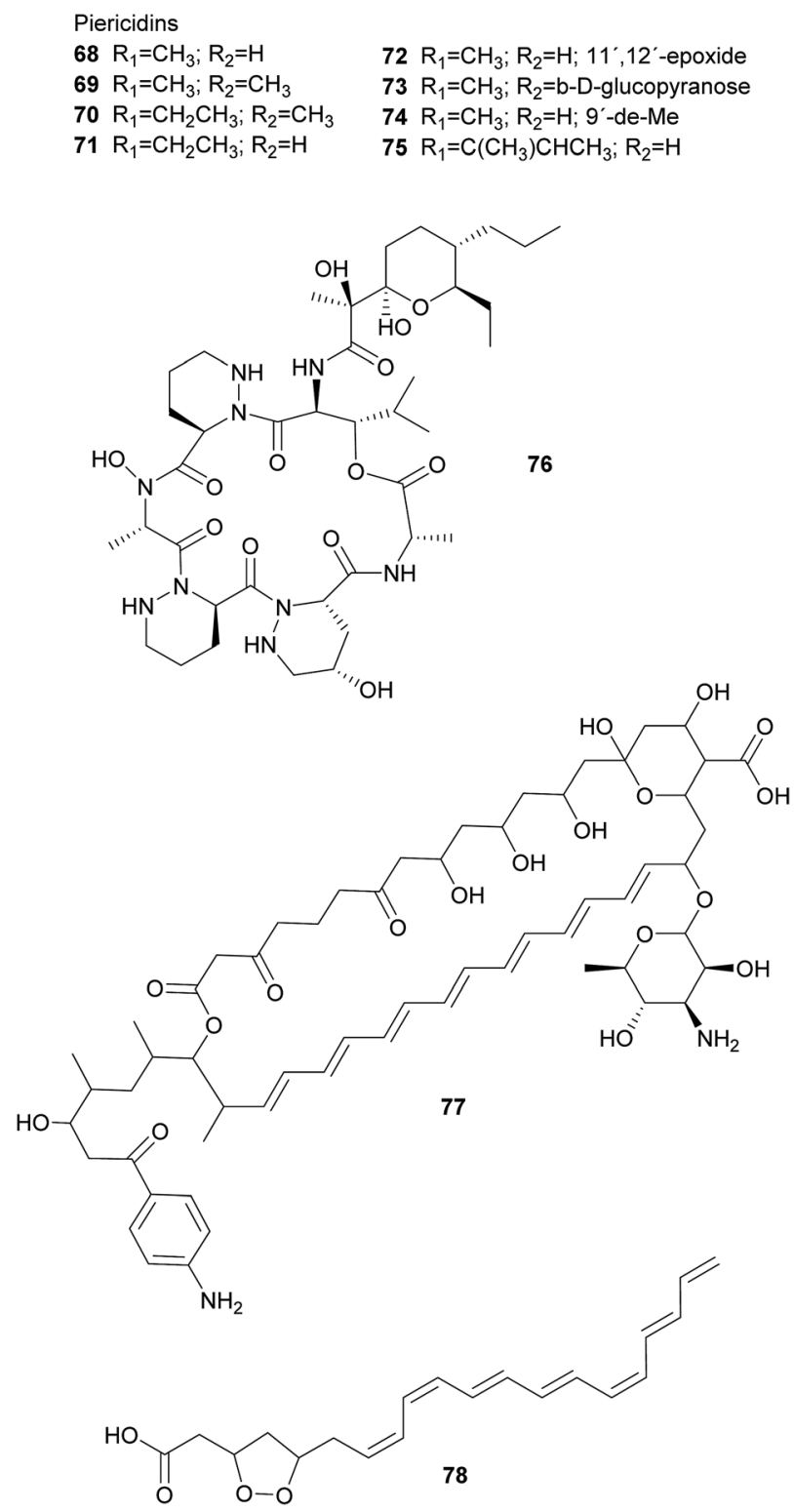

Compared to fungus-growing ants, much less is known about the role of defensive bacterial symbionts in the gardens of the other fungus-farming insect groups: termites and bark/ ambrosia beetles. ${ }^{329}$ Fungus-farming termites occupy the same 
ecological niche in the Paleotropics as leaf-cutter ants in the New World. As in leaf-cutter ants, Actinobacteria have been isolated from termite nests, but in vitro assays showed antifungal activity against Pseudoxylaria and Trichoderma fungal competitors as well as the termites' Termitomyces cultivar. ${ }^{330}$ This indicates that antifungals are either applied in a targeted fashion by the termites, or unspecific Actinobacteria were isolated that do not act as defensive symbionts in fungus-farming termites. The activity of the two microtermolides A and B that were identified from termite-associated Streptomyces spp. was not tested. ${ }^{331}$ Instead, it is possible that fungus-farming termites are associated with a Bacillus sp. as a defensive symbiont. This strain produces bacillaene A, which specifically inhibits several cultivar competitors in vitro. ${ }^{332}$

As in termites, comparatively little is known about the possible role of Actinobacteria in the defense of bark and ambrosia beetle nests. These beetles bore tunnels in the phloem (bark beetles) or xylem (ambrosia beetles), on the walls of which they cultivate food fungi in the orders Microascales and Ophiostomatales. ${ }^{333}$ Females transmit spores of their cultivars to new nests in highly specialized organs called mycetangia. ${ }^{334}$ As beetles typically nest in recently dead trees, cultivars are usually confronted with competition from other wood-colonizing fungi. Actinobacterial symbionts are typically isolated in very low abundance from beetles and their nests. In a study on Dendroctonus frontalis bark beetles, however, Scott et al. ${ }^{335}$ found Streptomyces thermosacchari to be present in the beetle's mycetangia as well as on the cultivars. These bacteria specifically inhibited the growth of Ophiostoma minus, a prevalent antagonist of the beetles, by producing the antifungal metabolite mycangimycin as well as other compounds that were not identified. In vitro, mycangimycin $\mathbf{7 8}$ turned out to be 20 times more effective against $O$. minus than against the beetle's cultivar Entomocorticium sp. A. ${ }^{335,336}$ Another Streptomyces strain displayed no activity in competition assays with associates of $D$. frontalis, but produces frontalamides A and B under certain culture conditions. ${ }^{337}$ However, Streptomyces are not consistently present in $D$. frontalis nests and are generally isolated at very low frequencies from other North American bark and ambrosia beetles. ${ }^{338}$ This underlines the importance of further in vivo studies to investigate the relevance of Actinobacteria for bark beetle defense in nature.

Protection against pathogens: gut and nutritional resources. Gut bacteria can play an important role in defense against invading microbial pathogens. In the locust Schistocerca gregaria, members of the intestinal microbiota can produce phenolic compounds with antimicrobial properties that have been suggested to derive from the conversion of plant secondary metabolites by microbes. Hydroquinone 79, as well as 3,4hydroxybenzoic and 3,5-hydroxybenzoic acids $\mathbf{8 0}$ and $\mathbf{8 1}$, are usually present in the guts and feces of locusts, while absent in insects lacking their normal gut microbiota. ${ }^{339}$ Interestingly, the entomopathogenic fungus Metarhizium anisopliae is inhibited by these compounds and fails to invade locust guts when the symbiotic microbiota is present. ${ }^{340}$ While Pantoea agglomerans appears to be responsible for producing at least one of the three antimicrobial phenols found in the locust gut, ${ }^{339}$ there is evidence from in vitro experiments that Klebsiella pneumoniae and Enterococcus cloacae may also contribute to the production of defensive compounds. ${ }^{340}$ Furthermore, a greater diversity of the bacterial community in the locust gut is associated with improved resistance against pathogens, suggesting that multiple players contribute to the efficient defense. ${ }^{341}$

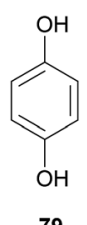

79

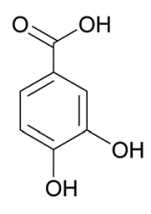

80

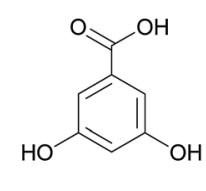

81
Besides protecting against direct pathogen colonization in or on the insect body, gut-associated microbes can also contribute to the preservation of nutritional resources, as is the case for bacteria in honeybees and stingless bees, and for yeasts in drosophilids (see below, Defensive symbioses with fungi). In bees, a number of lactic acid bacteria including Lactobacillus and Bifidobacterium frequently occur in propolis and in the honey crop, both of which exhibit antimicrobial properties. These lactic acid bacteria participate in the fermentation and preservation of an essential food source, the beebread. In addition, the bees line their hive with a layer of propolis, which serves as a sterilization mechanism protecting the brood against pathogens. ${ }^{17}$ In vitro, a set of compounds with antimicrobial properties were produced by lactic acid bacteria isolated from the honey crop of the honeybee Apis mellifera, including organic acids (lactic, formic, and acetic acid), hydrogen peroxide, different volatiles (benzene, toluene, octane, ethylbenzene and nonane), 3-OH fatty acids, 2 -heptanone and various peptides. ${ }^{342}$ These substances inhibit a number of bacteria and fungi that are commonly found on bee-visited flowers. However, the strongest inhibitory effects were observed when several different lactic acid bacteria were co-cultivated with the potential pathogens, suggesting a synergistic activity of the microbial consortium. ${ }^{32}$ Along with the sterilizing effects on resources and the hive, lactic acid bacteria can also enhance survival of honeybee larvae by conferring protection against the American and European foulbrood diseases, caused by Paenibacillus larvae $^{343}$ and Melisococcus plutonius, ${ }^{344}$ respectively.

In addition to lactic acid bacteria, there are other gut-associated microbes that can play important protective roles in bees, particularly bumblebees. By experimentally manipulating the gut microbiota of the bumblebee Bombus terrestris, Koch and colleagues provided evidence that the bacterial community plays a role in reducing infection rates by the trypanosomatid parasite Crithidia bombi. ${ }^{345}$ Furthermore, the abundance of this parasite was shown to correlate negatively with the presence of the gut symbiont Gilliamella apicola ( $\gamma$-Proteobacteria) in natural bumblebee populations. ${ }^{346}$ These and other studies on the bacterial community in different bees indicate that a balanced and stable microbiota plays a substantial role in bee health by reducing pathogen susceptibility. ${ }^{\mathbf{1 7}}$

Similar to the aforementioned gut microbes, bacteria present on the egg surface of house flies are also involved in the 
preservation of nutrient provisions. As house flies lay their eggs on manure that their offspring will use for nutrition, the larvae will most likely encounter fungal competitors that have been shown to reduce their chances of reaching adulthood. However, the bacterial community on the surface of the fly eggs can suppress the growth of these fungi on the manure and thereby play an important protective role for the developing larvae. ${ }^{347}$

Antiviral protection. Viruses can also pose a significant threat to many different insect species. The Drosophila C virus (DCV) is common in natural populations of Drosophila melanogaster and causes high mortality under laboratory conditions. However, $D$. melanogaster frequently carries the $\alpha$-Proteobacterium Wolbachia pipientis, which can reduce host susceptibility to DCV and other RNA viruses. ${ }^{348,349}$ These findings have stimulated investigation of other insect-symbiont-virus systems, particularly those involving vectors of human pathogenic viruses. ${ }^{350}$ In Culex quinquefasciatus, the natural occurrence of Wolbachia resulted in reduced titers and impaired transmission capacity of West Nile virus. ${ }^{351}$ Although the mechanistic basis underlying this effect is not yet completely understood, significant progress in this area has been made in non-naturally infected vectors of arboviruses and other human parasites. In Aedes aegypti mosquitoes, infections with dengue and chikungunya viruses, as well as the malaria-causing protozoan parasite Plasmodium, are restrained when the insect is artificially infected with a Wolbachia strain from $D$. melanogaster. ${ }^{352}$ This protective effect is achieved through activation of the host's immune system, which involves stimulating the expression of several Tollpathway genes as well as defensins and cecropins. ${ }^{8}$ In addition, the presence of symbiont genes potentially involved in the production of antimicrobial compounds might also play a role in inhibiting mosquito pathogens. ${ }^{352,353}$

Defensive symbioses with fungi: protection of food or the nesting environment. Most of the defensive fungal symbionts of animals have been described from fungus-farming insects, specifically from leaf-cutter ants, fungus-growing termites and bark and ambrosia beetles. All three groups farm their fungi in social societies and show behavioral adaptations to protect their fungi against fungal competitors and pathogens. ${ }^{329}$ Furthermore, in addition to defensive actinobacterial symbionts (see above), several studies implicated fungi in the protection of the host or its fungal cultivar against pathogens. Specifically, 'killer yeasts' were shown to inhibit the growth of Escovopsis cultivar pathogens within the gardens of Atta ants, ${ }^{354,355}$ and Ogataea pini, a yeast associated with fungus-growing Dendroctonus bark beetles, produces volatiles (ethanol, carbon disulfide and delta3-carene) that inhibit the growth of Beauvaria bassiana entomopathogens. ${ }^{356}$ Additionally, in some cases the cultivar fungi themselves produce defensive secondary metabolites. Among ambrosia beetles, Euwalecea validus is associated with a cultivar (likely an unidentified Fusarium sp.) that produces cerulenin $\mathbf{8 2}$ and helvolic acid 83 - antibiotics that inhibit the growth of mould fungi in vitro and likely also suppress bacterial contaminations. $^{357}$ Similarly, the Lepiota and Tyridiomyces cultivars of Cyphomyrmex fungus-growing ants produce lepiochlorin $\mathbf{8 4}^{358,359}$ and several diketopiperazines $\mathbf{8 5 - 8 7 , { } ^ { 3 6 0 }}$ respectively, which may be active against bacterial and fungal pathogens. Likewise, Leucocoprinus cultivars of Atta ants show in vitro suppression of fungi endophytic to the leaves that the ants provision as substrate for the cultivar. ${ }^{361}$ The active secondary metabolites, however, have not been identified yet. The importance of host protection by the cultivars of leaf-cutter ants is supported by the observation that almost all species cover their broods with the cultivar fungus. ${ }^{362,363}$ In fungus-growing termites, unknown myocins produced by the Termitomyces cultivars suppress the growth of related strains in vitro ${ }^{364}$ thereby reducing competition and ensuring the specificity of the symbiosis, analogous to the bacteriocins inhibiting close relatives in the bacterial symbionts of nematodes (see 2.2.1).
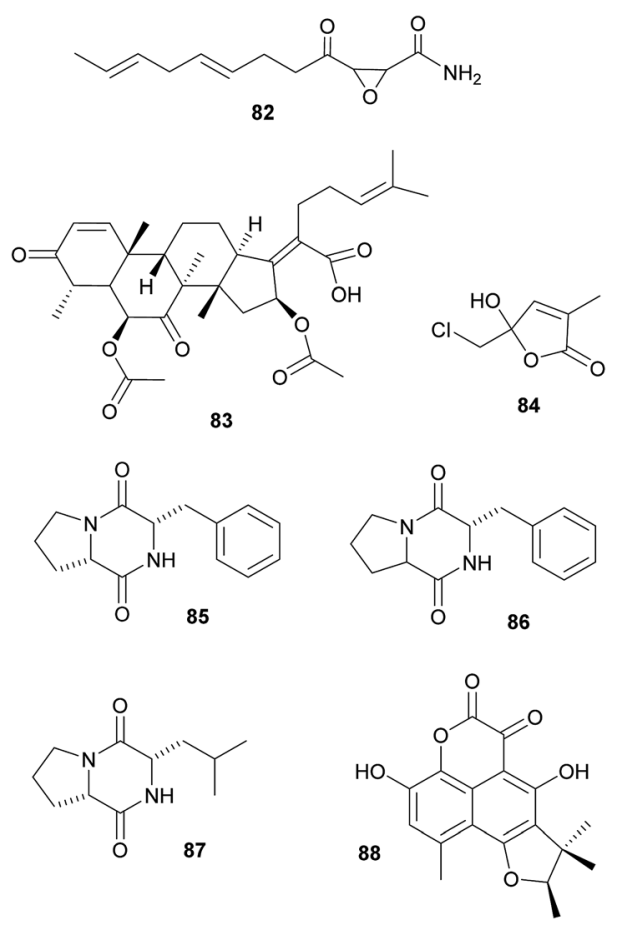

Beyond fungus-farming insects, leaf-rolling weevils in the genus Euops (Attelabidae) are associated with polysaccharidedegrading Penicillium symbionts that are planted on leaves in which eggs and larvae are rolled. Penicillium herquei, the associate of Euops chinensis, has been shown to produce (+)-scleroderolide 88 in vivo. ${ }^{365}$ This antibiotic inhibits the growth of several bacterial and fungal pathogens in competition assays on plates and keeps larval cradles free of other microbes ${ }^{365,367}$ In honeybees, Penicillium spp., Aspergillus spp. and several Mucorales have been shown to decrease colony failure due to chalkbrood disease caused by the fungus Ascosphaera apis, by competitive exclusion due to the production of antimycotic substances. ${ }^{368}$ Several mold fungi that are typically regarded as insect pathogens are also potent producers of antimycotic substances $^{369}$ and are potentially more common defensive symbionts than currently apparent. Finally, Drosophila melanogaster fruit flies strongly benefit from their association with yeasts that - in addition to their nutritional role - also inhibit the growth of fungal food competitors, like the noxious mold Aspergillus nidulans, by producing as yet unknown secondary metabolites. ${ }^{370}$ 


\subsection{Vertebrates}

In contrast to invertebrates, only a limited number of specific defensive symbioses with microorganisms have been discovered in vertebrates. The relatively complex nature of the vertebrate microbiota as well as the difficulty of manipulative experimentation in this group of organisms severely restricts our current understanding of potential key symbiotic relationships with specific bacteria and fungi. There are, however, a few examples suggesting that different vertebrate groups including fish, amphibians, birds and humans, engage in associations with microbial partners that can reduce their susceptibility to pathogens and predators.

Antipredator defense. In addition to the presence of tetrodotoxin (TTX) 37 in marine invertebrates like nemerteans and mollusks, this highly potent neurotoxin also occurs in fish as well as in amphibians. While the case of bacteria-mediated TTX production seems to be strongly supported in some marine organisms, there is little evidence for a bacterial origin of TTX in frogs, newts and salamanders. Several of these species possess unique analogs of TTX, which are absent or only present in very low quantities in marine animals or in bacteria. ${ }^{165}$ Despite the lack of conclusive evidence for the source organism, there are clear indications of its antipredator functions. For example,

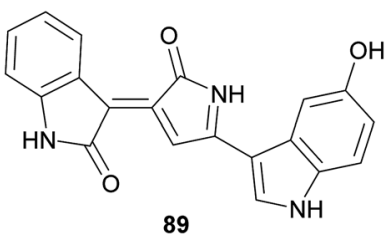

some amphibians actively secrete the toxin upon predator encounter. ${ }^{165}$ Also, coevolutionary signatures are observed between newts of the genus Taricha and garter snakes (Thamnophis spp.), where the spatial dynamics of TTX levels in the newt and the corresponding resistance in the predator are suggestive of an evolutionary arms race. ${ }^{\mathbf{1 6 4 , 1 6 5}}$

Protection against microbial pathogens on the skin and in the gut. Besides predators, microbial pathogens are a major threat to vertebrates and exert a strong selective pressure on evolving efficient defense mechanisms. Amphibians, which are particularly vulnerable to infectious diseases, ${ }^{371}$ have recently began to suffer devastating effects from chytridiomycosis caused by the fungus Batrachochytrium dendrobatidis. Populations from Australia as well as North, Central and South America have been affected, ${ }^{372}$ but resistance to the chytrid fungus infection varies both within and across species. ${ }^{373,374}$ One of the hypotheses that have been proposed to explain this variability in resistance is the presence of symbiotic bacteria, mainly on the skin, that can produce compounds capable of inhibiting the pathogen. Concordantly, the $\beta$-Proteobacterium Janthinobacterium lividum, isolated from the skin of the red-back salamander Plethodon cinereus, inhibits the growth of the chytrid fungus in vitro by producing indole 3-carboxaldehyde 89 and violacein $90 . .^{373}$ From the same salamander species, an isolate of Lysobacter gummosus was shown to produce 2,4-diacetylphloroglucinol 91, which also exhibits in vitro activity against $B$. dendrobatidis. ${ }^{375}$ Further work on protective bacteria in P. cinereus revealed that $63 \%$ of field collected individuals harbor J. lividum or other bacteria capable of violacein production. ${ }^{376}$ Such frequencies are in line with the often facultative nature of defensive symbioses. In addition to its in vitro activity, the presence of violacein was shown to be associated with increased survival in P. cinereus $^{376}$ as well as in the frog Rana muscosa. ${ }^{377,378}$ These results open the possibility for applying bacterial violaceinproducers directly on infected amphibians or their natural environment in order to mitigate the effects of the pathogen. ${ }^{373,374}$ An interesting aspect of this defensive symbiosis is the potential synergism between compounds produced by the bacteria and AMPs from the host, as demonstrated in vitro for the inhibitory effect of 2,4-diacetylphloroglucinol and a mixture of AMPs from $R$. muscosa against B. dendrobatidis. ${ }^{372}$ Furthermore, co-cultures of four different bacterial isolates from the red-back salamander including Janthinobacterium sp. resulted in synergistic inhibition of $B$. dendrobatidis. ${ }^{379}$ Thus, the pathogen defense of amphibians likely relies on a combined protective effect of the bacterial community and the host's immune response.<smiles>O=Cc1c[nH]c2ccccc12</smiles><smiles>CC(=O)c1c(O)cc(O)c(C(C)=O)c1O</smiles>

As in amphibians, the skin is also a potential entry gate for pathogens in other vertebrates including humans. In fact, human skin is one of the main habitats accommodating microbial partners. The variety of physicochemical conditions on the skin in terms of temperature, humidity, oiliness, and oxygen availability contribute to the high bacterial diversity on its surface. One of the main constituents on the healthy human skin is Staphylococcus epidermidis, a bacterium capable of producing a number of AMPs, including epidermin 92, Pep5 and epilancin $\mathrm{K} 7$, which are classified as lantibiotics owing to the presence of lanthionine and/or methyllanthionine in their structures. ${ }^{380,381}$ Both are unusual thioether amino acids, ${ }^{382}$ which account for the multiple rings in the structure of lantibiotics and are considered essential for their antibacterial activity. ${ }^{381}$ However, evidence for the efficacy of lantibiotics against pathogens is limited to in vitro studies. Phenol-soluble modulins (PSMs) are a second group of AMPs produced by $S$. epidermidis. In contrast to the lantibiotics, there is in vivo evidence for a role of PSMs in the protection of the skin surface, as their inoculation on mouse skin resulted in a significant reduction of the commonly pathogenic group A Streptococcus, while it does not affect the presence of $S$. epidermidis. ${ }^{381,383}$ In addition to the direct antimicrobial action, PSMs can also support the host's immune system. Specifically, the application 
of PSMs to isolated neutrophils resulted in increased eradication of pathogenic bacteria, co-localization with host AMPs and enhancement of extracellular trap formation by the neutrophils. ${ }^{381,384}$ Other mechanisms for pathogen inhibition by $S$. epidermis include blocking of quorum sensing via a thiolactonecontaining peptide and its derivatives, ${ }^{381,385}$ as well as inhibition of biofilm formation in the nasal cavity by the production of serine proteases. ${ }^{\mathbf{3 8 1 , 3 8 6}}$ Despite the numerous examples for a mutualistic potential of $S$. epidermidis on human skin, this symbiosis provides a good example for a context-dependent host-microbe association, as there are also clear indications of the potential for pathogenicity by $S$. epidermidis: an unbalanced microbiota composition possibly associated with an impairment of the host's innate immune response can allow for $S$. epidermidis' access to internal tissues and result in pathogenesis, which is often reflected in severe nosocomial infections. ${ }^{387}$ among fish-associated LAB has only been identified in Carnobacterium strains, which synthesize carnocin UI49, piscicocin V1, and divercin V41. However, the microbes' inhibitory activity has also been attributed to the production of additional compounds such as organic acids, hydrogen peroxide and siderophores. $^{395}$ In addition to the synthesis of bioactive compounds, there is evidence for the stimulation of the host's innate immune response caused by the $\mathrm{LAB}$, as demonstrated in vivo in gilthead seabream individuals infected with Lactobacillus delbrueckii. ${ }^{396}$

Protection against microbial pathogens on bird eggs. Perhaps the most remarkable defensive symbiosis between microbes and vertebrates is that of Enterococcus bacteria inhabiting the uropygial gland secretions of hoopoe birds (Upupa epops). This system is particularly interesting in terms of the elaborate set of behavioral and morphological adaptations underlying the

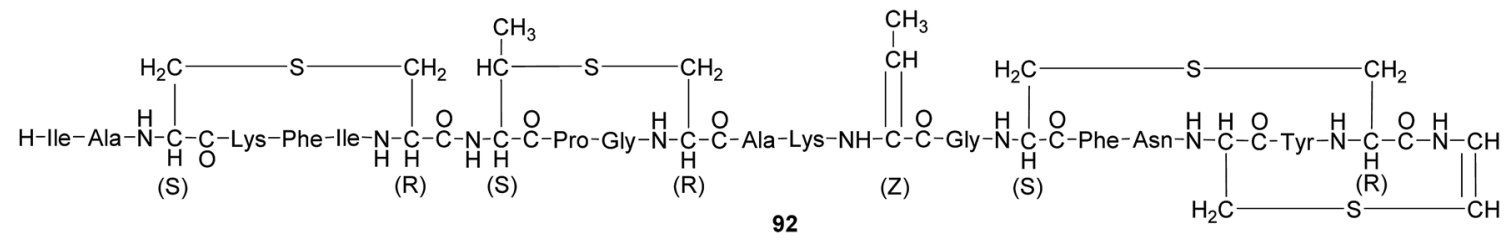

Similarly, while Bacterioides fragilis is frequently isolated from clinical samples and can be involved in human disease, ${ }^{388}$ it has also been recognized as a native member of the human gut microbiome and can be beneficial for the host. Its potential for a mutualistic role has been extensively investigated in mice, where there is strong evidence that the production of polysaccharide $\mathrm{A}$ by $B$. fragilis prevents intestinal inflammatory disease caused by the opportunistic pathogen Helicobacter hepaticus. Although the mechanistic details of this protective effect are not yet fully understood, the abundances of both symbiont and pathogen do not differ between healthy and diseased mice, so an immunomodulatory effect suppressing disease development (i.e. absence of detrimental consequences for the host), rather than pathogen clearance, appears to be the key to this bacteria-mediated protection. ${ }^{389}$ Concordantly, there is a growing body of evidence in humans suggesting that the microbial community, including both bacteria and fungi, plays a crucial role in immunoregulatory processes. ${ }^{390-392}$ In fact, the presence of a healthy microbiota cannot only regulate inflammatory responses but also train the host's immune system and thus confer an indirect defense to the action of pathogens. ${ }^{391}$

Gut pathogens are also a frequent threat for fish populations, which is particularly problematic in the case of intensive fish culture that facilitates the emergence of pathogens as well as the spread of antibiotic resistant bacterial strains. ${ }^{393}$ However, several lactic acid bacteria (LAB) such as Carnobacterium and Lactobacillus strains isolated from different fish species are capable of inhibiting pathogenic bacteria in vitro, in particular Aeromonas salmononicida and Vibrio anguillarum. $^{394,395}$ The production of specific inhibitory substances evolution and maintenance of the partnership. While male and non-breeding female hoopoes produce a white and odorless uropygial gland secretion with only the occasional presence of few bacteria, secretions from breeding females and nestlings are brown, emit a strong smell and contain high numbers of Firmicutes in the genus Enterococcus, mainly E. faecalis. ${ }^{397}$ Interestingly, female birds actively collect the secretions from the uropygial gland and deposit them on both feathers and eggs, the latter of which contain specialized structures to harbor the symbiont-containing secretions. ${ }^{398}$ Recent studies provide evidence that the bacteria in the secretions play a protective role by preventing the growth of detrimental microbes on the eggs. Notably, there is a positive correlation between hatching success and Enterococcus loads in the uropygial secretions and on the egg shells. ${ }^{398}$ Additionally, E. faecalis can inhibit the keratin-degrading action of pathogenic Bacillus licheniformis, thus playing a protective role on the feathers of adult hoopoes. ${ }^{399}$ When first isolated from the gland secretions, $E$. faecalis was shown to produce enterocins, later specified as enterocins MR10 and AS-48, which present in vitro inhibitory activity against a range of Gram-positive and Gram-negative bacteria. ${ }^{\mathbf{4 0 0 , 4 0 1}}$ Later on, it was discovered that also the volatile fraction of the brown secretions contained bacteria-produced compounds with antimicrobial activity, primarily butanoic acid, 2-methyl butanoic acid, 4-methyl pentanoic acid, indole, 3phenyl propanoic acid and 4-chloroindole. ${ }^{\mathbf{4 0 2}}$ While individual volatile compounds showed differential efficacy against various bacteria, a mixture resembling the composition of the brown secretions consistently inhibited a broad spectrum of microbes. ${ }^{402}$ 


\section{Ecological and evolutionary implications}

The previous sections illustrate the expanding body of literature describing symbiont-mediated chemical defense across diverse animal taxa inhabiting a broad range of habitats. In this section, we aim to draw some general conclusions on the key ecological and evolutionary factors shaping this diversity and point to novel directions for future research.

\subsection{Implications of host ecology and lifestyle}

Protective associations between microorganisms and animals are present across a range of phylogenetically distant metazoan taxa (Fig. 2 and Table S1†). This ubiquity not only reflects the general potential to evolve defensive symbioses but also its occurrence in organisms with markedly different natural histories. However, the identity and diversity of an organism's antagonists strongly depends on its environment, lifestyle and life history, so these factors are likely to have a major impact on the evolution of defensive symbioses. In marine environments, many organisms have a sessile life-stage that must be especially well defended due to its often conspicuous nature, predictability in space and time, and incapability to escape from predators. Thus, chemical protection is widespread among marine invertebrates, especially in taxa with soft bodies that lack structural protection. Concordantly, sponges, bryozoans,

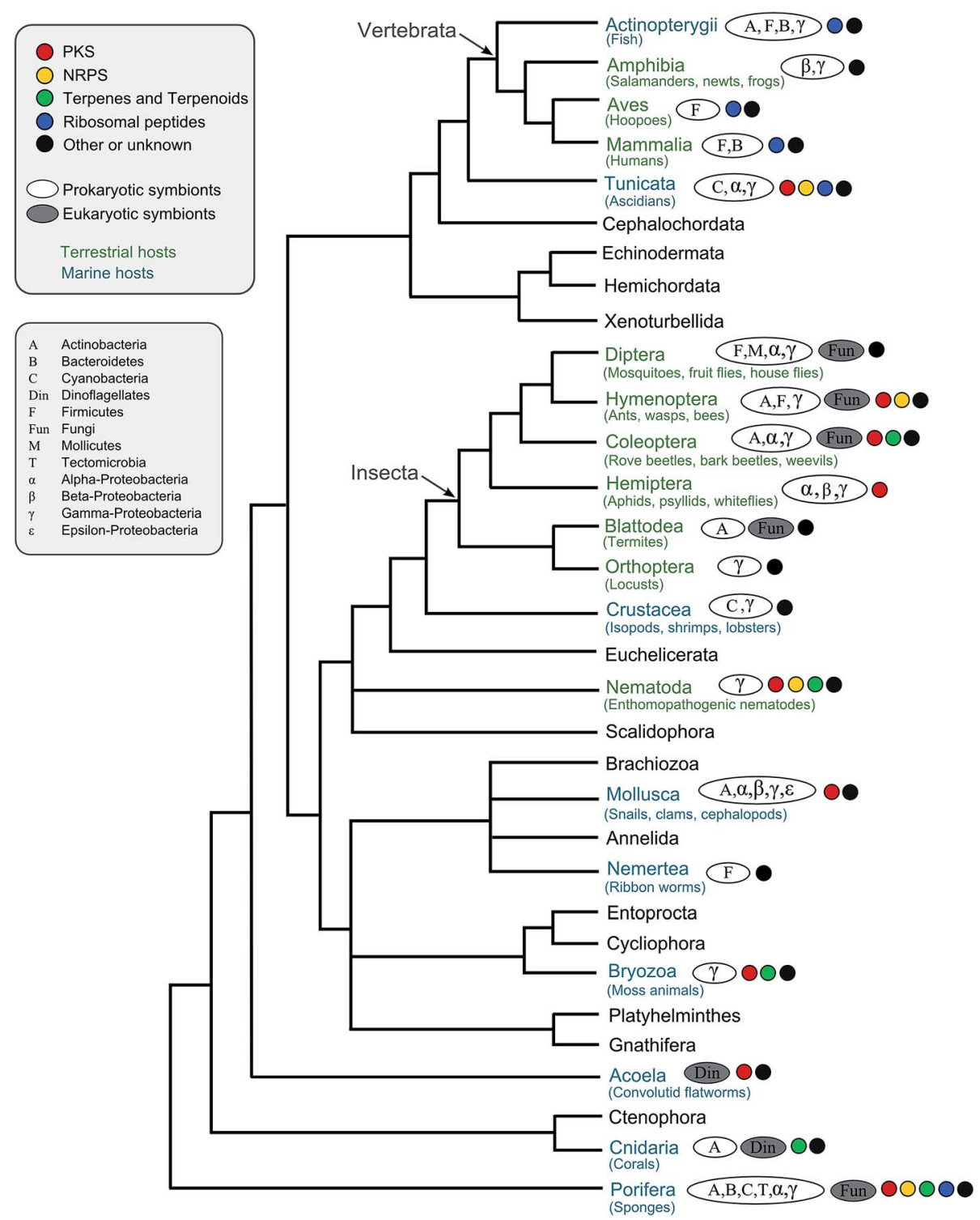

Fig. 2 Cladogram of selected animal groups highlighting those with described defensive microbial symbionts and the corresponding symbiont taxa. Colored circles represent the major biosynthetic pathways reported for symbiont-produced compounds. Branch lengths are not to scale and branch order is adapted from previous phylogenetic analyses for the deep branches, ${ }^{403}$ hexapods, ${ }^{404}$ and all other bilaterians. ${ }^{405,406}$. Common names in brackets denote selected groups within the respective taxon that harbor known defensive symbionts. 
tunicates, some corals and mollusks exhibit an arsenal of defensive chemicals, more and more of which are being discovered to be of symbiotic origin (Table $\mathbf{S 1 \dagger})^{.9-11,208}$ As the sessile lifestyle often goes along with filter feeding, these animals have a high probability to get in contact with microbes, thereby increasing the chances to acquire a beneficial symbiont, while at the same time risking exposure to pathogens. ${ }^{12}$ In terrestrial environments, by contrast, sessile animals are exceptionally rare. However, many terrestrial organisms have either a valuable, but immobile resource (nest, food) or immobile developmental stages (eggs, pupae) that are vulnerable to threats from predators, pathogens and parasites due to their predictability in time and space. Food resources that are available en masse, like fungus gardens of insects, insect cadavers killed by nematodes or mass-provisioned insect nests, for example, and eggs or brood that are exposed to a hostile environment for a long time (e.g. in nests within soil) run a high risk of pathogen infection. ${ }^{\mathbf{1 6 , 1 7}}$ While there are a few known examples of a symbiotic protection in these immobile life stages of terrestrial animals, ${ }^{302,397}$ the abundance of such associations in the marine environment suggests that there are likely many more to be discovered.

The transition between mobile and immobile stages during the life cycle of an animal can incur a trade-off between chemical and mechanical defenses, resulting in life-stage specific benefits of defensive symbioses. In bryozoans, for example, the larvae and early post-settlement stages are associated with higher mortality given the increased vulnerability to predation, competition and disease, as well as desiccation, temperature stress, and radiation. ${ }^{12}$ Concordantly, the concentration of symbiont-produced defensive bryostatins is particularly high in bryozoan larvae, while adults switch to a predominantly structural defense, with only reproductive tissues being chemically defended by the bryostatins. ${ }^{\mathbf{1 2 5}}$ Analogously, in a terrestrial system, high concentrations of symbiont-provided antibiotics are only produced during the cocoon stage of the European beewolf and provide protection during the immobile phase of hibernation. ${ }^{302}$ Thus, the symbionts' investment in chemical defense can vary during the host's life cycle, being complemented by alternative defenses of the host. ${ }^{12}$

Another important aspect of an organism's exposure to pathogens and thus its benefit to engage in defensive microbial symbiosis is its degree of sociality. Social or gregarious behavior in combination with an often high relatedness and low genetic variability among group members makes colonies and aggregations of members of an individual species particularly exploitable by pathogenic microbes. ${ }^{\mathbf{4 0 7 , 4 0 8}}$ On the other hand, group-living also confers the benefit of social immunity ${ }^{\mathbf{4 0 7}}$ and can facilitate the transmission and maintenance of beneficial microorganisms, e.g. such that provide protection against the colony's pathogens. ${ }^{409}$ Hence, it is not surprising that defensive symbionts are commonly found in social insect colonies and clonal groups of organisms (e.g. aphid colonies, fungal monocultures of farming insects), in which social behaviors commonly ensure the spreading of defensive symbionts. $^{344,345,410,411}$

\subsection{Diversity of defensive symbionts and protective chemicals}

Across animals, a wide diversity of microbial partners have been identified as defensive symbionts (Fig. 2 and Table S1 ). However, particular groups of microbial taxa stand out among these partnerships. Non-surprisingly, the high biosynthetic potential of Actinobacteria renders them effective defenders for a number of animals including sponges, ${ }^{54}$ corals, ${ }^{\mathbf{4 1 2}}$ mollusks, ${ }^{176,177,180}$ and insects. ${ }^{16}$ However, other bacterial groups like Proteobacteria and Firmicutes, as well as eukaryotic organisms like dinoflagellates, are also important and widespread players in defensive partnerships (Fig. 2 and Table S1†). Likewise, despite the predominance of PKS- and NRPS-derived compounds in protective symbioses across many taxa, an array of other chemical classes also appear repeatedly, particularly ribosomal peptides and terpenes, but also $\beta$-lactam and oligosaccharide antibiotics (Fig. 2 and Table S1 $\dagger$ ).

\subsection{Implications of symbiont localization}

For cases in which symbiont-mediated defense relies on the production of a bioactive compound, it has been suggested that an external localization of the microbial partner, i.e. on the body surface or in the lining of body cavities of the host, is more effective than an endosymbiotic localization, since the protective substances are readily exposed to potential enemies. ${ }^{\mathbf{1 2}}$ In fact, a majority of the microbial symbionts described to play an anti-pathogenic role are located directly on the body surface of the host, ${ }^{373,375,381}$ on specific superficial structures, ${ }^{202,302,310,398}$ within the gut, ${ }^{341,343,344,396}$ or externally on food provisions or the nesting environment. ${ }^{367}$ In such localizations, defensive symbionts can exert their protective activity before antagonists breach the host's surfaces, thereby reducing detrimental effects to a minimum. In addition, the localization outside of the host's body may reduce potentially harmful side effects that the noxious defensive chemicals may have on the host itself. There are, however, a number of symbionts providing chemical defense that are located within the host's body, ${ }^{47,287,298}$ sometimes even within the host's cells. ${ }^{\mathbf{1 0 5 , 2 2 9 , 2 3 0}}$ Interestingly, for many of these endosymbionts, the relevant antagonists identified so far are predators, so various types of antagonists may exert different selective pressures on symbiont localization. Yet, a correspondence between symbiont localization and type of enemy remains speculative, given the often limited information on the complete range of relevant antagonists.

\subsection{Evolutionary dynamics}

As opposed to many intracellular symbionts conferring nutritional benefits, those playing a defensive role are often found at intermediate infection frequencies in host populations. ${ }^{47,76,229,287,288,290,296,298,348,349,413}$ The underlying reasons are probably multiple, a primary one being the context-dependent nature of protective functions. In the absence of relevant antagonists, the host still pays a cost for harboring the symbiotic partners, ${ }^{\mathbf{4 1 4}}$ which can outweigh the benefits and shift the selective balance in favor of symbiont loss. A similar situation 
can occur when only certain life stages are protected and thus the relative benefit of carrying the symbionts changes during the life cycle of the host. In the long run, however, balancing selection is most likely responsible for maintaining the partnerships. ${ }^{\mathbf{1 9 , 2 9 0}}$

Another cause for intermediate infection rates may be the comparatively low degree of intimacy and stability observed in many - but not all ${ }^{230}$ - defensive symbioses, which stands in stark contrast to the known intracellular nutritional mutualists that have been associated with some groups of invertebrates for hundreds of millions of years. ${ }^{415}$ The often exposed localization of ecto- and extracellular symbionts increases the chances of environmental acquisition of other microbial strains and thus symbiont replacement, resulting in the general lack of strict cocladogenesis in many systems. ${ }^{416}$ Although a vertical transmission route does exist in several examples of defensive animal-bacteria symbioses, occasional horizontal transmission often occurs, e.g. in antibiotic-producing actinomycetes of fungus-growing ants ${ }^{314,315,417}$ and beewolves, ${ }^{303}$ in the secondary symbionts of aphids, ${ }^{\mathbf{4 1 8}}$ and in the defensive symbionts of bryozoans. ${ }^{\mathbf{1 4 4}}$ Also, in many other marine symbioses, intraspecific variation in both the associated microbial communities and the symbiont-provided defensive chemistry indicate a high probability of symbiont exchange by occasional horizontal transfer or environmental determination. ${ }^{47,76,413}$ The flexible acquisition of defensive symbionts might represent a fast and versatile adaptive process for defense against coevolving antagonists, but also requires sophisticated partner choice mechanisms to ensure the evolutionary stability of the symbiotic partnership. ${ }^{419}$

The acquisition of genetic material from unrelated microbes through horizontal gene transfer (HGT) can also mediate rapid chemical changes and thereby facilitate adaptations in defense against coevolving antagonists. While rare in nutritional symbioses, there are several examples of defensive traits that were likely acquired via HGT. The Pseudomonas symbiont of rove beetles shows strong indications of HGT of the genes for the defense toxin pederin. The striking similarity of the biosynthetic genes of pederin and diaphorin, the toxin produced by the intracellular symbiont of the asian citrus psyllid, ' $C a$. Profftella armatura', suggests that a horizontal transmission event, led to the convergent characteristics in distant lineages. ${ }^{230}$ The horizontal acquisition in the Paederus symbiont is also supported by the localization of the gene on a genomic island, ${ }^{289}$ and the occurrence of a similar gene cluster for onnamide biosynthesis in the marine sponge Theonella swinhoei. ${ }^{73,76,420}$ Although still lacking direct evidence, cases of potential HGT have also been suspected in several marine symbioses, particularly those of ascidians and bryozoans. The recent discovery of a plasmid-localized didemnin biosynthetic gene cluster in the free-living $\alpha$-proteobacteria Tistrella mobilis and $T$. bauzanensis ${ }^{\mathbf{2 1 9 , 2 2 0}}$ raises the possibility that the Synechocystis trididemni cyanobacterial symbiont of didemnid ascidians has acquired genes for didemnin biosynthesis via HGT. ${ }^{12}$ Furthermore, the synthesis of bioactive tambjamines by microbial partners of the distant marine groups of ascidians and bryozoans might be explained by horizontal gene transfer. ${ }^{12}$
Nevertheless, our understanding of the prevalence of HGT in defensive symbioses and its impact on the evolutionary dynamics of the host's interaction with antagonists remains rudimentary.

An interesting feature found repeatedly across different animal-microbe protective associations is the simultaneous employment of multiple defensive chemicals, produced by either a single or several symbiotic partners. In the beewolfStreptomyces symbiosis, for example, a "cocktail" of compounds produced by a single symbiotic strain per host species is capable of providing an efficient protection against an array of opportunistic bacterial and fungal pathogens. ${ }^{309}$ In a similar fashion, animal hosts with strikingly different life history strategies including hoopoe birds, ${ }^{\mathbf{4 0 0}-\mathbf{4 0 2}}$ locusts, ${ }^{339}$ entomopathogenic nematodes, ${ }^{20}$ didemnid ascidians, ${ }^{222,225}$ salamanders, ${ }^{373}$ and bryozoans, ${ }^{\mathbf{1 2 4}}$ are associated with a mixture of symbiont-derived compounds likely involved in defense. While in some cases, individual symbionts produce a range of different chemicals, in others - like the didemnid ascidians ${ }^{228}$ - multiple bacterial partners are responsible for the production of the defensive compounds. In both cases, effects are often not only complementary, but also synergistic. ${ }^{\mathbf{3 0 9 , 3 4 2}}$ These combined strategies are in line with the aforementioned versatility, as they are more likely effective against a range of antagonists. Additionally, coapplication of several antibiotic substances at the same time is known to strongly hamper the evolution of resistance in the targeted antagonists. ${ }^{\mathbf{4 2 1}}$

\subsection{Outlook: current status, challenges and opportunities of defensive symbiosis research}

Compared to nutritional symbioses, defensive ones are generally more difficult to detect, ${ }^{\mathbf{1 7}}$ because they are often of facultative nature and their effects are only perceived in the presence of the relevant antagonists, which are in many cases not known, not available under laboratory conditions, and/or not reliably detectable in short-term or site-restricted observations. ${ }^{19}$ Furthermore, defensive symbiont localization can be varied and unexpected, including occurrence of the symbionts on the surface of the host, within the food resource or the nesting environment, which makes distinction of symbionts from environmental contaminants challenging. ${ }^{17}$

Additional challenges of characterizing defensive symbioses are habitat-specific. In fact, defensive symbioses in marine and terrestrial animals have been explored from evidently different perspectives. A majority of the studies on marine associations has been motivated by the prospect to discover novel bioactive compounds, while the recognition of their bacterial origin has come much later. Hence, with few exceptions, research on marine defensive symbioses is characterized by a strong background on the chemical basis of defense, whereas the link to the producing microorganisms and the fitness consequences of the symbiosis for the host often remain enigmatic. Obviously, this is also due to the limitations for experimental manipulation in marine habitats, specifically the assessment of fitness benefits by artificially generating aposymbiotic hosts. On the other hand, terrestrial systems - represented to a great extent by 
insects and nematodes - have been most often approached from an ecological perspective and usually first described based on the identification of the key partners. However, there is often less information about the mode of action of protective symbionts in terrestrial animals and - with a few notable exceptions - on the chemistry involved in defense (Table $\mathrm{S} 1 \dagger$ ). Thus, while gaps in the ecological knowledge of many of the marine symbioses remain to be filled, terrestrial studies could take advantage of the advances in natural product discovery accomplished in the marine world. Certainly, an interdisciplinary approach integrating mechanistic and ecological studies, molecular characterization and natural product research is and will remain to be of utmost importance for the field.

In this context, current technological developments will continue to play an important role for the progress in defensive symbiosis research. Molecular biology tools, particularly nextgeneration-sequencing of microbial communities, RNAseq, and single-cell genomics can rapidly provide strong links between natural products and their producers, especially in systems not amenable to manipulative experimentation. Additionally, increasing sensitivity and resolution in mass spectrometry (MS) as well as improvements in MS-imaging (like nanoSIMS, MALDI imaging, and DESI imaging ${ }^{\mathbf{4 2 2 , 4 2 3}}$ ) allow for the detection and quantification of bioactive compounds in situ, which is currently missing for most (but not all ${ }^{309,323}$ ) terrestrial defensive symbioses.

In the search for novel defensive symbioses, special attention should be directed towards systems that exhibit ecological and evolutionary conditions predisposing them towards defensive alliances with microbes. For example, sessile or ground-nesting animals, those that have developed food domestication habits, or have gregarious or social lifestyles in combination with high relatedness, stand out as promising candidates. Beyond associations with bacteria, defensive symbiotic partnerships between animals and fungi remain heavily understudied..$^{25,83,424}$ Fungal partners are common nutritional symbionts of various animal groups, but have been rarely screened for their bioactive potential. This is surprising as fungi have a vast biosynthetic potential and are a rich source of antibiotics. ${ }^{\text {25,83,424-426 }}$ Likewise, only few cases of defensive symbiotic viruses have been described. Polydnaviruses in Microplitis demolitor and other parasitoid wasps (families Braconidae and Ichneumonidae) aid in suppressing the immune response of the parasitized host and thereby confer protection to the wasp. ${ }^{427,428}$ In another intriguing example, an RNA virus of the parasitoid wasp Dinocampus coccinellae manipulates the behavior of the wasp's coccinellid beetle host, inducing it to protect the wasp pupa from predation until it emerges from the cocoon. ${ }^{429}$ Finally, bacteriophages have been shown to adhere to metazoan mucosal surfaces and limit bacterial infections to their own and the host's benefit. ${ }^{\mathbf{4 3 0}}$ The potentially high degree of specificity of the interaction between viruses/phages and bacteria, along with the simplicity of acquiring viruses and the low cost of their maintenance make them appear as ideal defensive symbionts. In summary, it is quite possible that other cases of symbiotic relationships with fungi and viruses await discovery for those who venture to look beyond bacterial symbionts.

In conclusion, animal-microbe defensive symbioses are widespread, ecologically diverse and evolutionarily dynamic. They are a promising research target for the field of natural products discovery, due to their immense chemical potential and the advantages of studying the microbial producers directly embedded in an ecological context (i.e. fulfilling a role for their eukaryotic host), as opposed to free-living microorganisms. ${ }^{29,431}$ Furthermore, discovered natural products are more likely to be applicable in medical contexts, since they have been naturally tested for side effects on, at least some, eukaryotes. Although significant gaps in our understanding of symbiont-mediated defenses remain, the fast pace of technological advances and the momentum currently experienced by symbiosis research promise to quickly deepen our insights into these fascinating and promising associations.

\section{Acknowledgements}

We thank all colleagues in symbiosis research for their contributions to the knowledge on defensive associations, and we sincerely apologize to those whose work we may have overlooked during our literature searches or could not cite due to space constraints. We are grateful to Julia Kubanek, Jörn Piel, and Helge Bode for insightful comments on the manuscript, and we acknowledge financial support from the Max Planck Society (to LVF, PHWB, TE, MK), the German Science Foundation (to MK, DFG KA2846/2-1), and the Swiss National Science Foundation (to PHWB, P300P3_151134).

\section{References}

1 D. L. Evans and J. O. Schmidt, Insect defenses, State University of New York Press, Albany, NY, USA, 1990.

2 S. Yuan, X. Tao, S. Huang, S. Chen and A. Xu, Annu. Rev. Anim. Biosci., 2014, 2, 235-258.

3 T. Eisner, M. Eisner and M. V. S. Siegler, Secret weapons: defenses of insects, spiders, scorpions, and other many-legged creatures, Belknap Press, Cambridge, MA, USA, 2005.

4 M. E. Hay, J. Exp. Mar. Biol. Ecol., 1996, 200, 103-134.

5 K. Clay, Funct. Ecol., 2014, 28, 293-298.

6 J. F. White and M. S. Torres, Defensive Mutualism in Microbial Symbiosis, CRC Press, Boca Raton, FL, USA, 2009.

7 R. J. Dillon and V. M. Dillon, Annu. Rev. Entomol., 2004, 49, 71-92.

8 X. Pan, G. Zhou, J. Wu, G. Bian, P. Lu, A. S. Raikhel and Z. Xi, Proc. Natl. Acad. Sci. U. S. A., 2012, 109, E23-E31.

9 J. Piel, Nat. Prod. Rep., 2004, 21, 519-538.

10 J. Piel, Nat. Prod. Rep., 2009, 26, 338-362.

11 E. W. Schmidt, in Defensive Mutualism in Microbial Symbiosis, ed. J. F. White and M. S. Torres, Boca Raton, FL, USA, 2009, pp. 65-83.

12 N. B. Lopanik, Funct. Ecol., 2014, 28, 328-340.

13 G. M. Konig, S. Kehraus, S. F. Seibert, A. Abdel-Lateff and D. Muller, ChemBioChem, 2006, 7, 229-238. 
14 T. L. Simmons, R. C. Coates, B. R. Clark, N. Engene, D. Gonzalez, E. Esquenazi, P. C. Dorrestein and W. H. Gerwick, Proc. Natl. Acad. Sci. U. S. A., 2008, 105, 4587-4594.

15 J. C. Brownlie and K. N. Johnson, Trends Microbiol., 2009, 17, 348-354.

16 M. Kaltenpoth, Trends Microbiol., 2009, 17, 529-535.

17 M. Kaltenpoth and T. Engl, Funct. Ecol., 2014, 28, 315-327.

18 K. M. Oliver and N. A. Moran, in Defensive mutualism in microbial symbiosis, ed. J. F. White and M. S. Torres, CRC Press, Boca Raton, FL, USA, 2009, pp. 129-148.

19 K. M. Oliver, A. H. Smith and J. A. Russell, Funct. Ecol., 2014, 28, 341-355.

20 H. S. Koppenhoefer and R. Gaugler, in Defensive Mutualism in Microbial Symbiosis, ed. J. F. White and M. S. Torres, CRC Press, Boca Raton, FL, USA, 2009, vol. 27, pp. 99-116.

21 N. Morales-Soto, H. Snyder and S. Forst, in Defensive Mutualism in Microbial Symbiosis, ed. J. F. White and M. S. Torres, CRC Press, Boca Raton, FL, USA, 2009, pp. 117-127.

22 H. B. Bode, Curr. Opin. Chem. Biol., 2009, 13, 224-230.

23 S. S. Ebada and P. Proksch, in Handbook of Marine Natural Products, ed. E. Fattorusso, W. H. Gerwick and O. Taglialatela-Scafati, Springer, London, UK, 2012, pp. 191293.

24 R. L. Simister, P. Deines, E. S. Botte, N. S. Webster and M. W. Taylor, Environ. Microbiol., 2012, 14, 517-524.

25 N. S. Webster and M. W. Taylor, Environ. Microbiol., 2012, 14, 335-346.

26 N. S. Webster and L. L. Blackall, ISME J., 2008, 3, 1-3.

27 U. R. Abdelmohsen, K. Bayer and U. Hentschel, Nat. Prod. Rep., 2014, 31, 381-399.

28 A. Uria and J. Piel, Phytochem. Rev., 2009, 8, 401-414.

29 J. Piel, Annu. Rev. Microbiol., 2011, 65, 431-453.

30 M. C. Wilson and J. Piel, Chem. Biol., 2013, 20, 636-647.

31 U. Hentschel, J. Piel, S. M. Degnan and M. W. Taylor, Nat. Rev. Microbiol., 2012, 10, 641-654.

32 R. Thacker and C. Freeman, in Adv. Mar. Biol., ed. M. Becerro, M. Uriz, M. Maldonado and T. Xavier, Elsevier, London, UK, 2012, vol. 62, pp. 57-111.

33 J. W. Blunt, B. R. Copp, R. A. Keyzers, M. H. G. Munro and M. R. Prinsep, Nat. Prod. Rep., 2014, 31, 160-258.

34 T. R. A. Thomas, D. P. Kavlekar and P. A. LokaBharathi, Mar. Drugs, 2010, 8, 1417-1468.

35 O. K. Radjasa, Y. M. Vaske, G. Navarro, H. C. Vervoort, K. Tenney, R. G. Linington and P. Crews, Bioorg. Med. Chem., 2011, 19, 6658-6674.

36 J. A. Fuerst, Appl. Microbiol. Biotechnol., 2014, 98, 1-17.

37 K. Konya, N. Shimidzu, N. Otaki, A. Yokoyama, K. Adachi and W. Miki, Experientia, 1995, 51, 153-155.

38 S. Dash, C. L. Jin, O. O. Lee, Y. Xu and P. Y. Qian, J. Ind. Microbiol. Biotechnol., 2009, 36, 1047-1056.

39 S. Dash, Y. Nogata, X. J. Zhou, Y. F. Zhang, Y. Xu, X. R. Guo, X. X. Zhang and P. Y. Qian, Bioresour. Technol., 2011, 102, $7532-7537$.

40 W. Miki, N. Otaki, A. Yokoyama and T. Kusumi, Experientia, 1996, 52, 93-96.
41 M. D. Unson and D. J. Faulkner, Experientia, 1993, 49, 349353.

42 A. E. Flowers, M. J. Garson, R. I. Webb, E. J. Dumdei and R. D. Charan, Cell Tissue Res., 1998, 292, 597-607.

43 J. Faulkner, M. D. Unson and C. A. Bewley, Pure Appl. Chem., 1994, 66, 1983-1990.

44 M. D. Unson, N. D. Holland and D. J. Faulkner, Mar. Biol., 1994, 119, 1-11.

45 P. Flatt, J. Gautschi, R. Thacker, M. Musafija-Girt, P. Crews and W. Gerwick, Mar. Biol., 2005, 147, 761-774.

46 J. Vansande, F. Deneubourg, R. Beauwens, J. C. Braekman, D. Daloze and J. E. Dumont, Mol. Pharmacol., 1990, 37, 583589.

47 C. P. Ridley, P. R. Bergquist, M. K. Harper, D. J. Faulkner, J. N. A. Hooper and M. G. Haygood, Chem. Biol., 2005, 12, 397-406.

48 R. Thacker, M. Diaz, K. Ruetzler, P. Erwin, S. Kimble, M. Pierce and S. Dillard, in Porifera Research: Biodiversity, Innovation and Sustainability, ed. M. Custódio, G. LôboHajdu, E. Hajdu and G. Muricy, Série Licros, Rio de Janeiro, Brazil, 2007, pp. 621-626.

49 D. Erpenbeck, J. N. A. Hooper, I. Bonnard, P. Sutcliffe, M. Chandra, P. Perio, C. Wolff, B. Banaigs, G. Worheide, C. Debitus and S. Petek, Mar. Biol., 2012, 159, 1119-1127.

50 R. Sakai, H. Kamiya, M. Murata and K. Shimamoto, J. Am. Chem. Soc., 1997, 119, 4112-4116.

51 B. J. Rawlings, Nat. Prod. Rep., 2001, 18, 231-281.

52 M. A. Marahiel, T. Stachelhaus and H. D. Mootz, Chem. Rev., 1997, 97, 2651-2674.

53 J. Piel, D. Q. Hui, N. Fusetani and S. Matsunaga, Environ. Microbiol., 2004, 6, 921-927.

54 T. K. Kim, A. K. Hewavitharana, P. N. Shaw and J. A. Fuerst, Appl. Environ. Microbiol., 2006, 72, 2118-2125.

55 M. Laroche, C. Imperatore, L. Grozdanov, V. Costantino, A. Mangoni, U. Hentschel and E. Fattorusso, Mar. Biol., 2007, 151, 1365-1373.

56 M. D. Higgs and D. J. Faulkner, J. Org. Chem., 1978, 43, 3454-3457.

57 E. Fattorusso, S. Parapini, C. Campagnuolo, N. Basilico, O. Taglialatela-Scafati and D. Taramelli, J. Antimicrob. Chemother., 2002, 50, 883-888.

58 C. Campagnuolo, E. Fattorusso, A. Romano, O. TaglialatelaScafati, N. Basilico, S. Parapini and D. Taramelli, Eur. J. Org. Chem., 2005, 2005, 5077-5083.

59 V. Costantino, E. Fattorusso and A. Mangoni, J. Org. Chem., 1993, 58, 186-191.

60 C. Campagnuolo, E. Fattorusso, O. Taglialatela-Scafati, A. Ianaro and B. Pisano, Eur. J. Org. Chem., 2002, 2002, 61-69.

61 V. Costantino, E. Fattorusso, A. Mangoni, M. Di Rosa and A. Ianaro, J. Am. Chem. Soc., 1997, 119, 12465-12470.

62 V. Costantino, E. Fattorusso, A. Mangoni, M. Di Rosa and A. Ianaro, Bioorg. Med. Chem. Lett., 1999, 9, 271-276.

63 G. Della Sala, T. Hochmuth, V. Costantino, R. Teta, W. Gerwick, L. Gerwick, J. Piel and A. Mangoni, Environ. Microbiol. Rep., 2013, 5, 809-818. 
64 K. M. Fisch, C. Gurgui, N. Heycke, S. A. van der Sar, S. A. Anderson, V. L. Webb, S. Taudien, M. Platzer, B. K. Rubio, S. J. Robinson, P. Crews and J. Piel, Nat. Chem. Biol., 2009, 5, 494-501.

65 N. B. Perry, J. W. Blunt, M. H. G. Munro and L. K. Pannell, J. Am. Chem. Soc., 1988, 110, 4850-4851.

66 N. B. Perry, J. W. Blunt, M. H. G. Munro and A. M. Thompson, J. Org. Chem., 1990, 55, 223-227.

67 R. H. Cichewicz, F. A. Valeriote and P. Crews, Org. Lett., 2004, 6, 1951-1954.

68 C. A. Bewley, N. D. Holland and D. J. Faulkner, Experientia, 1996, 52, 716-722.

69 M. R. Bubb, I. Spector, A. D. Bershadsky and E. D. Korn, J. Biol. Chem., 1995, 270, 3463-3466.

70 C. A. Bewley and D. J. Faulkner, J. Org. Chem., 1994, 59, 4849-4852.

71 E. W. Schmidt, C. A. Bewley and D. J. Faulkner, J. Org. Chem., 1998, 63, 1254-1258.

72 E. W. Schmidt, A. Y. Obraztsova, S. K. Davidson, D. J. Faulkner and M. G. Haygood, Mar. Biol., 2000, 136, 969-977.

73 M. C. Wilson, T. Mori, C. Ruckert, A. R. Uria, M. J. Helf, K. Takada, C. Gernert, U. A. E. Steffens, N. Heycke, S. Schmitt, C. Rinke, E. J. N. Helfrich, A. O. Brachmann, C. Gurgui, T. Wakimoto, M. Kracht, M. Crusemann, U. Hentschel, I. Abe, S. Matsunaga, J. Kalinowski, H. Takeyama and J. Piel, Nature, 2014, 506, 58-62.

74 N. Fusetani, T. Sugawara and S. Matsunaga, J. Org. Chem., 1992, 57, 3828-3832.

75 S. Sakemi, T. Ichiba, S. Kohmoto, G. Saucy and T. Higa, J. Am. Chem. Soc., 1988, 110, 4851-4853.

76 J. Piel, D. Q. Hui, G. P. Wen, D. Butzke, M. Platzer, N. Fusetani and S. Matsunaga, Proc. Natl. Acad. Sci. U. S. A., 2004, 101, 16222-16227.

77 M. F. Freeman, C. Gurgui, M. J. Helf, B. I. Morinaka, A. R. Uria, N. J. Oldham, H. G. Sahl, S. Matsunaga and J. Piel, Science, 2012, 338, 387-390.

78 M. Iwamoto, H. Shimizu, I. Muramatsu, S. Matsunaga and S. Oiki, J. Physiol. Sci., 2010, 60, S121.

79 A. Schirmer, R. Gadkari, C. D. Reeves, F. Ibrahim, E. F. DeLong and C. R. Hutchinson, Appl. Environ. Microbiol., 2005, 71, 4840-4849.

80 W. M. Bruck, S. H. Sennett, S. A. Pomponi, P. Willenz and P. J. McCarthy, ISME J., 2008, 2, 335-339.

81 M. Kimura, T. Wakimoto, Y. Egami, K. C. Tan, Y. Ise and I. Abe, J. Nat. Prod., 2012, 75, 290-294.

82 T. Wakimoto, Y. Egami, Y. Nakashima, Y. Wakimoto, T. Mori, T. Awakawa, T. Ito, H. Kenmoku, Y. Asakawa, J. Piel and I. Abe, Nat. Chem. Biol., 2014, 10, 648-655.

83 T. S. Suryanarayanan, Bot. Mar., 2012, 55, 553-564.

84 M. Henríquez, K. Vergara, J. Norambuena, A. Beiza, F. Maza, P. Ubilla, I. Araya, R. Chávez, A. San-Martín, J. Darias, M. Darias and I. Vaca, World J. Microbiol. Biotechnol., 2014, 30, 65-76.

85 M. E. Rateb and R. Ebel, Nat. Prod. Rep., 2011, 28, 290-344.

86 M. Maldonado, N. Cortadellas, M. I. Trillas and K. Rutzler, Biol. Bull., 2005, 209, 94-106.
87 C. Rot, I. Goldfarb, M. Ilan and D. Huchon, BMC Evol. Biol., 2006, 6, 71.

88 S. Perovic-Ottstadt, T. Adell, P. Proksch, M. Wiens, M. Korzhev, V. Gamulin, I. M. Muller and W. E. G. Muller, Eur. J. Biochem., 2004, 271, 1924-1937.

89 K. Zhou, X. Zhang, F. L. Zhang and Z. Y. Li, Microb. Ecol., 2011, 62, 644-654.

90 R. D. Gates and T. D. Ainsworth, J. Exp. Mar. Biol. Ecol., 2011, 408, 94-101.

91 R. H. Burris, Mar. Biol., 1983, 75, 151-155.

92 M. P. Lesser, L. I. Falcon, A. Rodriguez-Roman, S. Enriquez, O. Hoegh-Guldberg and R. Iglesias-Prieto, Mar. Ecol.: Prog. Ser., 2007, 346, 143-152.

93 M. P. Lesser, C. H. Mazel, M. Y. Gorbunov and P. G. Falkowski, Science, 2004, 305, 997-1000.

94 K. B. Ritchie, Mar. Ecol.: Prog. Ser., 2006, 322, 1-14.

95 K. L. Rypien, J. R. Ward and F. Azam, Environ. Microbiol., 2010, 12, 28-39.

96 J. Mao-Jones, K. B. Ritchie, L. E. Jones and S. P. Ellner, PLoS Biol., 2010, 8, e1000345.

97 M. Shnit-Orland and A. Kushmaro, FEMS Microbiol. Ecol., 2009, 67, 371-380.

98 M. Shnit-Orland, A. Sivan and A. Kushmaro, Microb. Ecol., 2012, 64, 851-859.

99 W. Fenical and J. R. Pawlik, Mar. Ecol.: Prog. Ser., 1991, 75, 1-8.

100 A. D. Rodriguez, Tetrahedron, 1995, 51, 4571-4618.

101 W. O'Neal and J. R. Pawlik, Mar. Ecol.: Prog. Ser., 2002, 240, 117-126.

102 S. A. Look, W. Fenical, R. S. Jacobs and J. Clardy, Proc. Natl. Acad. Sci. U. S. A., 1986, 83, 6238-6240.

103 S. A. Look, W. Fenical, G. K. Matsumoto and J. Clardy, J. Org. Chem., 1986, 51, 5140-5145.

104 W. Fenical, J. Nat. Prod., 1987, 50, 1001-1008.

105 L. D. Mydlarz, R. S. Jacobs, J. Boehnlein and R. G. Kerr, Chem. Biol., 2003, 10, 1051-1056.

106 J. M. Boehnlein, L. Z. Santiago-Vazquez and R. G. Kerr, Mar. Ecol.: Prog. Ser., 2005, 303, 105-111.

107 D. Sica and D. Musumeci, Steroids, 2004, 69, 743-756.

108 R. D. A. Epifanio, L. F. Maia, J. R. Pawlik and W. Fenical, Mar. Ecol.: Prog. Ser., 2007, 329, 307-310.

109 N. W. Withers, W. Kokke, W. Fenical and C. Djerassi, Proc. Natl. Acad. Sci. U. S. A., 1982, 79, 3764-3768.

110 R. G. Kerr, L. C. Rodriguez and J. Kellman, Tetrahedron Lett., 1996, 37, 8301-8304.

111 S. Franzenburg, S. Fraune, P. M. Altrock, S. Kuenzel, J. F. Baines, A. Traulsen and T. C. G. Bosch, ISME J., 2013, 7, 781-790.

112 S. Fraune and T. C. G. Bosch, Proc. Natl. Acad. Sci. U. S. A., 2007, 104, 13146-13151.

113 S. Franzenburg, J. Walter, S. Kuenzel, J. Wang, J. F. Baines, T. C. G. Bosch and S. Fraune, Proc. Natl. Acad. Sci. U. S. A., 2013, 110, E3730-E3738.

114 S. Fraune, F. Anton-Erxleben, R. Augustin, S. Franzenburg, M. Knop, K. Schröder, D. Wolloweit-Ohl and T. C. G. Bosch, ISME J., 2014, DOI: 10.1038/ismej.2014.239. 
115 K. H. Sharp, S. K. Davidson and M. G. Haygood, ISME J., 2007, 1, 693-702.

116 M. Tischler, S. W. Ayer and R. J. Andersen, Comp. Biochem. Physiol., Part B: Biochem. Mol. Biol., 1986, 84, 43-45.

117 C. K. Narkowicz, A. J. Blackman, E. Lacey, J. H. Gill and K. Heiland, J. Nat. Prod., 2002, 65, 938-941.

118 J. T. Walls, A. J. Blackman and D. A. Ritz, J. Chem. Ecol., 1991, 17, 1871-1881.

119 J. T. Walls, A. J. Blackman and D. A. Ritz, Hydrobiologia, 1995, 297, 163-172.

120 Y. H. Choi, A. Park, F. J. Schmitz and I. Vanaltena, J. Nat. Prod., 1993, 56, 1431-1433.

121 F. J. Schmitz, F. S. Deguzman, Y. H. Choi, M. B. Hossain, S. K. Rizvi and D. Vanderhelm, Pure Appl. Chem., 1990, 62, 1393-1396.

122 L. Peters, A. D. Wright, A. Krick and G. M. Konig, J. Chem. Ecol., 2004, 30, 1165-1181.

123 G. R. Pettit, C. L. Herald, D. L. Doubek, D. L. Herald, E. Arnold and J. Clardy, J. Am. Chem. Soc., 1982, 104, 6846-6848.

124 A. E. Trindade-Silva, G. E. Lim-Fong, K. H. Sharp and M. G. Haygood, Curr. Opin. Biotechnol., 2010, 21, 834-842.

125 N. B. Lopanik, N. M. Targett and N. Lindquist, Mar. Ecol.: Prog. Ser., 2006, 327, 183-191.

126 T. J. Nelson and D. L. Alkon, Trends Biochem. Sci., 2009, 34, 136-145.

127 N. Lopanik, K. R. Gustafson and N. Lindquist, J. Nat. Prod., 2004, 67, 1412-1414.

128 N. Lopanik, N. Lindquist and N. Targett, Oecologia, 2004, 139, 131-139.

129 N. Lindquist and M. E. Hay, Ecol. Monogr., 1996, 66, 431450.

130 N. Lindquist, Mar. Biol., 1996, 126, 745-755.

131 U. Anthoni, P. H. Nielsen, M. Pereira and C. Christophersen, Comp. Biochem. Physiol., Part B: Biochem. Mol. Biol., 1990, 96, 431-437.

132 R. M. Woollacott, Mar. Biol., 1981, 65, 155-158.

133 R. M. Woollacott and R. L. Zimmer, J. Morphol., 1975, 147, 355-377.

134 M. G. Haygood and S. K. Davidson, Appl. Environ. Microbiol., 1997, 63, 4612-4616.

135 S. K. Davidson, S. W. Allen, G. E. Lim, C. M. Anderson and M. G. Haygood, Appl. Environ. Microbiol., 2001, 67, 45314537.

136 M. Hildebrand, L. E. Waggoner, H. B. Liu, S. Sudek, S. Allen, C. Anderson, D. H. Sherman and M. Haygood, Chem. Biol., 2004, 11, 1543-1552.

137 S. Sudek, N. B. Lopanik, L. E. Waggoner, M. Hildebrand, C. Anderson, H. B. Liu, A. Patel, D. H. Sherman and M. G. Haygood, J. Nat. Prod., 2007, 70, 67-74.

138 T. Nguyen, K. Ishida, H. Jenke-Kodama, E. Dittmann, C. Gurgui, T. Hochmuth, S. Taudien, M. Platzer, C. Hertweck and J. Piel, Nat. Biotechnol., 2008, 26, 225-233.

139 T. J. Buchholz, C. M. Rath, N. B. Lopanik, N. P. Gardner, K. Hakansson and D. H. Sherman, Chem. Biol., 2010, 17, 1092-1100.
140 N. B. Lopanik, J. A. Shields, T. J. Buchholz, C. M. Rath, J. Hothersall, M. G. Haygood, K. Hakansson, C. M. Thomas and D. H. Sherman, Chem. Biol., 2008, 15, 1175-1186.

141 S. K. Davidson and M. G. Haygood, Biol. Bull., 1999, 196, 273-280.

142 G. E. Lim and M. G. Haygood, Appl. Environ. Microbiol., 2004, 70, 4921-4929.

143 T. M. McGovern and M. E. Hellberg, Mol. Ecol., 2003, 12, 1207-1215.

144 G. E. Lim-Fong, L. A. Regali and M. G. Haygood, Appl. Environ. Microbiol., 2008, 74, 3605-3609.

145 J. S. Shellenberger and J. R. P. Ross, Northwest Sci., 1998, 72, 23-33.

146 S. Matsunaga, N. Fusetani and K. Hashimoto, Experientia, 1986, 42, 84 .

147 A. J. Blackman and C. P. Li, Aust. J. Chem., 1994, 47, 16251629.

148 B. Carte and D. J. Faulkner, J. Org. Chem., 1983, 48, 23142318.

149 R. Kazlauskas, J. F. Marwood, P. T. Murphy and R. J. Wells, Aust. J. Chem., 1982, 35, 215-217.

150 N. Lindquist and W. Fenical, Experientia, 1991, 47, 504-506. $151 \mathrm{H}$. H. Wasserman, D. J. Frieland and D. A. Morrison, Tetrahedron Lett., 1968, 6, 641-644.

152 A. Franks, P. Haywood, C. Holmstrom, S. Egan, S. Kjelleberg and N. Kumar, Molecules, 2005, 10, 1286-1291.

153 C. Holmstrom and S. Kjelleberg, FEMS Microbiol. Ecol., 1999, 30, 285-293.

154 H. Heindl, J. Wiese, V. Thiel and J. F. Imhoff, Syst. Appl. Microbiol., 2010, 33, 94-104.

155 J. P. Galkiewicz, Z. A. Pratte, M. A. Gray and C. A. Kellogg, FEMS Microbiol. Ecol., 2011, 77, 333-346.

156 C. Burke, T. Thomas, S. Egan and S. Kjelleberg, Environ. Microbiol., 2007, 9, 814-818.

157 D. M. Pinkerton, M. G. Banwell, M. J. Garson, N. Kumar, M. O. de Moraes, B. C. Cavalcanti, F. W. A. Barros and C. Pessoa, Chem. Biodiversity, 2010, 7, 1311-1324.

158 N. Lindquist, M. E. Hay and W. Fenical, Ecol. Monogr., 1992, 62, 547-568.

159 V. J. Paul, N. Lindquist and W. Fenical, Mar. Ecol.: Prog. Ser., 1990, 59, 109-118.

160 B. Carte and D. J. Faulkner, J. Chem. Ecol., 1986, 12, 795804.

161 A. Franks, S. Egan, C. Holmstrom, S. James, H. Lappin-Scott and S. Kjelleberg, Appl. Environ. Microbiol., 2006, 72, 60796087.

162 V. Bane, M. Lehane, M. Dikshit, A. Riordan and A. Furey, Toxins, 2014, 6, 693-755.

163 R. Ritson-Williams, M. Yotsu-Yamashita and V. J. Paul, Proc. Natl. Acad. Sci. U. S. A., 2006, 103, 3176-3179.

164 J. W. Daly, J. Nat. Prod., 2004, 67, 1211-1215.

165 C. T. Hanifin, Mar. Drugs, 2010, 8, 577-593.

166 T. Y. Magarlamov, I. A. Beleneva, A. V. Chernyshev and A. D. Kuhlevsky, Toxicon, 2014, 85, 46-51.

167 V. Pratheepa and V. Vasconcelos, Environ. Toxicol. Pharmacol., 2013, 36, 1046-1054. 
168 M. Asakawa, K. Ito and H. Kajihara, Toxins, 2013, 5, 376395.

169 D. F. Hwang, O. Arakawa, T. Saito, T. Noguchi, U. Simidu, K. Tsukamoto, Y. Shida and K. Hashimoto, Mar. Biol., 1989, 100, 327-332.

170 R. Chau, J. A. Kalaitzis and B. A. Neilan, Aquat. Toxicol., 2011, 104, 61-72.

171 S. K. Goffredi, A. Warén, V. J. Orphan, C. L. Van Dover and R. C. Vrijenhoek, Appl. Environ. Microbiol., 2004, 70, 30823090.

172 H. Yao, M. Dao, T. Imholt, J. Huang, K. Wheeler, A. Bonilla, S. Suresh and C. Ortiz, Proc. Natl. Acad. Sci. U. S. A., 2010, 107, 987-992.

173 Y. Suzuki, R. E. Kopp, T. Kogure, A. Suga, K. Takai, S. Tsuchida, N. Ozaki, K. Endo, J. Hashimoto, Y. Kato, C. Mizota, T. Hirata, H. Chiba, K. H. Nealson, K. Horikoshi and J. L. Kirschvink, Earth Planet. Sci. Lett., 2006, 242, 39-50.

174 O. Peraud, J. S. Biggs, R. W. Hughen, A. R. Light, G. P. Concepcion, B. M. Olivera and E. W. Schmidt, Appl. Environ. Microbiol., 2009, 75, 6820-6826.

175 Z. J. Lin, R. R. Antemano, R. W. Hughen, M. D. B. Tianero, O. Peraud, M. G. Haygood, G. P. Concepcion, B. M. Olivera, A. Light and E. W. Schmidt, J. Nat. Prod., 2010, 73, 19221926.

176 Z. Lin, C. A. Reilly, R. Antemano, R. W. Hughen, L. Marett, G. P. Concepcion, M. G. Haygood, B. M. Olivera, A. Light and E. W. Schmidt, J. Med. Chem., 2011, 54, 3746-3755.

177 Z. J. Lin, L. Marett, R. W. Hughen, M. Flores, I. Forteza, M. A. Ammon, G. P. Concepcion, S. Espino, B. M. Olivera, G. Rosenberg, M. G. Haygood, A. R. Light and E. W. Schmidt, Bioorg. Med. Chem. Lett., 2013, 23, 48674869.

178 Z. Lin, M. Koch, C. D. Pond, G. Mabeza, R. A. Seronay, G. P. Concepcion, L. R. Barrows, B. M. Olivera and E. W. Schmidt, J. Antibiot., 2014, 67, 121-126.

179 A. Marin, L. A. Alvarez, G. Cimino and A. Spinella, J. Molluscan Stud., 1999, 65, 121-131.

180 Z. J. Lin, J. P. Torres, M. A. Ammon, L. Marett, R. W. Teichert, C. A. Reilly, J. C. Kwan, R. W. Hughen, M. Flores, M. D. Tianero, O. Peraud, J. E. Cox, A. R. Light, A. J. L. Villaraza, M. G. Haygood, G. P. Concepcion, B. M. Olivera and E. W. Schmidt, Chem. Biol., 2013, 20, 73-81.

181 D. L. Distel, D. J. Beaudoin and W. Morrill, Appl. Environ. Microbiol., 2002, 68, 6292-6299.

182 M. A. Betcher, J. M. Fung, A. W. Han, R. O'Connor, R. Seronay, G. P. Concepcion, D. L. Distel and M. G. Haygood, PLoS One, 2012, 7, e45309.

183 D. L. Distel, W. Morrill, N. MacLaren-Toussaint, D. Franks and J. Waterbury, Int. J. Syst. Evol. Microbiol., 2002, 52, 2261-2269.

184 J. C. Yang, R. Madupu, A. S. Durkin, N. A. Ekborg, C. S. Pedamallu, J. B. Hostetler, D. Radune, B. S. Toms, B. Henrissat, P. M. Coutinho, S. Schwarz, L. Field, A. E. Trindade-Silva, C. A. G. Soares, S. Elshahawi, A. Hanora, E. W. Schmidt, M. G. Haygood, J. Posfai,
J. Benner, C. Madinger, J. Nove, B. Anton, K. Chaudhary, J. Foster, A. Holman, S. Kumar, P. A. Lessard, Y. A. Luyten, B. Slatko, N. Wood, B. Wu, M. Teplitski, J. D. Mougous, N. Ward, J. A. Eisen, J. H. Badger and D. L. Distel, PLoS One, 2009, 4, e6085.

185 S. I. Elshahawi, A. E. Trindade-Silva, A. Hanora, A. W. Han, M. S. Flores, V. Vizzoni, C. G. Schrago, C. A. Soares, G. P. Concepcion, D. L. Distel, E. W. Schmidt and M. G. Haygood, Proc. Natl. Acad. Sci. U. S. A., 2013, 110, E295-E304.

186 S. V. Nyholm and M. J. McFall-Ngai, Nat. Rev. Microbiol., 2004, 2, 632-642.

187 M. J. McFall-Ngai, Annu. Rev. Microbiol., 2014, 68, 177-194. 188 B. W. Jones and M. K. Nishiguchi, Mar. Biol., 2004, 144, 1151-1155.

189 E. G. Ruby, Annu. Rev. Microbiol., 1996, 50, 591-624.

190 A. J. Collins, B. A. LaBarre, B. S. Wong Won, M. V. Shah, S. Heng, M. H. Choudhury, S. A. Haydar, J. Santiago and S. V. Nyholm, Appl. Environ. Microbiol., 2012, 78, 4200-4208.

191 S. Grigioni, R. Boucher-Rodoni, A. Demarta, M. Tonolla and R. Peduzzi, Mar. Biol., 2000, 136, 217-222.

192 E. Barbieri, B. J. Paster, D. Hughes, L. Zurek, D. P. Moser, A. Teske and M. L. Sogin, Environ. Microbiol., 2001, 3, 151-167.

193 W. Decleir and A. Richard, in Biologisch Jaarboek (Dodonaea), Koninklijk Natuurwetenschappelijk Genootschap Dodonaea, Gent, Belgium, 1972.

194 C. Van den Branden, M. Gillis and A. Richard, Comp. Biochem. Physiol., Part B: Biochem. Mol. Biol., 1980, 66, 331-334.

195 A. Richard, C. Van den Branden and W. Decleir, in Cyclic Phenomena in Marine Plants and Animals: Proceedings of the 13th European Marine Biology Symposium, ed. E. Naylor and R. G. Hartnoll, Pergamon Press, Exeter, UK, 1979, pp. 173-180.

196 M. R. Kaufman, Y. Ikeda, C. Patton, G. Van Dykhuizen and D. Epel, Biol. Bull., 1998, 194, 36-43.

197 A. Lum-Kong, J. Zool., 1992, 226, 469-490.

198 P. Gomathi, J. R. Nair and P. M. Sherief, Indian J. Mar. Sci., 2010, 39, 100-104.

199 E. Barbieri, K. Barry, A. Child and N. Wainwright, Biol. Bull., 1997, 193, 275-276.

200 K. Benkendorff, A. R. Davis and J. Bremner, J. Invertebr. Pathol., 2001, 78, 109-118.

201 J. R. Nair, D. Pillai, S. M. Joseph, P. Gomathi, P. V. Senan and P. M. Sherief, Indian J. Geo-Mar. Sci., 2011, 40, 13-27.

202 M. S. Gil-Turnes, M. E. Hay and W. Fenical, Science, 1989, 246, 116-118.

203 M. S. Gil-Turnes and W. Fenical, Biol. Bull., 1992, 182, 105108.

204 A. Stoessl, Biochem. Biophys. Res. Commun., 1969, 35, 186191.

205 N. Claydon, J. F. Grove and M. Pople, Phytochemistry, 1985, 24, 937-943.

206 N. Lindquist, P. H. Barber and J. B. Weisz, Proc. R. Soc. B, 2005, 272, 1209-1216. 
207 E. W. Schmidt and M. S. Donia, Curr. Opin. Biotechnol., 2010, 21, 827-833.

208 E. W. Schmidt, M. S. Donia, J. A. McIntosh, W. F. Fricke and J. Ravel, J. Nat. Prod., 2012, 75, 295-304.

209 H. L. Sings and K. L. Rinehart, J. Ind. Microbiol. Biotechnol., 1996, 17, 385-396.

210 B. S. Davidson, Chem. Rev., 1993, 93, 1771-1791.

211 F. Lafargue and G. Duclaux, Ann. Inst. Oceanogr., 1979, 55, 163-184.

212 P. Kott, Mem. Queensl. Mus., 1980, 20, 1-48.

213 P. Kott, Micronesica, 1982, 18, 95-128.

214 I. Koike, M. Yamamuro and P. C. Pollard, Aust. J. Mar. Freshwater Res., 1993, 44, 173-182.

215 K. L. Rinehart, J. B. Gloer, J. C. Cook, S. A. Mizsak and T. A. Scahill, J. Am. Chem. Soc., 1981, 103, 1857-1859.

216 K. L. Rinehart, J. B. Gloer, R. G. Hughes, H. E. Renis, J. P. McGovren, E. B. Swynenberg, D. A. Stringfellow, S. L. Kuentzel and L. H. Li, Science, 1981, 212, 933-935.

217 N. Lindquist, J. Chem. Ecol., 2002, 28, 1987-2000.

218 N. Lindquist and M. E. Hay, Ecology, 1995, 76, 1347-1358.

219 M. Tsukimoto, M. Nagaoka, Y. Shishido, J. Fujimoto, F. Nishisaka, S. Matsumoto, E. Harunari, C. Imada and T. Matsuzaki, J. Nat. Prod., 2011, 74, 2329-2331.

220 Y. Xu, R. D. Kersten, S. J. Nam, L. Lu, A. M. Al-Suwailem, H. J. Zheng, W. Fenical, P. C. Dorrestein, B. S. Moore and P. Y. Qian, J. Am. Chem. Soc., 2012, 134, 8625-8632.

221 C. Ireland and P. J. Scheuer, J. Am. Chem. Soc., 1980, 102, 5688-5691.

222 M. S. Donia, B. J. Hathaway, S. Sudek, M. G. Haygood, M. J. Rosovitz, J. Ravel and E. W. Schmidt, Nat. Chem. Biol., 2006, 2, 729-735.

223 P. F. Long, W. C. Dunlap, C. N. Battershill and M. Jaspars, ChemBioChem, 2005, 6, 1760-1765.

224 E. W. Schmidt, J. T. Nelson, D. A. Rasko, S. Sudek, J. A. Eisen, M. G. Haygood and J. Ravel, Proc. Natl. Acad. Sci. U. S. A., 2005, 102, 7315-7320.

225 M. S. Donia, J. Ravel and E. W. Schmidt, Nat. Chem. Biol., 2008, 4, 341-343.

226 T. M. Zabriskie, C. L. Mayne and C. M. Ireland, J. Am. Chem. Soc., 1988, 110, 7919-7920.

227 A. D. Richardson, W. Aalbersberg and C. M. Ireland, AntiCancer Drugs, 2005, 16, 533-541.

228 M. S. Donia, W. F. Fricke, F. Partensky, J. Cox, S. I. Elshahawi, J. R. White, A. M. Phillippy, M. C. Schatz, J. Piel, M. G. Haygood, J. Ravel and E. W. Schmidt, Proc. Natl. Acad. Sci. U. S. A., 2011, 108, E1423-E1432.

229 J. C. Kwan, M. S. Donia, A. W. Han, E. Hirose, M. G. Haygood and E. W. Schmidt, Proc. Natl. Acad. Sci. U. S. A., 2012, 109, 20655-20660.

230 A. Nakabachi, R. Ueoka, K. Oshima, R. Teta, A. Mangoni, M. Gurgui, N. J. Oldham, G. van Echten-Deckert, K. Okamura, K. Yamamoto, H. Inoue, M. Ohkuma, Y. Hongoh, S.-y. Y. Miyagishima, M. Hattori, J. Piel and T. Fukatsu, Curr. Biol., 2013, 23, 1478-1484.

231 J. F. Biard, C. Grivois, J. F. Verbist, C. Debitus and J. B. Carre, J. Mar. Biol. Assoc. U. K., 1990, 70, 741-746.
232 J. F. Biard, C. Roussakis, J. M. Kornprobst, D. Gouiffesbarbin, J. F. Verbist, P. Cotelle, M. P. Foster, C. M. Ireland and C. Debitus, J. Nat. Prod., 1994, 57, 1336-1345.

233 D. Gouiffes, M. Juge, N. Grimaud, L. Welin, M. P. Sauviat, Y. Barbin, D. Laurent, C. Roussakis, J. P. Henichart and J. F. Verbist, Toxicon, 1988, 26, 1129-1136.

234 B. M. Degnan, C. J. Hawkins, M. F. Lavin, E. J. McCaffrey, D. L. Parry and D. J. Watters, J. Med. Chem., 1989, 32, 1354-1359.

235 C. S. Riesenfeld, A. E. Murray and B. J. Baker, J. Nat. Prod., 2008, 71, 1812-1818.

236 M. S. Donia, W. F. Fricke, J. Ravel and E. W. Schmidt, PLoS One, 2011, 6, e17897.

237 C. Moss, D. H. Green, B. Perez, A. Velasco, R. Henriquez and J. D. McKenzie, Mar. Biol., 2003, 143, 99-110.

238 A. E. Perez-Matos, W. Rosado and N. S. Govind, Antonie van Leeuwenhoek, 2007, 92, 155-164.

239 C. M. Rath, B. Janto, J. Earl, A. Ahmed, F. Z. Hu, L. Hiller, M. Dahlgren, R. Kreft, F. A. Yu, J. J. Wolff, H. K. Kweon, M. A. Christiansen, K. Hakansson, R. M. Williams, G. D. Ehrlich and D. H. Sherman, ACS Chem. Biol., 2011, 6, 1244-1256.

240 R. Gaugler, Entomopathogenic Nematology, CABI Publishing, New York, NY, USA, 2002.

241 S. Forst and K. Nealson, Microbiol. Rev., 1996, 60, 21-43.

$242 \mathrm{~J} . \mathrm{Li}, \mathrm{K} . \mathrm{Hu}$ and J. M. Webster, Chem. Heterocycl. Compd., 1998, 34, 1331-1339.

243 S. Forst, B. Dowds, N. Boemare and E. Stackebrandt, Annu. Rev. Microbiol., 1997, 51, 47-72.

244 S. R. Dutky, Adv. Appl. Microbiol., 1959, 1, 175-200.

245 V. J. Paul, S. Frautschy, W. Fenical and K. H. Nealson, J. Chem. Ecol., 1981, 7, 589-597.

246 S. Forst and D. Clarke, in Entomopathogenic Nematology, ed. R. Gaugler, CABI Publishing, New York, NY, USA, 2002, pp. 57-77.

247 E. E. Lewis, in Entomopathogenic Nematology, ed. R. Gaugler, CABI Publishing, New York, NY, USA, 2002, pp. 205-223.

248 G. O. Poinar, Fundam. Appl. Nematol., 1993, 16, 333-338.

249 G. Chen, G. B. Dunphy and J. M. Webster, Biol. Control, 1994, 4, 157-162.

250 R. J. Akhurst, J. Gen. Microbiol., 1982, 128, 3061-3065.

251 J. M. Webster, G. Chen, K. Hu and J. Li, in Entomopathogenic Nematology, ed. R. Gaugler, CABI Publishing, New York, NY, USA, 2002, pp. 99-114.

252 S. Sharma, N. Waterfield, D. Bowen, T. Rocheleau, L. Holland, R. James and R. ffrench-Constant, FEMS Microbiol. Lett., 2002, 214, 241-249.

253 R. ffrench-Constant, N. Waterfield, P. Daborn, S. Joyce, H. Bennett, C. Au, A. Dowling, S. Boundy, S. Reynolds and D. Clarke, FEMS Microbiol. Rev., 2003, 26, 433-456.

254 H. Hawlena, F. Bashey and C. M. Lively, Ecol. Evol., 2012, 2, 2516-2521.

255 N. E. Boemare, M. H. Boyergiglio, J. O. Thaler, R. J. Akhurst and M. Brehelin, Appl. Environ. Microbiol., 1992, 58, 30323037. 
256 J. O. Thaler, S. Baghdiguian and N. Boemare, Appl. Environ. Microbiol., 1995, 61, 2049-2052.

257 L. Lango-Scholey, A. O. Brachmann, H. B. Bode and D. J. Clarke, PLoS One, 2013, 8, e82152.

$258 \mathrm{~J} . \mathrm{Li}, \mathrm{G}$. Chen, H. Wu and J. M. Webster, Appl. Environ. Microbiol., 1995, 61, 4329-4333.

259 F. Sztaricskai, Z. Dinya, G. Y. Batta, E. Szallas, A. Szentirmai and A. Fodor, ACH - Models Chem., 1992, 129, 697-707.

260 T. A. Ciche, M. Blackburn, J. R. Carney and J. C. Ensign, Appl. Environ. Microbiol., 2003, 69, 4706-4713.

261 S. W. Fuchs, F. Grundmann, M. Kurz, M. Kaiser and H. B. Bode, ChemBioChem, 2014, 15, 512-516.

262 B. V. McInerney, R. P. Gregson, M. J. Lacey, R. J. Akhurst, G. R. Lyons, S. H. Rhodes, D. R. Smith, L. M. Engelhardt and A. H. White, J. Nat. Prod., 1991, 54, 774-784.

263 J. Li, G. Chen, J. M. Webster and E. Czyzewska, J. Nat. Prod., 1995, 58, 1081-1086.

264 J. Li, G. Chen and J. M. Webster, Can. J. Microbiol., 1997, 43, 770-773.

265 Q. Zhou, F. Grundmann, M. Kaiser, M. Schiell, S. Gaudriault, A. Batzer, M. Kurz and H. B. Bode, Chem.Eur. J., 2013, 19, 16772-16779.

266 G. Lang, T. Kalvelage, A. Peters, J. Wiese and J. F. Imhoff, J. Nat. Prod., 2008, 71, 1074-1077.

267 B. V. McInerney, W. C. Taylor, M. J. Lacey, R. J. Akhurst and R. P. Gregson, J. Nat. Prod., 1991, 54, 785-795.

268 D. Ji, Y. Yi, G. H. Kang, Y. H. Choi, P. Kim, N. I. Baek and Y. Kim, FEMS Microbiol. Lett., 2004, 239, 241-248.

269 M. Kronenwerth, K. A. J. Bozhüyük, A. S. Kahnt, D. Steinhilber, S. Gaudriault, M. Kaiser and H. B. Bode, Chem.-Eur. J., 2014, 20, 17478-17487.

270 M. Kronenwerth, C. Dauth, M. Kaiser, I. Pemberton and H. B. Bode, Eur. J. Org. Chem., 2014, 2014, 8026-8028.

271 F. Grundmann, M. Kaiser, M. Schiell, A. Batzer, M. Kurz, A. Thanwisai, N. Chantratita and H. B. Bode, J. Nat. Prod., 2014, 77, 779-783.

272 F. I. Nollmann, A. Dowling, M. Kaiser, K. Deckmann, S. Grosch, R. Ffrench-Constant and H. B. Bode, Beilstein J. Org. Chem., 2012, 8, 528-533.

273 B. Ohlendorf, S. Simon, J. Wiese and J. F. Imhoff, Nat. Prod. Commun., 2011, 6, 1247-1250.

274 J. M. Crawford, C. Portmann, X. Zhang, M. B. J. Roeffaers and J. Clardy, Proc. Natl. Acad. Sci. U. S. A., 2012, 109, 10821-10826.

275 G. Chen, Y. Zhang, J. Li, G. B. Dunphy, Z. K. Punja and J. M. Webster, J. Invertebr. Pathol., 1996, 68, 101-108.

276 P. J. Isaacson and J. M. Webster, J. Invertebr. Pathol., 2002, 79, 146-153.

277 S. Derzelle, E. Duchaud, F. Kunst, A. Danchin and P. Bertin, Appl. Environ. Microbiol., 2002, 68, 3780-3789.

278 W. H. Richardson, T. M. Schmidt and K. H. Nealson, Appl. Environ. Microbiol., 1988, 54, 1602-1605.

279 I. Eleftherianos, S. Boundy, S. A. Joyce, S. Aslam, J. W. Marshall, R. J. Cox, T. J. Simpson, D. J. Clarke, R. H. ffrench-Constant and S. E. Reynolds, Proc. Natl. Acad. Sci. U. S. A., 2007, 104, 2419-2424.
$280 \mathrm{~K} . \mathrm{Hu}$ and J. M. Webster, FEMS Microbiol. Lett., 2000, 189, 219-223.

281 A. O. Brachmann, S. A. Joyce, H. Jenke-Kodama, G. Schwar, D. J. Clarke and H. B. Bode, ChemBioChem, 2007, 8, 17211728.

282 K. Hu, J. Li, W. Wang, H. Wu, H. Lin and J. M. Webster, Can. J. Microbiol., 1998, 44, 1072-1077.

283 S. Paik, Y. H. Park, S. I. Suh, H. S. Kim, I. S. Lee, M. K. Park, C. S. Lee and S. H. Park, Bull. Korean Chem. Soc., 2001, 22, 372-374.

284 M. E. Baur, H. K. Kaya and D. R. Strong, Biol. Control, 1998, 12, 231-236.

285 X. S. Zhou, H. K. Kaya, K. Heungens and H. Goodrich-Blair, Appl. Environ. Microbiol., 2002, 68, 6202-6209.

286 A. E. Douglas, Cell Host Microbe, 2011, 10, 359-367.

287 R. L. L. Kellner, Insect Biochem. Mol. Biol., 2002, 32, 389395.

288 R. L. L. Kellner and K. Dettner, Oecologia, 1996, 107, 293300.

289 J. Piel, I. Hofer and D. Q. Hui, J. Bacteriol., 2004, 186, 12801286.

290 K. M. Oliver, J. A. Russell, N. A. Moran and M. S. Hunter, Proc. Natl. Acad. Sci. U. S. A., 2003, 100, 1803-1807.

291 P. Łukasik, M. A. Dawid, J. Ferrari and H. C. Godfray, Oecologia, 2013, 173, 985-996.

292 J. Xie, I. Vilchez and M. Mateos, PLoS One, 2010, 5, e12149.

293 A. K. Hansen, G. Jeong, T. D. Paine and R. Stouthamer, Appl. Environ. Microbiol., 2007, 73, 7531-7535.

294 T. H. Hsiao, in The Ecology of Agricultural Pests: Biochemical Approaches, ed. E. O. C. Symondson and J. E. Liddell, Chapman and Hall, London, UK, 1996, p. 517.

295 P. Łukasik, M. van Asch, H. Guo and J. Ferrari, Ecol. Lett., 2013, 16, 214-218.

296 C. L. Scarborough, J. Ferrari and H. C. J. Godfray, Science, 2005, 310, 1781.

297 P. T. Hamilton, J. S. Leong, B. F. Koop and S. J. Perlman, Mol. Ecol., 2014, 23, 1558-1570.

298 J. Jaenike, R. Unckless, S. N. Cockburn, L. M. Boelio and S. J. Perlman, Science, 2010, 329, 212-215.

299 G. Yim, H. Huimi Wang and J. Davies Frs, Philos. Trans. $R$. Soc. London, Ser. B, 2007, 362, 1195-1200.

300 J. Clardy, M. A. Fischbach and C. R. Currie, Curr. Biol., 2009, 19, R437-R441.

301 M. Kaltenpoth, W. Goettler, C. Dale, J. W. Stubblefield, G. Herzner, K. Roeser-Mueller and E. Strohm, Int. J. Syst. Evol. Microbiol., 2006, 56, 1403-1411.

302 M. Kaltenpoth, W. Gottler, G. Herzner and E. Strohm, Curr. Biol., 2005, 15, 475-479.

303 M. Kaltenpoth, K. Roeser-Mueller, S. Koehler, A. Peterson, T. Nechitaylo, J. W. Stubblefield, G. Herzner, J. Seger and E. Strohm, Proc. Natl. Acad. Sci. U. S. A., 2014, 111, 63596364.

304 M. Kaltenpoth, T. Schmitt, C. Polidori, D. Koedam and E. Strohm, Physiol. Entomol., 2010, 35, 196-200.

305 M. Kaltenpoth, E. Yildirim, M. F. Gürbüz, G. Herzner and E. Strohm, Appl. Environ. Microbiol., 2012, 78, 822-827. 
306 M. Kaltenpoth, W. Goettler, S. Koehler and E. Strohm, Evol. Ecol., 2010, 24, 463-477.

307 S. Koehler, J. Doubsky and M. Kaltenpoth, Front. Zool., 2013, 10, 13.

308 S. Koehler and M. Kaltenpoth, J. Chem. Ecol., 2013, 39, 978988.

309 J. Kroiss, M. Kaltenpoth, B. Schneider, M.-G. G. Schwinger, C. Hertweck, R. K. Maddula, E. Strohm and A. Svatos, Nat. Chem. Biol., 2010, 6, 261-263.

310 C. R. Currie, J. A. Scott, R. C. Summerbell and D. Malloch, Nature, 1999, 398, 701-704.

311 A. S. Vieira, E. D. Morgan, F. P. Drijfhout and M. I. Camargo-Mathias, J. Chem. Ecol., 2012, 38, 1289-1297.

312 C. R. Currie, U. G. Mueller and D. Malloch, Proc. Natl. Acad. Sci. U. S. A., 1999, 96, 7998-8002.

313 C. R. Currie and A. E. Stuart, Proc. R. Soc. B, 2001, 268, 10331039.

314 M. J. Cafaro, M. Poulsen, A. E. F. Little, S. L. Price, N. M. Gerardo, B. Wong, A. E. Stuart, B. Larget, P. Abbot and C. R. Currie, Proc. R. Soc. B, 2011, 278, 1814-1822.

315 U. G. Mueller, D. Dash, C. Rabeling and A. Rodrigues, Evolution, 2008, 62, 2894-2912.

316 M. Poulsen, M. Cafaro, J. J. Boomsma and C. R. Currie, Mol. Ecol., 2005, 14, 3597-3604.

317 J. Barke, R. F. Seipke, S. Gruschow, D. Heavens, N. Drou, M. J. Bibb, R. J. Goss, D. W. Yu and M. I. Hutchings, BMC Biol., 2010, 8, 10.

318 R. Sen, H. D. Ishak, D. Estrada, S. E. Dowd, E. Hong and U. G. Mueller, Proc. Natl. Acad. Sci. U. S. A., 2009, 106, 17805-17810.

319 C. Kost, T. Lakatos, I. Bottcher, W. R. Arendholz, M. Redenbach and R. Wirth, Naturwissenschaften, 2007, 94, 821-828.

320 G. Carr, E. R. Derbyshire, E. Caldera, C. R. Currie and J. Clardy, J. Nat. Prod., 2012, 75, 1806-1809.

321 D. C. Oh, M. Poulsen, C. R. Currie and J. Clardy, Nat. Chem. Biol., 2009, 5, 391-393.

322 S. Haeder, R. Wirth, H. Herz and D. Spiteller, Proc. Natl. Acad. Sci. U. S. A., 2009, 106, 4742-4746.

323 I. Schoenian, M. Spiteller, M. Ghaste, R. Wirth, H. Herz and D. Spiteller, Proc. Natl. Acad. Sci. U. S. A., 2011, 108, 19551960.

324 T. D. Zucchi, A. S. Guidolin and F. L. Consoli, Microbiol. Res., 2011, 166, 68-76.

325 M. X. Ruiz-González, P.-J. G. Malé, C. Leroy, A. Dejean, H. Gryta, P. Jargeat, A. Quilichini and J. Orivel, Biol. Lett., 2011, 7, 475-479.

326 A. Dejean, P. J. Solano, J. Ayroles, B. Corbara and J. Orivel, Nature, 2005, 434, 973.

327 R. F. Seipke, J. Barke, M. X. Ruiz-Gonzalez, J. Orivel, D. W. Yu and M. I. Hutchings, Antonie van Leeuwenhoek, 2012, 101, 443-447.

328 T. R. Ramadhar, C. Beemelmanns, C. R. Currie and J. Clardy, J. Antibiot., 2014, 67, 53-58.

329 U. G. Mueller, N. M. Gerardo, D. K. Aanen, D. L. Six and T. R. Schultz, Annu. Rev. Ecol. Evol. Syst., 2005, 36, 563-595.
330 A. A. Visser, T. Nobre, C. R. Currie, D. K. Aanen and M. Poulsen, Microb. Ecol., 2012, 63, 975-985.

331 G. Carr, M. Poulsen, J. L. Klassen, Y. Hou, T. P. Wyche, T. S. Bugni, C. R. Currie and J. Clardy, Org. Lett., 2012, 14, 2822-2825.

332 S. Um, A. Fraimout, P. Sapountzis, D.-C. Oh and M. Poulsen, Sci. Rep., 2013, 3, 3250.

333 T. C. Harrington, in Ecological and evolutionary advances in insect-fungal associations, ed. F. E. Vega and M. Blackwell, Oxford University Press, New York, NY, USA, 2005, pp. 257-291.

334 H. Francke-Grosmann, in Symbiosis, ed. S. M. Henry, Academic Press, New York, NY, USA, 1967, pp. 141-205.

335 J. J. Scott, D. C. Oh, M. C. Yuceer, K. D. Klepzig, J. Clardy and C. R. Currie, Science, 2008, 322, 63.

336 D. C. Oh, J. J. Scott, C. R. Currie and J. Clardy, Org. Lett., 2009, 11, 633-636.

337 J. A. V. Blodgett, D. C. Oh, S. G. Cao, C. R. Currie, R. Kolter and J. Clardy, Proc. Natl. Acad. Sci. U. S. A., 2010, 107, 11692-11697.

338 J. Hulcr, A. Adams, K. Raffa, R. Hofstetter, K. Klepzig and C. Currie, Microb. Ecol., 2011, 61, 759-768.

339 R. J. Dillon and A. K. Charnley, J. Invertebr. Pathol., 1995, 66, 72-75.

340 R. Dillon and K. Charnley, Res. Microbiol., 2002, 153, 503509.

341 R. J. Dillon, C. T. Vennard, A. Buckling and A. K. Charnley, Ecol. Lett., 2005, 8, 1291-1298.

342 T. C. Olofsson, E. Butler, P. Markowicz, C. Lindholm, L. Larsson and A. Vásquez, Int. Wound J., 2014, DOI: 10.1111/iwj.12345.

343 E. Forsgren, T. C. Olofsson, A. Vásquez and I. Fries, Apidologie, 2010, 41, 99-108.

344 A. Vásquez, E. Forsgren, I. Fries, R. J. Paxton, E. Flaberg, L. Szekely and T. C. Olofsson, PLoS One, 2012, 7, e33188.

345 H. Koch and P. Schmid-Hempel, Proc. Natl. Acad. Sci. U. S. A., 2011, 108, 19288-19292.

346 D. P. Cariveau, J. Elijah Powell, H. Koch, R. Winfree and N. A. Moran, ISME J., 2014, 8, 2369-2379.

347 K. Lam, K. Thu, M. Tsang, M. Moore and G. Gries, Naturwissenschaften, 2009, 96, 1127-1132.

348 L. M. Hedges, J. C. Brownlie, S. L. O'Neill and K. N. Johnson, Science, 2008, 332, 702.

349 L. Teixeira, Á. Ferreira and M. Ashburner, PLoS Biol., 2008, 6, e1000002.

350 P. T. Hamilton and S. J. Perlman, PLoS Pathog., 2013, 9, e1003808.

351 R. L. Glaser and M. A. Meola, PLoS One, 2010, 5, e11977.

352 L. A. Moreira, I. Iturbe-Ormaetxe, J. A. Jeffery, G. Lu, A. T. Pyke, L. M. Hedges, B. C. Rocha, S. Hall-Mendelin, A. Day, M. Riegler, L. E. Hugo, K. N. Johnson, B. H. Kay, E. A. McGraw, A. F. van den Hurk, P. A. Ryan and S. L. O'Neill, Cell, 2009, 139, 1268-1278.

353 E. Rances, H. Y. Yixin, M. Woolfit and E. A. McGraw, PLoS Pathog., 2012, 8, e1002548. 
354 S. C. Carreiro, F. C. Pagnocca, M. Bacci, O. C. Bueno, M. J. A. Hebling and W. J. Middelhoven, Folia Microbiol., 2002, 47, 259-262.

355 A. Rodrigues, R. Cable, U. Mueller, M. Bacci Jr and F. Pagnocca, Antonie van Leeuwenhoek, 2009, 96, 331-342.

356 T. S. Davis, R. W. Hofstetter, J. T. Foster, N. E. Foote and P. Keim, Microb. Ecol., 2011, 61, 626-634.

357 T. Nakashima, T. Iizuka, K. Ogura, M. Maeda and T. Tanaka, J. Fac. Agric., Hokkaido Univ., 1982, 61, 60-72.

358 A. Hervey and M. S. R. Nair, Mycologia, 1979, 71, 1064-1066.

359 M. S. R. Nair and A. Hervey, Phytochemistry, 1979, 18, 326327.

360 Y. Wang, U. Mueller and J. Clardy, J. Chem. Ecol., 1999, 25, 935-941.

361 S. A. Van Bael, H. Fernandez-Marin, M. C. Valencia, E. I. Rojas, W. T. Wcislo and E. A. Herre, Proc. R. Soc. B, 2009, 276, 2419-2426.

362 S. A. O. Armitage, H. Fernandez-Marin, W. T. Wcislo and J. J. Boomsma, Evolution, 2012, 66, 1966-1975.

363 U. G. Mueller, A. Ortiz and M. Bacci Jr, Insectes Soc., 2010, 57, 209-215.

364 D. K. Aanen, H. H. D. Licht, A. J. M. Debets, N. A. G. Kerstes, R. F. Hoekstra and J. J. Boomsma, Science, 2009, 326, 11031106.

365 L. Wang, Y. Feng, J. Tian, M. Xiang, J. Sun, J. Ding, W.-B. Yin, M. Stadler, Y. Che and X. Liu, ISME J., 2015, DOI: 10.1038/ismej.2014.26.

366 X. Li, G. Wheeler and J. Ding, Arthropod Plant Interact., 2012, vol. 6, pp. 417-424.

367 C. Kobayashi, Y. Fukasawa, D. Hirose and M. Kato, Evol. Ecol., 2008, 22, 711-722.

368 M. Gilliam, S. Taber III, B. J. Lorenz and D. B. Prest, J. Invertebr. Pathol., 1988, 52, 314-325.

369 J. Frisvad, U. Thrane, R. Samson and J. Pitt, in Advances in Food Mycology, ed. A. D. Hocking, J. I. Pitt, R. Samson and U. Thrane, Springer, New York, NY, USA, 2006, pp. 3-31.

370 M. Rohlfs and L. Kurschner, J. Appl. Entomol., 2010, 134, 667-671.

371 P. Daszak, A. A. Cunningham and A. D. Hyatt, Divers. Distrib., 2003, 9, 141-150.

372 J. M. Myers, J. P. Ramsey, A. L. Blackman, A. E. Nichols, K. P. C. Minbiole and R. N. Harris, J. Chem. Ecol., 2012, 38, 958-965.

373 R. M. Brucker, R. N. Harris, C. R. Schwantes, T. N. Gallaher, D. C. Flaherty, B. A. Lam and K. P. C. Minbiole, J. Chem. Ecol., 2008, 34, 1422-1429.

374 P. J. Wiggins, J. M. Smith, R. N. Harris and K. P. C. Minbiole, J. Herpetol., 2011, 45, 329-332.

375 M. R. Brucker, C. M. Baylor, R. L. Walters, A. Lauer, R. N. Harris and K. P. C. Minbiole, J. Chem. Ecol., 2008, 34, 39-43.

376 M. H. Becker, R. M. Brucker, C. R. Schwantes, R. N. Harris and K. P. Minbiole, Appl. Environ. Microbiol., 2009, 75, 6635-6638.

377 B. A. Lam, J. B. Walke, V. T. Vredenburg and R. N. Harris, Biol Conservat, 2010, 143, 529-531.
378 R. N. Harris, R. M. Brucker, J. B. Walke, M. H. Becker, C. R. Schwantes, D. C. Flaherty, B. A. Lam, D. C. Woodhams, C. J. Briggs, V. T. Vredenburg and K. P. C. Minbiole, ISME J., 2009, 3, 818-824.

379 A. H. Loudon, J. A. Holland, T. P. Umile, E. A. Burzynski, K. P. Minbiole and R. N. Harris, Front. Microbiol., 2014, 5, e00441.

380 M. C. Bastos, H. Ceotto, M. L. Coelho and J. S. Nascimento, Curr. Pharm. Biotechnol., 2009, 10, 38-61.

381 R. L. Gallo and T. Nakatsuji, J. Invest. Dermatol., 2011, 131, 1974-1980.

382 H. Muellner, M. A. Folger, A. Werner, U. Gierlich, K. Eyer, K. Heinzmann, N. M. Shaw and F. Wyer, Germany Pat., WO/2007/093548, 2008.

383 A. L. Cogen, K. Yamasaki, K. M. Sanchez, R. A. Dorschner, Y. Lai, D. T. MacLeod, J. W. Torpey, M. Otto, V. Nizet, J. E. Kim and R. L. Gallo, J. Invest. Dermatol., 2010, 130, 192-200.

384 A. L. Cogen, K. Yamasaki, J. Muto, K. M. Sanchez, L. C. Alexander, J. Tanios, Y. Lai, J. E. Kim, V. Nizet and R. L. Gallo, PLoS One, 2010, 5, e8557.

385 T. Iwase, Y. Uehara, H. Shinji, A. Tajima, H. Seo, K. Takada, T. Agata and Y. Mizunoe, Nature, 2010, 465, 346-349.

386 M. Otto, R. Süssmuth, C. Vuong, G. Jung and F. Götz, FEBS Lett., 1999, 450, 257-262.

387 J. H. Daskin and R. A. Alford, Proc. R. Soc. B, 2012, 279, 1457-1465.

388 H. M. Wexler, Clin. Microbiol. Rev., 2007, 20, 593-621.

389 S. K. Mazmanian, J. L. Round and D. L. Kasper, Nature, 2008, 453, 620-625.

390 S. Yurist-Doutsch, M.-C. C. Arrieta, S. L. Vogt and B. B. Finlay, Annu. Rev. Genet., 2014, 48, 361-382.

391 L. Rizzetto, C. De Filippo and D. Cavalieri, Eur. J. Immunol., 2014, 44, 3166-3181.

392 J. C. Clemente, L. K. Ursell, L. Wegener Parfrey and R. Knight, Cell, 2012, 148, 1258-1270.

393 F. J. Gatesoupe, J. Mol. Microbiol. Biotechnol., 2008, 14, 107114.

394 S. Ghosh, E. Ringø, A. D. G. Selvam, M. Rahinam, N. Sathyan, N. John and A. A. M. Hatha, Int. J. Fish. Aquacult., 2014, 4, 1-11.

395 E. Ringø, U. Schillinger and W. Holzapfel, in Biology of Growing Animals, ed. W. H. Holzapfel and P. J. Naughton, Elsevier, Edinburgh, UK, 2005, pp. 416-453.

396 E. Ringø, L. Løvmo, M. Kristiansen and Y. Bakken, Aquacult. Res., 2010, 41, 451-467.

397 J. J. Soler, M. Martín-Vivaldi, M. Ruiz-Rodriguez, E. Valdivia, A. M. Martín-Platero, M. Martínez-Bueno, J. M. Peralta-Sanchez and M. Méndez, Funct. Ecol., 2008, 22, 864-871.

398 M. Martín-Vivaldi, J. J. Soler, J. M. Peralta-Sánchez, L. Arco, A. M. Martín-Platero, M. Martínez-Bueno, M. RuizRodríguez and E. Valdivia, J. Anim. Ecol., 2014, 83, 12891301.

399 M. Ruiz-Rodriguez, E. Valdivia, J. J. Soler, M. MartínVivaldi, A. M. Martín-Platero and M. Martínez-Bueno, J. Exp. Biol., 2009, 212, 3621-3626. 
400 A. M. Martín-Platero, E. Valdivia, M. Ruiz-Rodriguez, J. J. Soler, M. Martin-Vivaldi, M. Maqueda and M. Martínez-Bueno, Appl. Environ. Microbiol., 2006, 72, 4245-4249.

401 M. Ruiz-Rodriguez, M. Martínez-Bueno, M. Martín-Vivaldi, E. Valdivia and J. J. Soler, FEMS Microbiol. Ecol., 2013, 85, 495-502.

402 M. Martin-Vivaldi, A. Pena, J. M. Peralta-Sanchez, L. Sanchez, S. Ananou, M. Ruiz-Rodriguez and J. J. Soler, Proc. R. Soc. B, 2010, 277, 123-130.

403 T. Nosenko, F. Schreiber, M. Adamska, M. Adamski, M. Eitel, J. Hammel, M. Maldonado, W. E. Müller, M. Nickel, B. Schierwater, J. Vacelet, M. Wiens and G. Wörheide, Mol. Phylogenet. Evol., 2013, 67, 223-233.

404 W. Wheeler, Cladistics, 2001, 17, 113-169.

405 G. D. Edgecombe, G. Giribet, C. W. Dunn, A. Hejnol, R. M. Kristensen, R. C. Neves, G. W. Rouse, K. Worsaae and M. V. Sørensen, Org. Divers. Evol., 2011, 11, 151-172.

406 G. Giribet and G. D. Edgecombe, Annu. Rev. Entomol., 2012, 57, 167-186.

407 S. Cremer, S. A. O. Armitage and P. Schmid-Hempel, Curr. Biol., 2007, 17, R693-R702.

408 W. D. Hamilton, in Animal societies: Theories and Facts, ed. Y. Ito, J. L. Brown and J. Kikkawa, Japan Scientific Society Press, Tokyo, Japan, 1987, pp. 81-102.

409 M. P. Lombardo, Behav. Ecol. Sociobiol., 2007, 62, 479-497.

410 S. E. Marsh, M. Poulsen, A. Pinto-Tomás and C. R. Currie, PLoS One, 2014, 9, e103269.

411 V. G. Martinson, J. Moy and N. A. Moran, Appl. Environ. Microbiol., 2012, 78, 2830-2840.

412 F. Romero, F. Espliego, J. P. Baz, T. G. DeQuesada, D. Gravalos, F. DelaCalle and J. L. FernadezPuertes, J. Antibiot., 1997, 50, 734-737.

413 R. Sakai, K. Yoshida, A. Kimura, K. Koike, M. Jimbo, K. Koike, A. Kobiyama and H. Kamiya, ChemBioChem, 2008, 9, 543-551.

414 C. Vorburger and A. Gouskov, J. Evol. Biol., 2011, 24, 16111617.
415 N. A. Moran, P. Tran and N. M. Gerardo, Appl. Environ. Microbiol., 2005, 71, 8802-8810.

416 H. Salem, L. Flórez, N. M. Gerardo and M. Kaltenpoth, Proc. R. Soc. B, 2015, 282, DOI: 10.1098/rspb.2014.2957.

417 M. J. Cafaro and C. R. Currie, Can. J. Microbiol., 2005, 51, 441-446.

418 L. M. Henry, J. Peccoud, J.-C. C. Simon, J. D. Hadfield, M. J. Maiden, J. Ferrari and H. C. Godfray, Curr. Biol., 2013, 23, 1713-1717.

419 P. H. W. Biedermann and M. Kaltenpoth, J. Chem. Ecol., 2014, 40, 99.

420 J. Piel, D. Butzke, N. Fusetani, D. Q. Hui, M. Platzer, G. P. Wen and S. Matsunaga, J. Nat. Prod., 2005, 68, 472479.

421 R. J. Worthington and C. Melander, Trends Biotechnol., 2013, 31, 177-184.

422 A. Svatoš, Trends Biotechnol., 2010, 28, 425-434.

423 A. Svatoš, Anal. Chem., 2011, 83, 5037-5044.

424 C. M. Gibson and M. S. Hunter, Ecol. Lett., 2010, 13, 223234.

425 W. B. Turner and D. C. Aldridge, Fungal metabolites, Academic Press, London, UK, 1971.

426 P. Steyn, The Biosynthesis of Mycotoxins: A study in secondary Metabolism, Elsevier Science, New York, NY, USA, 2012.

427 N. E. Beckage and J.-M. Drezen, Parasitoid viruses: symbionts and pathogens, Academic Press, San Diego, CA, USA, 2012.

428 H. Thoetkiattikul, M. H. Beck and M. R. Strand, Proc. Natl. Acad. Sci. U. S. A., 2005, 102, 11426-11431.

429 N. M. Dheilly, F. Maure, M. Ravallec, R. Galinier, J. Doyon, D. Duval, L. Leger, A.-N. Volkoff, D. Misse, S. Nidelet, V. Demolombe, J. Brodeur, B. Gourbal, F. Thomas and G. Mitta, Proc. R. Soc. B, 2015, 282, 20142773.

430 J. J. Barr, R. Auro, M. Furlan, K. L. Whiteson, M. L. Erb, J. Pogliano, A. Stotland, R. Wolkowicz, A. S. Cutting, K. S. Doran, P. Salamon, M. Youle and F. Rohwer, Proc. Natl. Acad. Sci. U. S. A., 2013, 110, 10771-10776.

431 E. W. Schmidt, Nat. Chem. Biol., 2008, 4, 466-473. 